University of Nebraska - Lincoln

DigitalCommons@University of Nebraska - Lincoln

Papers in the Earth and Atmospheric Sciences

Earth and Atmospheric Sciences, Department

\title{
Defining the morphological quality of fossil footprints. Problems and principles of preservation in tetrapod ichnology with examples from the Palaeozoic to the present
}

\author{
Lorenzo Marchetti \\ Urweltmuseum GEOSKOP/Burg Lichtenberg (Pfalz), lorenzo.marchetti85@gmail.com \\ Matteo Belvedere \\ Office de la Culture, Porrentruy, Canton Jura, Switzerland \\ Sebastian Voigt \\ Urweltmuseum GEOSKOP/Burg Lichtenberg (Pfalz) \\ Hendrik Klein \\ Saurierwelt Paläontologisches Museum, Neumarkt, Germany \\ Diego Castanera \\ Institut Català de Paleontologia 'Miquel Crusafont'
}

See next page for additional authors

Follow this and additional works at: https://digitalcommons.unl.edu/geosciencefacpub

Part of the Paleobiology Commons, and the Paleontology Commons

Marchetti, Lorenzo; Belvedere, Matteo; Voigt, Sebastian; Klein, Hendrik; Castanera, Diego; Díaz-Martínez, Ignacio; Marty, Daniel; Xing, Lida; Feola, Silverio; Melchor, Ricardo N.; and Farlow, James O., "Defining the morphological quality of fossil footprints. Problems and principles of preservation in tetrapod ichnology with examples from the Palaeozoic to the present" (2019). Papers in the Earth and Atmospheric Sciences. 642.

https://digitalcommons.unl.edu/geosciencefacpub/642

This Article is brought to you for free and open access by the Earth and Atmospheric Sciences, Department of at DigitalCommons@University of Nebraska - Lincoln. It has been accepted for inclusion in Papers in the Earth and Atmospheric Sciences by an authorized administrator of DigitalCommons@University of Nebraska - Lincoln. 


\section{Authors}

Lorenzo Marchetti, Matteo Belvedere, Sebastian Voigt, Hendrik Klein, Diego Castanera, Ignacio DíazMartínez, Daniel Marty, Lida Xing, Silverio Feola, Ricardo N. Melchor, and James O. Farlow 


\title{
Defining the morphological quality of fossil footprints.
}

\section{Problems and principles of preservation} in tetrapod ichnology with examples from the Palaeozoic to the present

\author{
Lorenzo Marchetti, ${ }^{1}$ Matteo Belvedere, ${ }^{2}$ Sebastian Voigt, ${ }^{1}$ \\ Hendrik Klein, ${ }^{3}$ Diego Castanera, ${ }^{4}$ Ignacio Díaz-Martínez, ${ }^{5,6}$ \\ Daniel Marty, ${ }^{7}$ Lida Xing, ${ }^{8,9}$ Silverio Feola, ${ }^{10}$ \\ Ricardo N. Melchor, ${ }^{11}$ \& James O. Farlow ${ }^{12}$
}

\footnotetext{
1 Urweltmuseum GEOSKOP/Burg Lichtenberg (Pfalz), Burgstrasse 19, 66871 Thallichtenberg, Germany 2 Section d'Archéologie et Paléontologie, Paléontologie A16, Office de la Culture, Porrentruy, Canton Jura, Switzerland 3 Saurierwelt Paläontologisches Museum, Alte Richt 7, D-92318 Neumarkt, Germany 4 Mesozoic Research Group, Institut Català de Paleontologia 'Miquel Crusafont', C/Escola Industrial 23, 08201 Sabadell, Catalonia, Spain 5 CONICET, Buenos Aires, Argentina 6 Instituto de Investigacion en Paleobiología y Geología (IIPG), Universidad Nacional de Río Negro, Av. Roca 1242, General Roca 8332, Río Negro, Argentina 7 Natural History Museum Basel, Augustinergasse 2, 4001 Basel, Switzerland 8 State Key Laboratory of Biogeology and Environmental Geology, China University of Geosciences, Beijing 100083, China

9 School of the Earth Sciences and Resources, China University of Geosciences, Beijing 100083, China

10 Instituto Geológico del Sur (CONICET), Universidad Nacional del Sur, San Juan 670, 8000 Bahía Blanca, Argentina

11 Instituto de Ciencias de la Tierra y Ambientales de La Pampa, (CONICET and Universidad Nacional de La Pampa), Av, Uruguay 151,6300, Santa Rosa, La Pampa, Argentina 12 Department of Biology, Purdue University Fort Wayne, Indiana 46805, USA Corresponding author: lorenzo.marchetti85@gmail.com (L. Marchetti).
}

Published in Earth-Science Reviews 193 (2019) 109-145

DOI: 10.1016/j.earscirev.2019.04.008

Copyright (C) 2019 Elsevier B.V. Used by permission.

Submitted 28 January 2019; revised 29 March 2019; accepted 6 April 2019 


\begin{abstract}
The morphology of fossil footprints is the basis of vertebrate footprint ichnology. However, the processes acting during and after trace fossil registration which are responsible for the final morphology have never been precisely defined, resulting in a dearth of nomenclature. Therefore, we discuss the concepts of ichnotaphonomy, ichnostratinomy, taphonomy, biostratinomy, registration and diagenesis and describe the processes acting on footprint morphology. In order to evaluate the morphological quality of tetrapod footprints, we introduce the concept of morphological preservation, which is related to the morphological quality of footprints (M-preservation, acronym MP), and distinguish it from physical preservation (P-preservation, acronym PP), which characterizes whether or not a track is eliminated by taphonomic and diagenetic processes. M-preservation includes all the morphological features produced during and after track registration prior to its study, and may be divided into substages (ichnostratinomic, registrational, taphonomic, stratinomic, diagenetic). Moreover, we propose an updated numerical preservation scale for M-preservation. It ranges from 0.0 (worst preservation) to 3.0 (best preservation); intermediate values may be used and specific features may be indicated by letters. In vertebrate footprint ichnotaxonomy, we regard the anatomy-consistent morphology and to a lesser extent the trackway pattern as the only acceptable ichnotaxobases. Only footprints showing a good morphological preservation (grade 2.0-3.0) are useful in ichnotaxonomy, whereas ichnotaxa based on poor morphological preservation (grade 0.0-1.5) are considered ichnotaphotaxa (nomina dubia) characterized by extramorphologies. We applied the preservation scale on examples from the Palaeozoic to the present time, including three ichnotaphotaxa and 18 anatomy-consistent ichnotaxa/morphotypes attributed to several vertebrate footprint producers. Results indicate the utility, feasibility and suitability of this method for the entire vertebrate footprint record in any lithofacies, strongly recommending its use in future ichnotaxonomic studies.
\end{abstract}

Keywords: Morphological preservation, Preservation scale, Ichnotaxobases, Foot anatomy, Dinosaur tracks

\title{
1. Introduction
}

Taxonomy is the branch of science dedicated to the classification and grouping of living and fossilized organisms. In palaeontology, it is based on morphological characters (although genetic information is also used in Quaternary fossils) and aims to place all organisms in the tree of life, in different and well-established hierarchic groups. Ichnotaxonomy is considered as a parataxonomy, because it is based on the life activities of organisms, which however can generally not be determined with certainty. Therefore, it is a parallel classification not directly nested in the tree of life (International Commission on Zoological Nomenclature, 1999). 
The aim of vertebrate footprint ichnotaxonomy is to classify traces produced during life activities of terrestrial vertebrate producers that allows faunal, biostratigraphic, palaeoecologic and palaeoenvironmental studies (e.g. Thulborn, 1990; Leonardi, 1994; Lockley and Hunt, 1995; Rindsberg, 2012). In vertebrate footprints, it is mainly based on track morphology that is conditioned by the anatomy of the producer autopodium, its behavior, the substrate conditions at the time of the impression and any other cause (i.e. taphonomy, diagenesis) occurring after footprint registration. Classically, the term "preservation" is used to evaluate how different the track shape is with respect to the original producer's autopod morphology. Therefore, all other morphological effects have to be excluded from an anatomy-consistent ichnotaxonomic study (e.g. Haubold et al., 1995). These differences can be characterized by a preservation scale (e.g., Belvedere and Farlow, 2016) and have valuable information for ichnotaxonomic studies.

The aim of this contribution is to provide a new definition and use of the term "preservation of a vertebrate footprint". The preservation concept is discussed in relation to the different processes acting on the morphology of footprints and to the different phases of footprint fossilization. Moreover, a protocol for ichnotaxonomic studies is proposed. Finally, the preservation scale of Belvedere and Farlow (2016) is refined, based on multiple examples of different vertebrate footprints from the Palaeozoic to the present time including different terrestrial vertebrate groups such as: non-mammalian synapsids, quadrupedal mammals and humans; diapsids including birds, dinosaurs and other archosaurs; lizard-like eureptiles and parareptiles and anamniotes.

\section{Track morphology vs track ethology}

A trace fossil is a "morphologically recurrent structure resulting from the life activity of an individual organism (or homotypic organisms) modifying the substrate" (Bertling et al., 2006, p. 266). As with any other fossil, the taxonomy of trace fossils (ichnotaxonomy) is based on morphology, although parallel classifications based on ethological (Seilacher, 1967) and stratinomic (Buatois and Mángano, 2011) information exist. The morphology of trace fossils is the direct consequence of four different causes: 1. Anatomy of the producer, 2. Behavior of the producer, 3. Substrate conditions at time of trace registration, 4. 
Post-registration processes. The term 'trace registration' is used here in place of the term 'trace formation' by Gatesy and Falkingham (2017), because 'registration' implies a passive action of the biogenic structure, therefore is more appropriate than 'formation', which suggests an active action of the biogenic structure. In all other aspects, the two terms are synonyms. Following the definition by Gatesy and Falkingham (2017), we consider as post-registration processes all the agents which act on the trace from its registration until its study, including: sedimentary processes, superimposition of other trace fossils, diagenesis, tectonics and recent weathering (Figs. 1-2). It is important to stress that the ichnotaxonomy of trace fossils relies only on the morphology of the trace, with a few exceptions, e.g. composition in case of coprolites and principal substrate type (e.g., soft sediment, firm sediment, wood, bone) in case of invertebrate trace fossils (Bertling

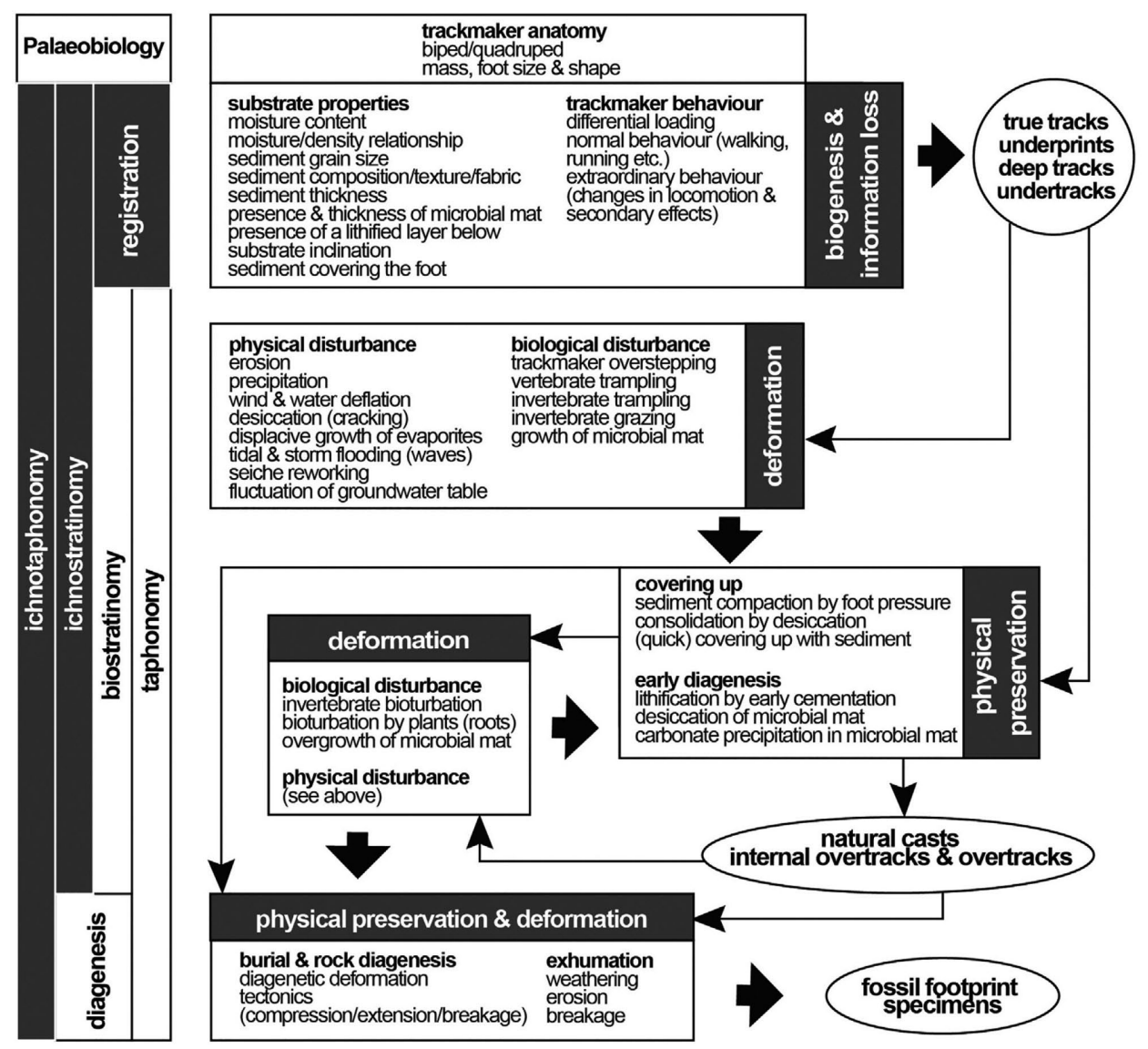

Fig. 1. Scheme of the ichnotaphonomic processes acting on the fossil footprints, based on Marty et al. (2009). 


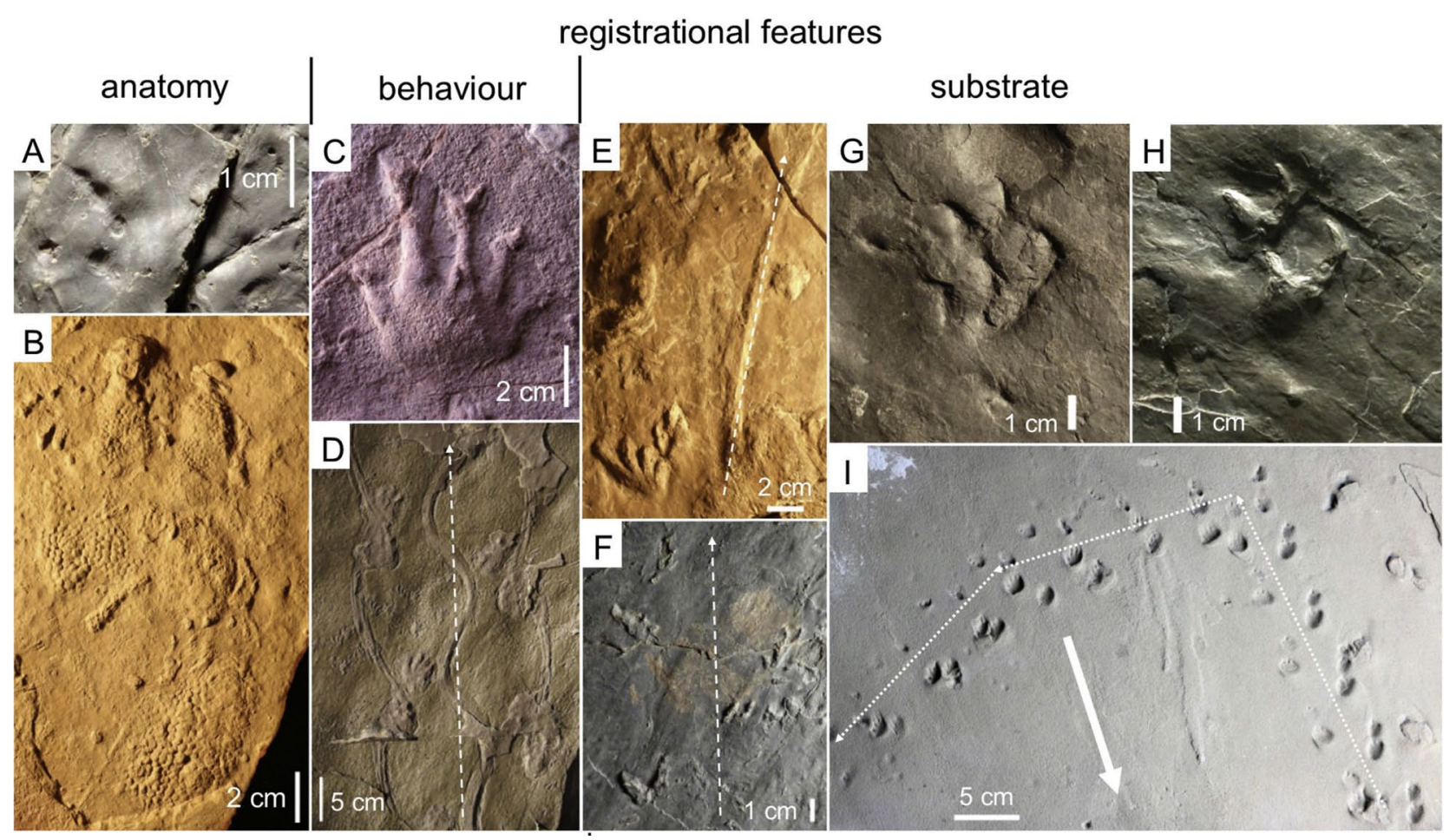

Fig. 2, Part I. Palaeozoic-Mesozoic examples of morphologic features linked to registrational (A-I), biostratinomic (J-L) and diagenetic (M-O) processes. A-B) Features derived from the trackmaker foot anatomy, scale skin impression. Note the incomplete preservation of tracks. A) Reptile footprint (Dromopus), concave epirelief. Permian, Pizzo del Diavolo Formation, Italy. B) Archosauromorph pes imprint (Isochirotherium), convex hyporelief. Triassic, Grès d'Antully Formation, France. C-D) Features derived from the behavior of the trackmaker. C) Digit tip bifurcation impression. Synapsid manus imprint (Dimetropus), convex hyporelief. Carboniferous, Salop Formation, England. D) Continuous digit scratch marks and tail impression. Anamniote trackway (Amphisauropus), convex hyporelief. Permian, Pizzo del Diavolo Formation, Italy. E-I) Features conditioned by the substrate conditions at time of impression. E) Different digit width along the same trackway. Reptile pesmanus couples (Rhynchosauroides) and tail impression, Permian, convex hyporelief. Val Gardena Formation, Italy. F) Different digit morphology at the two sides of the trackway. Reptile trackway (Dromopus), convex hyporelief. Permian, Pizzo del Diavolo Formation, Italy. G-H) Different morphology on different stratigraphic layers. Reptile pes-manus couple (Dromopus), Permian, Collio Formation, Italy. G) True track, concave epirelief. H) Undertrack, convex hyporelief. The image was reflected horizontally to better compare the morphology. I) Different trackway pattern and footprint morphology due to the substrate inclination. Reptile trackway on aeolian foreset surface, Permian, concave epireleif. Coconino Formation, Arizona. The arrow indicates the original dip direction. (Continued) 


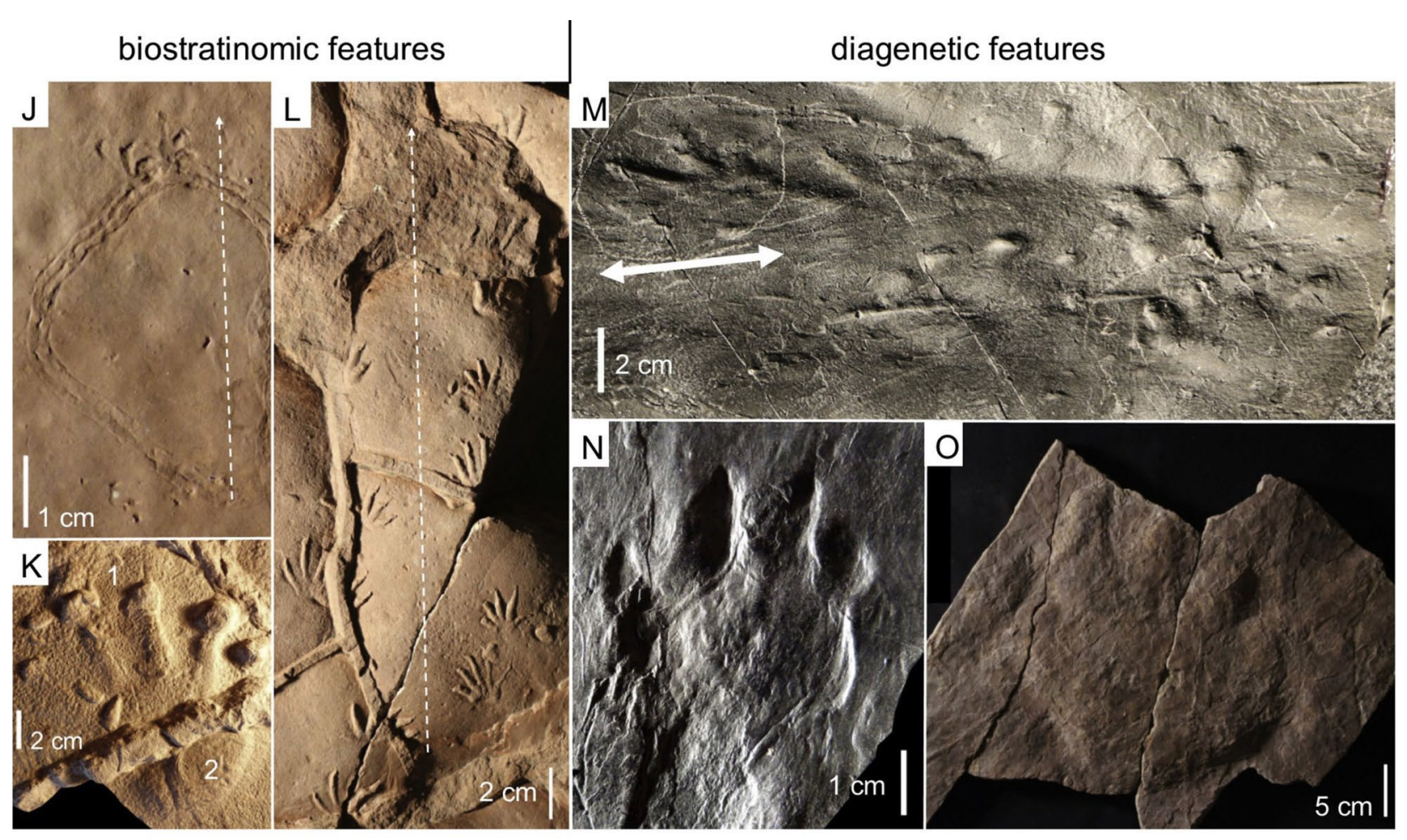

Fig. 2, Part II. J) Invertebrate trace fossil superimposition on reptile pes-manus couples (Erpetopus), concave epirelief. Permian, Choza Forrmation, Texas. K) Tetrapod footprint superimposition (1), invertebrate trace fossil (2) and mud crack superimposition on anamniote pes (Ichniotheirum), convex hyporelief. Permian, Tambach Formation, Germany. L) Mud crack superimposition on reptile trackway (Varanopus), convex hyporelief. Permian, Tambach Formation, Germany. M) Unidirectional stretch due to tectonics on anamniote (Amphisauropus) and reptile (Hyloidichnus) footprints, concave epirelief (artificial cast). Permian, Pizzo del Diavolo Formation, Italy. The arrow indicates the stretch direction. N) Footprint flattened due to tectonics on anamniote pes (Limnopus), concave epirelief (artificial cast). Permian, Pizzo del Diavolo Formation, Italy. O) Post-exhumation footprint breakage on parareptile pes (Pachypes), convex hyporelief. Permian, Val Gardena Formation, Italy. Dashed arrows indicate the trackway midline and the direction of locomotion.

et al., 2006). Therefore, trace morphology (effect) is the most important ichnotaxobase (morphological feature of a trace fossil considered valid for ichnotaxonomy; Bromley, 199ob; for a discussion see chapter 6), whereas the producer and the processes which made or modified it (causes 1-4, see above) are not ichnotaxobases adequate for tetrapod footprints, although they obviously have a great impact on morphology. In other words, the different kinds of vertebrate trace fossils (e.g., footprints, resting impressions, swim traces, burrows and coprolites) 
are the result of different kinds of behaviors (e.g., locomotion, resting, swimming, dwelling and defecating. Note that the concept of behavior in ichnology may differ from the concept of behavior used for extant animals; e.g., Plotnick, 2012). Nevertheless, the ichnotaxonomy of vertebrate footprints is independent from ethology (i.e. behavior is not an ichnotaxobase) and, with the exception of coprolites, should rely only on morphological features and spatial arrangement of the trace, independent of the behavior and kind of trackmaker, although the trace fossil structure may vary considerably (a concept known as ichnodisparity in invertebrate ichnology; Buatois et al., 2017). Vertebrate footprints rely primarily on morphological features and secondarily on trackway pattern (e.g. Wright, 2005; Castanera et al., 2016). Adapting the definition of trace fossils given by Bertling et al. (2006), vertebrate footprints are: morphologically recurrent biogenic structures resulting from the locomotion of an individually limbed vertebrate modifying the substrate. This does not include traces that are the result of different kinds of vertebrate behavior which have a different structure, such as: crawling traces (such as those of snakes), resting traces, nests, burrows and swim traces.

The morphology of vertebrate footprints results from causes 1-4 (as mentioned above), and vertebrate footprint ichnotaxonomy relies on morphology only, and almost exclusively on the anatomy-consistent morphological features (cause 1). For anatomy-consistent we mean an impression which is (as far as possible) similar to the producer's foot base and thus direct expression of the anatomic and skeleton-muscularskin characteristics of the producer. Even if the producer is not known, the footprint's expression of anatomy is clearly recognizable, because not affected by taphonomy or other processes which cause loss of information. This is verifiable in both the fossil and present time record (e.g., Marty et al., 2009). It allows the comparison with similar footprint shapes which are a direct expression of the locomotor characteristics of the producer groups (e.g., Voigt et al., 2007), and are classified following an independent parataxonomic system (International Commission on Zoological Nomenclature, 1999). Therefore, the critiques to a mold-based system (Gatesy and Falkingham, 2017) are rejected. All the morphological features derived from deviation from the anatomy-consistent footprint shape are instead of interest for understanding processes of track registration and preservation, and 
locomotor mechanisms involved in producing the track (e.g. Gatesy et al., 1999; Milàn and Bromley, 2006; Milan and Bromley, 2007; Gatesy and Falkingham, 2017).

\section{Ichnotaphonomy}

As for any other fossil, the trace fossil record is biased by several processes that cause losses and alteration of the original information about the biocoenose (palaeobiology). In palaeontology, the study of these processes is called taphonomy (e.g. Behrensmeyer et al., 2000). Taphonomy was originally defined as "the study of the transition (in all its details) of animal remains from the biosphere into the lithosphere" (Efremov, 1940; p. 85). More recently, it was defined as: "the study of processes of preservation and how they affect information in the fossil record" (Behrensmeyer and Kidwell, 1985). In ichnology, the concept of taphonomy generally has not been extensively treated (e.g. Thulborn, 1990; Seilacher, 2007; Buatois and Mángano, 2011) with the exception of the books by Bromley (199ob, 1996), which however only treat taphonomy as a tool for interpreting trace fossils without providing specific definitions of the term taphonomy in ichnology. In tetrapod footprint ichnology, some pioneering works were done, but again precise definitions are lacking (Laporte and Behrensmeyer, 1980; Cohen et al., 1991, 1993; Genise et al., 2009 and Scott et al., 2010, 2012).

Therefore, various interpretations exist about what the meaning and boundaries of taphonomy should be in ichnology (e.g. Savrda, 2007; Marty et al., 2009). Unlike other fossils, trace fossils are not subject to necrolysis, because they are biogenic structures produced on or in the sediment by living organisms (e.g. Seilacher, 2007). Therefore, the death of the organism, that is usually the starting point of the taphonomy, doesn't apply.

Some researchers consider the end of trace registration to be analogous to an organism's death, and so use the term taphonomy to describe post-registration processes that alter information encapsulated in the traces, similarly to the processes of degradation that occur in the creation of body fossils (e.g. Cohen et al., 1991; Marty et al., 2009). However, a conspicuous loss of information can occur 
also during trace registration (e.g. Savrda, 2007; Gatesy and Falkingham, 2017; Marchetti, 2018). Since the modern usage of taphonomy tends to include any kind of bias in the fossil record ("Strictly speaking, the logical limits of taphonomy are defined by its focus on processes and patterns of fossil preservation, but in practice, taphonomy serves a broader role in stimulating research on all types of biases affecting palaeontological information"; Behrensmeyer et al., 2000, p. 104), we think that taphonomic concepts in ichnology should include all the possible processes which alter information during and after track registration (Fig. 1). However, because the registration process is exclusive to trace (as opposed to body) fossils, and it is potentially important to distinguish processes acting during, from those operating after, the trace registration, we propose the use of different terms to describe them.

We re-define the concept of ichnotaphonomy introduced by Bromley (1990a) as follows: the study of processes of preservation and how they affect information in the ichnologic record, including the process of trace registration. Instead, the concept of taphonomy in ichnology is more restrictively defined as follows: the study of processes of preservation and how they affect information in the ichnologic record, excluding (that is, after) the process of trace registration. Therefore, the first term is a broadly inclusive concept that is restricted to ichnology (it has no counterpart in the study of body fossils), and includes all the possible modes of deformation of the trace morphology. In contrast, the second includes only those processes which act after the trace registration, here compared to an organism's death (Fig. 1). Taphonomy is usually considered to include two different phases, biostratinomy and fossil diagenesis (e.g. Fernández-López and Fernández Jalvo, 2002). Biostratinomy describes all the processes acting on the organism after its death but before final burial (sensu Lyman, 1994), whereas diagenesis includes all processes occurring after the organism's final burial. Here we compare organism death to the end of trace formation (Fig. 1), so we consider biostratinomy in ichnology as: the study of processes of preservation and how they affect information in the ichnologic record, from the end of the trace registration until its final burial (Fig. 1). Nevertheless, if we consider biostratinomy as a process, it denotes the sedimentary history of biogenic remains (e.g. Seilacher, 1973), and this starts during trace registration, because the 
substrate is a key factor in trace registration (e.g. Milàn and Bromley, 2006; Milan and Bromley, 2007). Therefore, we re-define the concept of ichnostratinomy introduced by Savrda (2007) as: the study of processes of preservation and how they affect information in the ichnologic record, from the beginning of the trace registration until its final burial (Fig. 1).

We consider diagenesis in ichnology as: the study of processes of preservation and how they affect information in the ichnologic record, from the trace final burial until its study. Using the proposed nomenclature, the terms ichnotaphonomy, taphonomy, ichnostratinomy, biostratinomy, registration and diagenesis describe all the phases of the trace fossil creation and fossilization (Fig. 1). In the following subchapters (3.1-3.3) we describe some of the ichnotaphonomic processes which may alter footprint morphology during the phases of registration, biostratinomy and diagenesis (Fig. 2).

\subsection{Track registration}

The phase of track registration is a dynamic interaction between the living producer and the substrate, and so the producer's foot anatomy and behavior and the substrate properties at the time of impression play a central role in this phase (e.g. Padian and Olsen, 1984; Milàn and Bromley, 2006; Milan and Bromley, 2007; Falkingham, 2014; Farlow et al., 2018a). Usually, the footprints start to be registered in their proximal part (sole, palm, proximal part of digits), which act as a support during the foot's landing, and they end to be registered in their distal part (distal part of digits, claws), which act as a lever for the foot propulsion (e.g. Thulborn, 1990). This phase comprises all the processes happening during the contact of the producer's foot with the substrate, and ends when the footprint is registered. It produces true tracks, underprints, deep tracks and undertracks (Fig. 1) (Allen, 1997; Romano and Whyte, 2003; Marty et al., 2009). Under ideal conditions for footprint registration, when the substrate properties are adequate for the trackmaker's size and gait and the trackmaker behavior is adequate to produce a complete foot impression, the footprint is an almost perfect natural cast of the underside of the producer's foot. In this case, footprint morphology (including palm/sole, digital pads, digits and claws) is anatomy-consistent and suitable for ichnotaxonomy 
and trackmaker attribution (e.g. Peabody, 1955; Carrano and Wilson, 2001; Voigt et al., 2007; Belvedere and Farlow, 2016; Marchetti et al., 2017a; Farlow et al., 2018a). However, some anatomical features, such as scale impressions, are not relevant for ichnotaxonomy. In fact, they can be very similar in different ichnotaxa, and they can also be wellpreserved in cases of poor preservation of the footprint (Fig. 2A, B; Marchetti et al., 2015a), although they can be useful to distinguish producer groups (e.g., reptiles from amphibians or stegosaurs from sauropods; e.g., Lockley, 2009). Other anatomical features are instead considered to be result of the producer's foot injury, and therefore are not relevant for ichnotaxonomy because they are linked to the individual's pathology, which may affect different producers in the same way (e.g. McCrea et al., 2015; Razzolini et al., 2016). Still other morphological features, such as digit tip bifurcation and tail/digit drag impressions, are instead behavior-related and identical in different ichnotaxa, so they are here considered without ichnotaxonomic value (Fig. 2C-D) (Tucker and Smith, 2004; Marchetti et al., 2017a; Farlow et al., 2018b). Many other morphological features are substrate-related and therefore also considered as ichnotaphonomic effects. These include: anomalous digit width and morphology, probably caused by an excessively water-saturated substrate (Fig. 2E-F) (Razzolini et al., 2014; Marchetti et al., 2015a, 2017b; Marchetti, 2018); incomplete impressions in the underlying layers (undertracks, Fig. 2G-H) (Castanera et al., 2013a; Marchetti et al., 2015b; Marchetti, 2018); uni-directional deformation and anomalous trackway pattern due to the substrate slope, common in aeolian facies (Fig. 2I) (Loope, 1992) and possibly also in other environments (Razzolini and Klein, 2018).

\subsection{Track biostratinomy}

Track biostratinomy includes all the processes acting on footprint morphology in the sediment, after the track registration until its final burial (Fig. 1). This includes physical processes such as covering of the tracks with other sediment (which produces natural casts and overtracks in the overlying layers) and processes of early diagenesis; and all the biogenic and sedimentary processes which may deform the footprint morphology (Figs. 1-2). These biogenic processes include trace fossil superimposition, such as other vertebrate traces (Fig. 2K, 
Marchetti et al., 2018; cf. Farlow et al., 2012 for the Paluxy River sauropod-theropod "chase sequence"), possible other traces made by the same producer (e.g. pes-manus overlap) and invertebrate traces, which may act before and after burial (Fig. 2J, K, Marchetti et al., 2015a). Other biogenic processes include microbial mat overgrowth and root penetration, which act after the covering up (Fig. 1; Marty et al., 2009). Among non-biogenic sedimentary processes, a common agent is mud crack displacement and deformation occurring after sediment drying (Fig. 2K, L; Marchetti et al., 2018). Other disruptive sedimentary processes include water precipitation (rain drops), wind and water erosion, wind deflation, evaporite crystal growth and shrinkage and swelling of clays (Fig. 1, Marty et al., 2009; Scott et al., 2010).

\subsection{Track diagenesis}

Following the definition of diagenesis provided by Behrensmeyer and Kidwell (1985), Wilson (1988), Seilacher (1992), Dauphin et al. (1999) and Fernández-López and Fernández Jalvo (2002) we consider as track diagenesis the phase that operates after final burial of the trace but before study. It therefore includes rock diagenesis, exhumation, sedimentary processes acting after exhumation (including excavation and transport to the repository) until the study of the specimen. This phase does not include the early diagenesis because this process acts before the final burial.

Other authors prefer to restrict diagenesis to the processes acting from the final burial until the final exhumation/discovery of the specimen (Singer and Müller, 1979; Lawrence, 1979; Seilacher, 1984).

During burial, sediment is compacted and the footprints may be subject to flattening (Fig. 2N, Marchetti et al., 2013; Lockley and Xing, 2015). Tectonic processes other than post-burial compaction may deform the footprint as well, resulting in lateral uni-directional extension or compression of the footprints (Fig. 2M; Marchetti et al., 2013; Fichman et al., 2015). A very common process occurring after exhumation is footprint weathering, erosion and breakage (Fig. 2O, Marchetti et al., 2017b). 


\section{Track preservation}

In vertebrate footprint ichnology, the possibility of recognizing actual anatomical characters in a track specimen is usually attached to the term preservation (e.g. Thulborn, 1990; Haubold et al., 1995; Lockley, 1994, 1998; Lockley et al., 2018; Gand and Durand, 2006; Voigt et al., 2007; Marty, 2008; Marty et al., 2009, 2010, 2018; Klein and Lucas, 2010a, 2018; Klein and Niedzwiedzki, 2012; Castanera et al., 2013a, 2013b, 2018; Díaz-Martínez et al., 2015a, 2015b, 2018; Belvedere and Farlow, 2016; Belvedere et al., 2018; Marchetti et al., 2017a,b; Marchetti, 2016, 2018; Farlow et al., 2018a; Voigt and Lucas, 2018; Xing et al., 2018). In this usage, preservation is a direct expression of the morphological quality of the specimen. The morphological quality coincides with preservation of the diagnostic features of known or new ichnotaxa, disentangled from the ichnotaphonomic effects produced during and after locomotion (Figs. 1-2).

We understand the need for more precise definitions and goals for use of the term preservation in ichnology (Gatesy and Falkingham, 2017; Marchetti, 2018). Therefore, we name the preservation of trace fossil morphology as: morphological preservation (or M-preservation, acronym MP). Emending the definition of preservation (quality) by Marchetti (2018), we define morphological preservation as: The existence, to varying degrees, of a set of selected morphological features and track parameters which are recurrent in the track sample and expression of specific morpho-functional anatomical features of a trackmaker or group of trackmakers and therefore diagnostic in ichnotaxonomy. The goal of evaluating morphological preservation is an anatomy-consistent ichnotaxonomy. Since in trace fossils we only see the resulting morphology and we cannot examine the trackmaker's actual autopod, we must rely on those features which occur consistently and repeatedly (and that are not produced by deformational ichnotaphonomic effects) in the traces, and therefore constitute diagnostic features for systematic assignments. However, we do not know a priori precisely what anatomical features should be visible. Consequently, large samples are required in order to determine if a feature is anatomical or expression of ichnotaphonomic processes. In the systematic study of the entire sample, it is necessary to select footprints that preserve morphological characters useful for ichnotaxonomic 
purposes. In order to do this, their morphological preservation of diagnostic characters is evaluated. (Very) well-(optimally)-preserved, elite tracks (sensu Lockley, 1994; the concept is not equivalent to elite trace fossil of Bromley, 1990a,b) and trackways are not negatively affected by ichnotaphonomic effects, and they are the basis of tetrapod track ichnotaxonomy, whereas poorly-preserved tracks are substantially influenced by ichnotaphonomy and have little ichnotaxonomic value, although they can give valuable information about substrate conditions at the time of track registration, locomotion, or the palaeoenvironment (e.g. Lockley, 1986; Marty, 2008) (Fig. 2).

We think that the concept of morphological preservation must be related to all the morphological features produced during and after track registration (ichnotaphonomy) (Fig. 1). The choice to include registrational effects in evaluating the morphological preservation of tracks (in contrast to what has been proposed by Gatesy and Falkingham (2017) in their definition of "preservation [quality"]) has a simple explanation: the ichnotaphonomy of trace fossils is largely dependent on registrational effects, but only to a minor extent on postregistration influences (although in some cases the latter may be important; e.g. Marty et al., 2009; Scott, 2010; Fichman et al., 2015; Lockley and Xing, 2015). This is evident in the laboratory experiment provided by Gatesy and Falkingham (2017): all the deviations from the anatomy-controlled footprint shape (which is represented in Fig. $2 \mathrm{~b}$ of the same paper) are related to substrate consistency, and so they are registrational effects. So, if the goal of evaluating morphological preservation is to exclude deformational ichnotaphonomic processes from ichnotaxonomy as it is for taphonomic processes and taxonomy in body fossils, registrational effects must be included in defining morphological preservation. Otherwise we would be obliged to use terms denoting high morphological quality for low-quality traces and vice versa, and this would be confusing or even harmful for systematic assignments. Moreover, although interesting for non-ichnotaxonomic studies, it may be very difficult to decide if a morphological feature is due to a registrational or post-registrational process, and attribute it to a specific cause. Nevertheless, we understand the need for different terms to denote the morphological preservation in different fossilization phases. Therefore, we define as: registrational (r), taphonomic (t), ichnostratinomic (i), biostratinomic (b), 


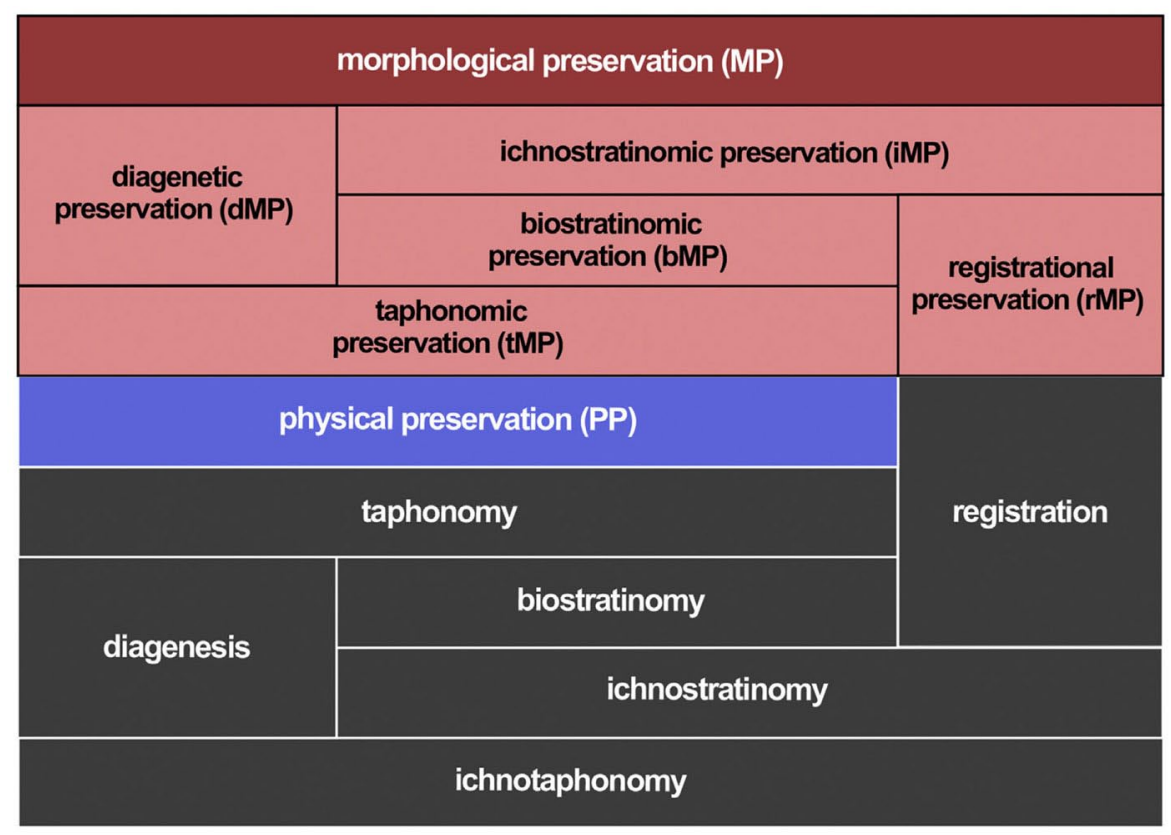

Fig. 3. Scheme of preservation nomenclature in ichnology.

diagenetic (d) preservation the sub-stages of the morphological preservation, and propose to add the corresponding lower-case letter to the acronym MP (Fig. 3).

We do not believe that use of the term morphological preservation could be confused with use of the term preservation to denote the existence of the footprint specimen itself (basically the other two meanings explained by Gatesy and Falkingham, 2017), which we here name: physical preservation (or P-preservation, acronym PP) and define as the possibility of a footprint not being eliminated by taphonomic processes until its study (also known as preservation potential).

Being radically different concepts, morphological and physical preservation can be referred to simply as "preservation" if the context is clear. Conversely, when referring to a specific phase, it is necessary to specify the sub-category of morphological preservation, because a well-preserved specimen in a specific phase can be poorly-preserved because of different ichnotaphonomic processes. Accordingly, the preservation (quality) as defined by Gatesy and Falkingham (2017) is here considered a sub-category of morphological preservation named "taphonomic preservation" and indicated by the acronym tMP. 
In conclusion, we do not see the necessity of dramatically changing a decades-long convention (started with Marsh, 1894; Bock, 1952; Baird, 1957; among others) in assessing morphological quality of footprints for ichnotaxonomic purposes by excluding the registration phase from the evaluation of the M-preservation. Consequently, we will use the term morphological preservation as previously defined to assess the morphological quality of footprints including both registrational and post-registrational processes. Nevertheless, we agree with Gatesy and Falkingham (2017) on the importance of distinguishing the separate causes responsible for track registration and subsequent modification (distinguishing registrational and post-registrational processes is useful for studies about track registration and taphonomy) although they must be kept separate from the evaluation of track morphology for ichnotaxonomy.

\section{Preservation scale}

In vertebrate footprint ichnotaxonomy, an ordinal numerical scale based on morphological preservation can be a helpful tool, the better to improve comparisons between different ichnotaxa and ichnoassociations in space and time and reduce subjectivity in the assessment of anatomy-consistent morphological features. The lack of precise, detailed and uniform classifications can negatively affect the definition and understanding of preservation, therefore tracks that are actually non-informative for ichnotaxonomy can be considered wellpreserved and even used for the erection of new ichnotaxa. As a final consequence, this will also lower the scientific credibility in the discipline. Such a numerical classification was provided by the preservation scale of Belvedere and Farlow (2016). This scale was modified from one initially created by JOF during a study of footprint registration by emus (Dromaius novaehollandiae), the details of which were published in Farlow et al. (2018a).

The scale of Belvedere and Farlow (2016) evaluates the morphological quality of tracks, giving them discrete ordinal values, from o to 3 , in ascending order by means of morphological preservation of the diagnostic features in the analysed track specimen. Intermediate values may additionally be used, together with letters to indicate specific features (e.g., 's' to indicate the occurrence of skin impression). 
We provide an updated version of this preservation scale (also known as preservation grade; Castanera et al., 2018), including more detailed morphological features and agents that might have been responsible for their registration (Tables 1-2). Evaluating the M-preservation of the anatomy-consistent morphological features, it is possible to define a preservation series (0.0-3.0), useful for detecting and describing the best-preserved material, which should be used for ichnotaxonomy, excluding ichnotaphonomic artefacts. We propose the use of different discrete numerical values (from 0.0 to 3.0, with the possibility to utilize intermediate values such as 0.5 , 1.5, 2.5), describe correlations with some widely-used qualitative descriptors associated with M-preservation (e.g., well-, poorly-) and revise the use of letters as proposed by Belvedere and Farlow (2016) further to denote important additional information (Table 1). We keep the letters: $\mathrm{p}=$ partial preservation and $\mathrm{s}=$ skin/scale impression. We introduce the letters: $\mathrm{c}=$ morphology cut, $\mathrm{d}=$ drag marks, $\mathrm{b}=$ digit tip bifurcation, $\mathrm{w}=$ anomalous width, $\mathrm{f}=$ flattened footprint, $\mathrm{a}$ = anomalous morphology, $\mathrm{m}$ = mono-directional deformation. We do not keep the letter $\mathrm{t}$ (tail impression) because it is only applicable to trackways and not to single footprints. Also, we consider the letter st (skin/scale striations) to be too similar to the letter $s$, therefore not very informative. Informations about the stratigraphic layer ( $\mathrm{o}=$ overtrack, $\mathrm{u}=$ undertrack, $\mathrm{e}=$ epireleif and $\mathrm{h}=$ hyporelief) are here considered not informative for the M-preservation, therefore we consider their use unnecessary.

Note that we do not recommend the use of any specific qualitative descriptor (this is a choice of the ichnologist), we just show how the most used ones are likely correlated with the numerical values of the preservation scale. The use of letters is recommended but considered optional. We do not recommend to classify the whole track record of extensive ichnosites, although the scale can help during the material selection. We recommend to use the scale on a selection of figured tracks which are considered diagnostic (ichnotaxonomically relevant) plus some others which are considered a deviation from the expected morphology (ichnotaphonomically relevant), especially along trackways. This should be associated with a paragraph dedicated to the Mpreservation. Note that we recommend to assign values only to tracks that are figured through photographs and/or $3 \mathrm{D}$ models in the paper or in the supplemental files associated with the paper, and 
Table 1 Preservation scale including: discrete numerical values (o-4) indicating the preservation and lower case letters (p, c, w, f, a, m, s, d, b) indicating some additional information related to the preservation; a description of the general morphological features (I-VII) related to these numerical values and a comparison with widely used descriptors for the footprint preservation.

Description

3 All digit impressions, palm/sole, ungual marks, digital pads present and complete (if taxonomically relevant) (I). They are completely sharp and clear, imprint walls are well defined (II). For quadrupeds, manus prints distinguishable from pes prints. Possible occurrence of secondary features such as tail impression, digit drag marks, \& skin impressions (III). Absence of monoor multidirectional deformation of the anatomically-related morphology (IV-VI). Absence of superimposition/erosion (VII)

2 All digit impressions and palm/sole present and nearly complete (if taxonomically relevant) (I). Some ungual marks and digital pads may be missing. Footprints are fairly sharp and clear, \& imprint walls are rather well defined (II). For quadrupeds, manus prints distinguishable from pes prints. Possible occurrence of secondary features such as tail impression, digit drag marks, \& skin impressions (III). Low occurrence of monoor multidirectional deformation of the anatomicallyrelated morphology (IV-VI). Low occurrence of superimposition/erosion (VII)

1 Digit impressions and palm/sole recognizable but incomplete (if taxonomically relevant) (I). Ungual marks and digital pads may be missing. Footprints may be faint, blurred or distorted, imprint walls may be not well defined (II). For quadrupeds, manus prints distinguishable from pes prints. Possible occurrence of secondary features such as tail impression, digit drag marks,\& skin impressions (III). Considerable monoor multidirectional deformation of the anatomically-related morphology (IV-VI). Extensive superimposition/erosion (VII).

o Digit impressions and palm/sole not recognizable (I). Ungual marks and digital pads missing. Footprints completely distorted, imprint walls may be not defined (II). For quadrupeds, manus prints distinguishable from pes prints only by size. Possible occurrence of secondary features such as tail impression and digit drag marks (III). Preponderance of monoor multidirectional deformation of the anatomically-related morphology (IV-VI) or of superimposition/erosion (VII)

p Partial preservation (e.g., missing toe impressions)

c Morphology cut (superimposition, breakage)

w Anomalous width (e.g., collapsed tracks/very broad digits)

f Flattened footprint

a Anomalous morphology (multi-directional deformation)

$\mathrm{m}$ Anomalous morphology (mono-directional deformation)

$\mathrm{s}$ Skin/scale impressions

d Drag marks

b Digit tip bifurcation
Use

Associated terms

Excellent prints upon which to base new ichnotaxa, even at the level of ichnospecies. Excellent prints to recognize morpho-functional characters useful for trackmaker attribution. These are the only footprints that allow reliable landmark identifications for shape analyses.

Some higher, at best at generic level, ichnotaxonomy possible but not always certain. New ichnotaxonomy at species level not recommended. Relatively good information on the trackmaker. Can be used for general shape comparisons. Tracks preserved to this extent can be used to determine precise heteropody for quadrupeds.

Assignment to previously defined ichnogenus likely possible, open nomenclature suggested; should not be used for new ichnotaxon. The print provides some information about the kind of trackmaker and poor information about the shape of the autopodium. Determination of movement direction and possibly body carriage posture (plantigrade vs. digitigrade) feasible.

Provides only a general indication of the passage of the animal, very little information about the trackmaker, if organized in trackway, possibly allows determining some parameters, e.g., print alignment, probable posture, probable direction of travel.

Additional information on the specimen Additional information on the specimen Additional information on the specimen Additional information on the specimen Additional information on the specimen Additional information on the specimen Additional information on the specimen Additional information on the specimen Additional information on the specimen
Well, good, fine, suboptimal

Poor, very poor
Poor, intermediate, suboptimal raptimal
Optimal, exceptional, elite

.


Table 2 Morphological features (I-VII) and registrational and post-registrational causes which may have produced them.

\begin{tabular}{|c|c|c|}
\hline Morphologic features & Registrational causes & Post-registrational causes \\
\hline $\begin{array}{l}\text { I Presence and completeness of digit impressions, palm/sole, } \\
\text { ungual marks, digital pads }\end{array}$ & $\begin{array}{l}\text { Foot anatomy } \\
\text { Substrate grain size/consistency } \\
\text { Undertrack layer } \\
\text { Substrate inclination } \\
\text { Locomotion and Behavior }\end{array}$ & Overtrack layer \\
\hline $\begin{array}{l}\text { II Sharpness and clarity of morphologic features, definition } \\
\text { of imprint walls }\end{array}$ & $\begin{array}{l}\text { Foot anatomy } \\
\text { Substrate grain size/consistency } \\
\text { Undertrack/overtrack layer }\end{array}$ & Overtrack layer \\
\hline $\begin{array}{l}\text { III Occurrence of secondary features (tail/body impression, } \\
\text { digit scratches, digit bifurcation, skin impression) }\end{array}$ & $\begin{array}{l}\text { Foot anatomy } \\
\text { Substrate grain size/consistency } \\
\text { Undertrack layer } \\
\text { Locomotion and Behavior }\end{array}$ & Overtrack layer \\
\hline $\begin{array}{l}\text { V Anomalous mono-directional } \\
\text { length/width/depth/sliding/bending }\end{array}$ & Substrate inclination & Compaction/tectonics \\
\hline $\begin{array}{l}\text { VI Digits cut/deformed on one side only, irregular trackway } \\
\text { pattern ("limping") }\end{array}$ & Pathology (injury, disease) & \\
\hline VII Morphology cut/superimposed/eroded & & $\begin{array}{l}\text { Biogenic/sedimentary structures } \\
\text { Weathering }\end{array}$ \\
\hline
\end{tabular}

recommend to put the numerical value of the scale beneath the track in the figure, in order to be able to verify the author's interpretation.

The use of the preservation scale is very important to compare material of different sites and to be able to correctly distinguish the diagnostic tracks from those which are non-informative due to ichnotaphonomy, avoiding the erection of ichnotaxa based on poorlypreserved material, especially in case of limited quantity of material.

In order to distinguish the causes from the effects, which can be important in studies about ichnotaphonomy and biomechanics, the morphological features (labelled I-VII) are compared with the supposed registrational and post-registrational causes (sensu Gatesy and Falkingham, 2017) (Table 2).

Note that the morphological features refer equally to true tracks, undertracks and overtracks and their natural casts (causes), and so the effects of undertracking, overtracking and cast creation are included. The preservation scale is independent of the morphological features produced by ichnotaphonomic effects, including substrate characteristics, gait and behavior of the trackmaker (Belvedere and Farlow, 2016), meaning that the features that define the different numerical values 
are all morphological features useful for an anatomy-consistent ichnotaxonomy. Of course, these features can be lightlyto heavilymodified by ichnotaphonomic effects.

Note that we avoid the term "undertrack preservation" for poorlypreserved footprints since it should be used only for preservation in the underlying layers, something that is not easily and consistently determinable, especially for isolated tracks. In fact, undertracks are registered only in laminated/layered sediment, and can only be unambiguously identified in cross-section or by level-by-level excavation (e.g. Marty et al., 2009, 2016). Moreover, the undertrack and overtrack layers are not always more poorly-preserved than footprints on the actual trampled surface; in some cases it is the opposite (e.g. Milàn and Bromley, 2006; Milan and Bromley, 2007; Avanzini et al., 2012; Falkingham and Gatesy, 2014; Marchetti, 2018). Therefore, the stratigraphic layer in which a footprint is preserved is not a useful criterion upon which to define morphological preservation; it is a possible cause for different $\mathrm{M}$-preservation rather than an effect (Table 2).

The preservation series varies depending on substrate properties and possible producers, although the M-preservation of tetrapod footprints generally takes values between 0.0 and 1.0; values of 2.0 are rather uncommon, and values of 3.0 are rare. Note that morphological preservation usually varies among tracks in the same trackway, even between impressions of pedes and manus pertaining to the same couple, and the digits of the same imprint usually show a different morphological preservation. However, the preservation scale only refers to single tracks, so a different morphological preservation of digits in the same track will result in an intermediate preservation grade, taking into account the diagnostic value of all the differently-preserved track parts.

Note that in ichnotaxonomy, the anatomy-consistent morphological features used in diagnoses differ consistently among ichnotaxa in type and number, depending on the structural complexity of the footprint and on the occurrence of morphologically-similar ichnotaxa. Therefore, the highest numeric values in the scale (2.0-3.0) require a different number and type of diagnostic features depending on the ichnotaxon. Vertebrate footprint ichnotaxonomy is the result of study of the tracks and the trackway pattern, whereas associated traces such 
as body/tail impressions or digit scratch marks have no meaning for the ichnotaxonomic definition of footprints (although vertebrate resting traces of the body or scratch marks related to swimming behavior may have their own ichnotaxonomy, e.g., Fillmore et al., 2012). Use of poorlypreserved (o.0-1.0) and isolated tracks (if not supported by the description of more complete specimens) for ichnotaxonomic purposes should be avoided. Ichnotaxa defined on poor material, after a proper and detailed revision of the type material, should be considered as nomina dubia.

The proposed scale was refined comparing ichnotaxonomic studies of hundreds of sites, including tracks attributed to all main groups of terrestrial vertebrates, coming from several different track-bearing lithofacies and spanning from the Palaeozoic to the Recent, including neoichnological experiments.

\section{Track ichnotaxobases}

Ichnotaxobases were defined in invertebrate ichnology by Bromley (1990b, 1996), and can be defined as "morphological feature[s] of a trace fossil considered as valid basis for ichnotaxonomy”. In vertebrate footprint ichnology, the use of this term is not so common (e.g. Demathieu and Demathieu, 2003; de Valais and Melchor et al., 2018; Melchor et al., 2018), although anatomy-consistent vertebrate footprint ichnology is based on precise and definite ichnotaxobases. In vertebrate footprint ichnotaxonomy, morphological characters have a very different relative impact, depending on the agent which is supposed to generate them (causes 1-4, Fig. 4). Generally, anatomy-controlled influences (cause 1) and, to a lesser extent, morphological features related to the specific type of locomotion (cause 2) are the only acceptable ichnotaxobases (Fig. 4). These criteria include the anatomyconsistent track morphology and the trackway pattern and arrangement, especially for evident differences generated by biped/quadruped or very different locomotion styles such as hopping, jumping, walking, trotting. In other cases, trackway parameter differences can be misleading (e.g. Díaz-Martínez et al., 2015a; Farlow et al., 2018a). In anatomy-consistent track morphology we include track measurements (Leonardi, 1987). 


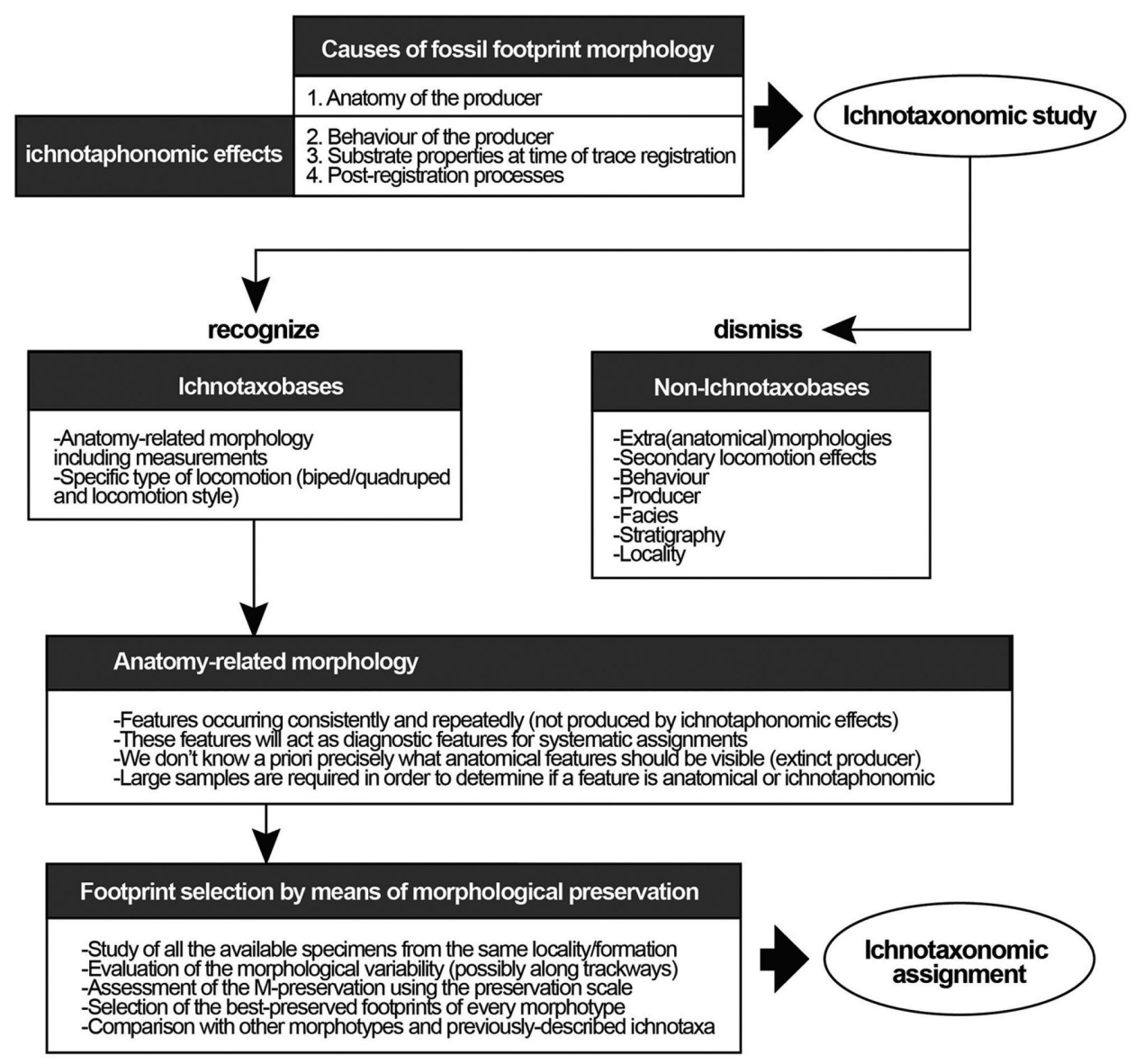

Fig. 4. Scheme of an anatomy-consistent ichnotaxonomic study.

Morphological characters which are due to secondary locomotion effects (such as digit drag impressions; cause 2), substrate conditions at the time of trace registration (cause 3) and post-registration processes (cause 4) are instead dismissed (Fig. 4). We agree with Bertling et al. (2006) in dismissing location and facies as possible ichnotaxobases, as instead suggested by Haubold (1996), because we notice several vertebrate footprint morphologies which are not faciesand localitydependant (e.g. Ichniotherium, which is found in fluvial and aeolian facies; Voigt, 2005; Francischini et al., 2018; Marchetti et al., 2019). In addition, if we consider hosting sedimentary facies in ichnotaxonomy, the potential usage of that ichnotaxon in the recognition of ichnofacies is precluded because of circular reasoning. This does not mean that the environment may not play an important role in the ichnofaunal composition of vertebrate footprint ichnoassociations, but it 
is rather evident that vertebrate footprint ichnotaxa are very faciescrossing (e.g. Marchetti et al., 2017c).

Another aspect is the selection of a hierarchy of ichnotaxobases at the (ichno)family, (ichno)genus and (ichno)species level (e.g. Sarjeant and Langston Jr, 1994; De Valais and Melchor, 2008; Melchor et al., 2018). Traditionally, ichnogenera were named on the basis of morphological features of footprints with an anatomical relation, while, trackway parameters can be regarded as an aid for distinction of ichnospecies (e.g. De Valais and Melchor, 2008; Melchor et al., 2018) and the ichnotaxobases of family rank are broad footprint (and trackway) features (e.g. overall footprint shape and proportions, number of digits, heteropodial or homopodial character). It is suggested that authors working on the ichnotaxonomy of a tetrapod track group, explicitly indicate the ichnotaxobases considered useful for that group, distinguishing between those of ichnofamiliar (if applicable), ichnogeneric and ichnospecific rank. A good way to make this clear is by constructing a key to discriminate the different ichnotaxa (e.g. Genise, 2004; Melchor et al., 2018).

In the tetrapod track record, morphological features related to the anatomy of the producer (the most important ichnotaxobase) are only recognizable if the analysis and discrimination of substrate conditions, anatomy, kinematics and post-registration processes are adequate.

Therefore, it becomes necessary to distinguish those morphologies which are meaningful for ichnotaxonomy (anatomy-consistent) from those which do not have ichnotaxonomic significance. This is generally achieved with the study of large samples, starting from a specific area and geological formation, then comparing contemporary sites and, if possible, by including different facies associations, and finally comparing sites of different age. It includes the study of trackways showing transitional morphologies, in order to recognize variability, as well as recurrent and consistent diagnostic morphological features which can be used in ichnotaxonomy. These features are evident in well-preserved tracks (preservation grade 2.0-3.0), which will act as a base for the ichnotaoxnomic study (Fig. 4). All the other morphological effects are generally regarded as extramorphological features or ichnotaphonomic effects.

Following the original meaning of Peabody (1948) the extra(anatomical)morphologies are defined as: track characters which tend 
to obscure the anatomy-consistent morphology, due to secondary locomotion effects, substrate conditions at time of track registration and post-registration processes (Fig. 2). These characters can be considered morphological effects of little or no ichnotaxonomic value, responsible for a high track disparity, which in the past and partly down to the present day, created ichnotaxonomic oversplitting with a disproportionate number of ichnotaxa (e.g. Ellenberger, 1983a, 1983b; Boy and Fichter, 1988; Lockley et al., 2013) that have been termed phantom taxa (sensu Haubold, 1996) or taphotaxa (sensu Lucas, 2001). In order to exclude extramorphologies, that can neither be reduced nor erased by the use of statistical methods or advanced techniques applied to the entire specimen sample (Haubold et al., 1995; Belvedere et al., 2018) it is very important to proceed to a careful selection of the studied material (e.g. Castanera et al., 2018). Only the tracks showing evident diagnostic (anatomical) features should be used for ichnotaxonomic classification (e.g. Sarjeant, 1989). The so-defined and assigned ichnotaxa are the basis for any further study on statistics, trackmaker identification, biostratigraphy, biogeography and palaeoecology (e.g. Voigt et al., 2007; Díaz-Martínez et al., 2017; Marchetti et al., 2017a; Marty et al., 2018). They determine the tetrapod track diversity and, being related to anatomical characters, also the faunal meaning of the ichnoassociation.

\section{Ichnotaphotaxa}

An incorrect evaluation of the preservation of fossils leads to the creation of taphonomy-controlled taxa (taphotaxa), which can lead to incorrect faunal interpretations (Lucas, 2001). Similarly, an incorrect evaluation of the morphological preservation of trace fossils leads to the introduction of ichnotaphonomy-controlled ichnotaxa, which are here defined as "ichnotaphotaxa". This is a synonym of the term phantom taxa, introduced by Haubold (1996).

If the type material is poorly-preserved, the diagnostic features controlled by anatomy are hardly recognized, incomplete or absent, and some features produced by ichnotaphonomic processes may instead be interpreted as anatomy-consistent morphologies (see Díaz-Martínez et al., 2015a). Consequently the type material may be incorrectly classified, and even the interpretation of the trackmaker's locomotion 
may be incorrect, along with any hypothesis about the identity of the trackmaker (e.g. Gilmoreichnus Haubold, 1971 interpreted as a pelycosaur track, while actually it is probably a captorhinid track; Voigt, 2005). This can be a major problem for extending the implications of the ichnologic study, and can lead to erroneous faunal, evolutionary, biostratigraphic, palaeobiogeographic, palaeoecologic and ichnofacies interpretations. An even bigger problem is the possibility that these illdefined ichnotaxa may be used to identify and classify different specimens (usually showing a comparable M-preservation). In that case, any further interpretation based on the misidentified material is potentially erroneous (e.g. supposed earliest reptile tracks by Falcon-Lang et al., 2007, which are probably anamniote tracks after Keighley et al., 2008). Therefore, we recommend that ichnotaphonomy-controlled ichnotaxa should not be used, and to always choose the best-preserved material in the erection of new ichnotaxa. All ichnotaxonomy based on poorlypreserved material can be considered a taphotaxonomy, and any interpretation coming from it is dubious. In the case of names introduced based on poorly-preserved material and later widely used, a revision with the description of additional material from the type locality or the use of different (but possibly not new) names based on adequatelypreserved material should be urgently done.

\section{Ichnotaxonomy}

The ichnotaxonomy of vertebrate footprints is (i.e., should be) based on their morphology (e.g. Hitchcock, 1858; Lull, 1904; Pabst, 1908; Peabody, 1955; Baird, 1957; Haubold, 1971; Gillette, 1986; Gand, 1988; Thulborn, 1990; Farlow, 1992; Haubold et al., 1995; Lockley, 1998; Voigt, 2005; Klein and Lucas, 2010a,b; Marty et al., 2010, 2018; Castanera et al., 2013a,b; Díaz-Martínez et al., 20o9; Marchetti et al., 2015a,b, 2017b; Marchetti, 2016; Razzolini et al., 2017). More specifically, it is based on their morphological quality by means of presence/ absence of diagnostic morphological features derived from trackmaker anatomy (preservation grade 2.0-3.0) in both pes and manus (quadrupeds) or in the pes (biped), and to a lesser extent, on the associated type of locomotion (trackway pattern and configuration). 
In order to select anatomy-consistent material (preservation grade 2.0-3.0), it is necessary to study the largest specimen sample as possible, including trackways (Fig. 4). Of particular interest are variations along the same (ipsilateral) side (left vs. right tracks) of a trackway, or between the two sides (contralateral) of a trackway, or between different sedimentary levels, because such comparisons provide the greatest amount of information about possible extramorphological variation (Fig. 2). Because such extramorphological variants may be found as single prints, it is best to find such deviant forms in association with well-preserved material in order not to misinterpret such variants as reflecting anatomical characters useful for ichnotaxonomy.

In the erection of new ichnotaxa, the choice of the type material has a central role, because the type series will act as a reference for that ichnotaxon (International Commission on Zoological Nomenclature, 1999). Therefore, the type material must be the most complete and best-preserved available. In the case of vertebrate footprints, the type material may include: single footprints (isolated or not), single pesmanus couples (isolated or not), incomplete step cycles or trackways. This material can be preserved in concave epirelief or convex hyporelief.

In the past, several ichnotaxa were erected based on isolated footprints (e.g. Eubrontes giganteus Hitchcock, 1845). This is not ideal for ichnotaxonomy, even if the isolated footprints are well-preserved, because they do not take into account the intra-trackway morphological variability and do not include the trackway parameters (e.g. Sarjeant, 1989; Díaz-Martínez et al., 2015a). So, we do not recommend the institution of a new ichnotaxon based on an isolated track or pesmanus couple. Nevertheless, this type material can be considered valid if the M-preservation is good and/or more complete material, possibly including trackways, is known from the same site (e.g. Pachypes dolomiticus Leonardi et al., 1975; Evazoum sirigui Nicosia and Loi, 2003). However, type material too poorly-preserved or incomplete to be confidently assigned should be considered nomina dubia (e.g. the ichnotaxa considered nomina dubia by Díaz-Martínez et al., 2015a; Marchetti et al., 2019).

In recent years, two main approaches were followed in the choice of type specimens when a trackway was available: single tracks or pes/ manus couples of a trackway as types (e.g. Gand et al., 1995, 2000; 
Avanzini and Wachtler, 2012; Razzolini et al., 2017; Xing et al., 2018) or entire trackways as types (e.g. Farlow et al., 1989; Nicosia and Loi, 2003; Valentini et al., 2007; Voigt et al., 2013; Aramayo et al., 2015; Buck et al., 2017; Mujal et al., 2017; D’Orazi Porchetti et al., 2018; Lee et al., 2018). The choice of single tracks along trackways as types is driven by the necessity to select the most representative material for the erection of a new ichnotaxa after examining the intra-trackway variability (e.g. Razzolini et al., 2017). Conversely, the choice of trackways as types is driven by the necessity to consider the intra-trackway variability and the trackway pattern and parameters, which are part of the diagnosis (e.g., Buck et al., 2017).

We recommend the second choice, because the type series should include all the diagnostic features for the erection of the new ichnotaxon (International Commission on Zoological Nomenclature, 1999), and in case of tetrapod trackways, the trackway pattern and parameters (if available) must be part of the diagnosis, although less diagnostic than track morphology. Nevertheless, the intra-trackway variability of track morphology and trackway parameters can be high, because of different track M-preservation or change of trackway pattern along the same trackway. Therefore, we recommend the use of the preservation scale to indicate which footprints are best-preserved and act as a reference for ichnotaxonomy, and to indicate whether some trackway sections are not adequate to represent the trackway pattern of the new ichnotaxon (e.g., much lower pace due to a turn along the trackway course).

The type material for erecting new ichnotaxa must have the best possible morphological quality of the analysed sample (2.0-3.0, preferably 3.0) in at least one pedal and manual impression (quadruped) or one pedal impression (biped) along a clearly-defined trackway. This trackway constitutes the holotype trackway, and shows the ichnotaxonomic variability. Consequently it should preferably be long (for instance, six or more consecutive pes-manus couples for quadrupeds or pes prints for bipeds). The pes and manus must be complete tracks, and the diagnostic features must be clearly recognizable/measurable. Additional trackways from the type surface (type locality/type formation) with high morphological quality (preservation grade 2.0-3.0, preferably 3.0) should be included as paratypes or topotypes, in order to correctly show the recurrent diagnostic features 
and the inter-taxonomic variability (Belvedere and Farlow, 2016). The description of additional material from the same site can compensate for the possible lack of trackways or incompleteness of tracks in the case of previouslyintroduced ichnotaxa (e.g., Pachypes; Marchetti et al., 2017b). Nevertheless, an ichnotaxon should be considered valid only if the quality of the type material is acceptable (preservation grade 2.0-3.0) and clearly shows the minimum number of anatomy-consistent diagnostic features necessary to distinguish it from other, morphologically-similar ichnotaxa, making it possible to assign more complete material to that ichnotaxon. In all other cases, pending a proper detailed ichnotaxonomical revision, an ichnotaxon may or should be considered a nomen dubium. The diagnosis should include a concise description of the distinctive features, which must be clearly differentiated from all other morphologically-similar ichnotaxa, as recommended by the International Commission on Zoological Nomenclature (1999); (art 13.1). The ichnospecific diagnoses have to be differentiated from the ichnogeneric diagnoses only in case of multiple ichnospecies belonging to the same ichnogenus (Sarjeant, 1989). If possible, mediotypes and stat-tracks of the type specimens can be added to the descriptions of new ichnotaxa (Belvedere et al., 2018).

It is important to note that ichnotaxonomy must be completely independent from the taxonomic affinities of the supposed producer, and use a parallel nomenclature (International Commission on Zoological Nomenclature, 1999). Therefore, in systematic assignments, we discourage the use of supposed taxonomic names of the trackmaker together with the ichnotaxonomic group, because the trackmaker group is often unclear or there may be several possible trackmaker groups (e.g. Haubold, 1971; Gand and Durand, 2006).

We encourage the use of ichnofamilies, although they are often not well-defined. Ideal definition for ichnofamilies should be based on broad morphological features, as suggested by Sarjeant and Langston Jr, 1994 and contrary to the detailed diagnoses proposed by Lockley et al. (2006). In fact, well-defined ichnofamilies can potentially simplify ichnogeneric diagnoses, containing several features which characterize ichnogenera that belong to the same ichnofamily. This does not mean that ichnofamilies should correspond to trackmaker groups, because pes and manus morphologies are largely due to trackmaker adaptations which can be result of evolutionary convergence (e.g., 
Dromopus and Tambachichnium may fall under a single ichnofamily because are morphologically similar, but they were probably produced by very different groups such as diapsids, parareptiles and synapsids; Voigt and Lucas, 2018).

Anyway, the most important ichnotaxonomic groups are ichnogenera and ichnospecies. When the ichnotaxonomy of ichnospecies is unclear because of morphological preservation or lack of adequate revision studies, we recommend the use of open nomenclature (e.g., Matthews, 1973). Nevertheless, when an ichnogenus is clearly monospecific, the assignment to the corresponding ichnospecies is acceptable because the ichnogeneric and ichnospecific diagnosis coincide in this case.

\section{Material and methods}

In order to verify the utility of the preservation scale in ichnotaxonomic studies, we tested this method on tracks and trackways spanning from the Palaeozoic to Recent times. For each selected ichnotaphotaxon, ichnotaxon or morphotype, a short description of the material is provided, identifying the diagnostic features which allowed the assignment. Footprint measurements and footprint orientation are taken from the best-preserved pes and manus of the specimens; other trackway measurements are taken along the entire trackway, if pes and manus imprints are well-recognized. The track measurements generally follow the conventions of Leonardi (1987). The pedal mesaxony for trior tetradactyl footprints composing bipedal trackways is expressed by the Te/PW ratio ( $\mathrm{Te}=$ maximum height of the anterior triangle, PW = pes width), as defined by Lockley (2009). Statements about track size are always relative to the average dimensions of the ichnoassociation typical for that specific time-interval. The morphological preservation of the diagnostic/potentially diagnostic morphological features is evaluated, and a numeric value of the preservation scale is assigned to every relevant footprint, and so labelled beside the corresponding track in the figure (in some cases with lower-case letters from the preservation scale), so that the reader can immediately understand the evaluation of the morphological preservation in all the figures. 
We did not include 3D models of the same footprints because adequate photos are sufficient for the understanding of the M-preservation, although their use is recommended for new ichnotaxonomical revisions or new ichnotaxa erections. However, the preservation scale can be easily figured on 3D models as well, which are complementary to the photos and provide additional information (e.g. Razzolini et al., 2017; Marty et al., 2018; Meyer et al., 2018).

In the text we explain which feature(s) of which footprint of the selected specimen is (are) relevant for an anatomy-consistent assignment, and which feature(s) of the footprint is (are) instead controlled by ichnotaphonomic processes. The selected ichnotaphotaxa include an additional section about previous incorrect track assignments and trackmaker attributions due to the use of these ichnotaphotaxa in the track record.

Pes-manus couples (pes alone for bipeds) are numbered progressively along the trackway along the direction of locomotion, for both left (L) and right footprints (R), which are counted separately. Note that left and right only refer to the orientation on the original trampled surface (concave epirelief), therefore they are reversed for footprints preserved as natural casts (convex hyporelief). If a pes or a manus in a couple are missing, the couple is numbered anyway, so that the number of a pes or a manus on the same side corresponds to the same pes-manus couple. Instead, if the entire couple is missing, that couple is not counted. Pes and manus imprints are indicated with $\mathrm{P}$ and $\mathrm{M}$, respectively. $\mathrm{P}$ is not used for trackways of bipedal trackmakers, because all the tracks are pes imprints. Trackways are indicated with T.

\section{Institutional abbreviations}

BSY, $\mathrm{TCH}=$ Bois-des-Sylleux tracksite and Tchâfouè tracksite as labelled in the PALA16, Jurassica Museum collections, Porrentruy, Switzerland.

CIBR = Centro de Información de Bardenas Reales, Arguedas, Navarra, Spain.

$\mathrm{CMN}=$ Canadian Museum of Nature, Ottawa, Canada. HF = University of Halle, Halle, Germany. 
IGF = Museum of Natural History of the University of Florence, Florence, Italy.

MB = Museum of Natural History, Berlin, Germany. MD.YPI = Museo Municipal de Ciencias Naturales Carlos Darwin, Punta Alta, Buenos Aires, Argentina.

MHNA = Muséum d'Histoire Naturelle, Autun, France. MNA = Museum of Northern Arizona, Flagstaff, Arizona, USA. MNG = Museum of Natural History of Gotha, Gotha, Germany. MPE = Museo Paleontológico de Enciso, La Rioja, Spain.

MPT = Museum of Nature and Technology, Wióry collection, Starachowice, Poland.

NBMG = New Brunswick Museum, Saint John, Canada. NMMNH = New Mexico Museum of Natural History and Science, Albuquerque, New Mexico, USA.

SKF-UMBD = Collection H. Klein, Saurierwelt Palaeontologic Museum, Neumarkt, Germany.

SMP = State Museum of Pennsylvania, Harrisburg, Pennsylvania, USA. UCMP = University of California, Berkeley, California, USA. UD = University of Burgundy, Dijon, France.

UGKU = Urweltmuseum Geoskoip, Thallichtenberg, Germany. USNM

= Smithsonian National Museum of Natural History, Columbia District, USA.

YPM = Yale Peabody Museum, New Haven, Connecticut, USA.

\section{Examples of ichnotaphotaxa}

Here we discuss and evaluate with the preservation scale three different ichnotaxa which were defined based on poorly-preserved material: Pseudobradypus unguifer (Dawson, 1872) (Fig. 5A-B), Gilmoreichnus hermitanus (Gilmore, 1927) (Fig. 6A) and Coelurosaurichnus toscanus Huene, 1941 (Fig. 7A-D). These ichnotaxa were chosen as examples because they were based on poorly-preserved material probably assignable to other ichnotaxa, and because several specimens showing comparable M-preservation from different localities and formations were incorrectly assigned to these ill-defined ichnotaxa (e.g. Demathieu and Gand, 1972; Haubold et al., 1995; Courel and Demathieu, 2000; Gand and Demathieu, 2005; Falcon-Lang et al., 


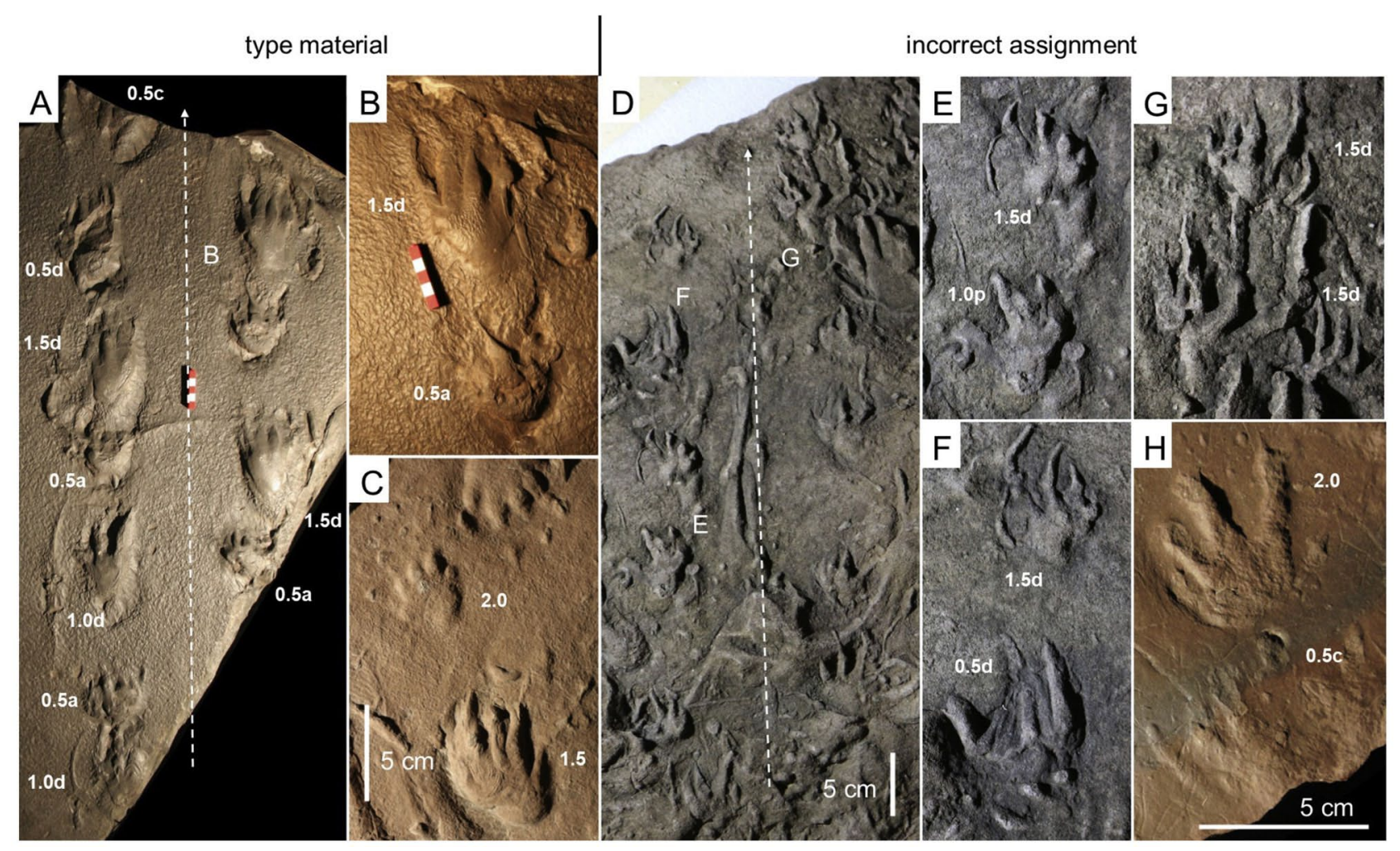

Fig. 5. Ichnotaphotaxa and incorrect assignments, Carboniferous. A) CMN 4630. cf. Dimetropus isp., holotype of Pseudobradypus unguifer (nomen dubium), trackway, convex hyporelief, Carboniferous, Cumberland Group, Nova Scotia. B) Enlargement of A. Left manus and pes of two different couples. C) MNG 1828. Dimetropus leisnerianus, left pes-manus couple with a similar M-preservation of the pes, convex hyporelief, Permian, Tambach Formation, Germany. D-G) NBMG 14143. Carboniferous, Grande Anse Formation, New Brunswick. D) Poorly-preserved trackway, convex hyporelief, Hylopus isp., attributed to anamniote trackmakers. Incorrectly assigned to Pseudobradypus and attributed to reptile producers in Falcon-Lang et al. (2007). E-G) pes-manus couples, enlargements of D. H) NMMNH-NN 1. Hylopus hardingi, left pes-manus couple showing a similar M-preservation of the manus, convex hyporelief, Carboniferous, Mauch Chunk Formation, Pennsylvania. Numbers aside tracks are the preservation values according to our scale, arrows indicate the trackway midline and the direction of locomotion.

2007; Fillmore et al., 2012). Therefore, all interpretations based on these three ichnotaxa and their potential trackmaker were misleading, as proved by subsequent work (e.g. Haubold and Klein, 2002; Voigt, 2005; Keighley et al., 2008). Because of the poor morphological preservation, these three ichnotaxa are here considered as ichnotaphotaxa and nomina dubia. The holotypes of Pseudobradypus unguifer, 
Gilmoreichnus hermitanus and Coelurosaurichnus toscanus are here re-assigned to cf. Dimetropus isp., cf. Hylopus isp. and undetermined dinosauromorph tracks, respectively.

\subsection{Carboniferous}

\subsection{1 cf. Dimetropus isp.}

11.1.1.1 Material. CMN 4630, holotype of the ichnogenus Pseudobradypus Matthew, 1903 and of the ichnospecies Pseudobradypus unguifer (Dawson, 1872) (nomina dubia). Trackway with 11 footprints pertaining to 7 consecutive pes-manus couples (L13, R1-4), convex hyporelief (Fig. 5A-B).

11.1.1.2 Stratigraphy and provenance. Cumberland Group, ian. Nova Scotia, Canada.

11.1.1.3. Lithofacies and depositional environment. Reddish-brown finegrained sandstone, fluvial environment (Selwyn, 1872).

11.1.1.4 Description. Tracks of a relatively large quadruped. The pes is distinctly larger than the manus (pes length $9.4-13.6 \mathrm{~cm}$, manus length $6.4-7.0 \mathrm{~cm}$ ) and is pentadactyl. The sole impression is elongated proximo-laterally. Pedal digit impressions are tapering. The pes is probably ectaxonic; digit impression $\mathrm{V}$ seems more proximally positioned. The manus morphology is completely blurred, so it is impossible to assess with certainty the number and proportions of digit impressions. All the digit tips and the basal pads of digit impression I of the pes slide in the direction of locomotion, producing thin drag marks which obfuscate the trackway morphology and proportions. The trackway is broad, and shows secondary overstep of the pes on the manus and a low pace angulation $\left(63-83^{\circ}\right)$. The pes is turned outwards $\left(28-48^{\circ}\right)$.

11.1.1.5 M-preservation. Because pedal tracks are turned outward and the digit tips of both the pes and the manus end in drag marks parallel to the direction of locomotion, there is poor M-preservation of both pes (grade 0.5-1.5) and manus (grade 0.5). The manus does not show any feature useful for ichnotaxonomic assignments. Therefore, 
we consider Pseudobradypus unguifer a nomen dubium. This material, because of the morphology of the pes, can be assigned to cf. Dimetropus isp. Nevertheless, a comprehensive revision of the Canadian material is necessary to confirm this assignment. See for comparison the specimen MNG 1828 from the Permian Tambach locality, Germany (Fig. $5 \mathrm{C}$ ). It shows a similar morphological preservation of the pes, a well-preserved manus and has been classified as Dimetropus leisnerianus by Voigt (2005).

11.1.1.6. Incorrect assignments. Because of the poor morphological preservation of the type material, several specimens showing similar M-preservation were assigned to Pseudobradypus, causing incorrect faunal interpretations (e.g. Falcon-Lang et al., 2007; Fillmore et al., 2012). Several Mississippian specimens were assigned to Pseudobradypus, although this material is either classifiable as Hylopus or unclassifiable due to poor morphological preservation (e.g. Wood and Miller, 2007; Fillmore et al., 2012). Falcon-Lang et al. (2007) hypothesized the earliest occurrence of amniote footprints based on tracks compared in the same work to Pseudobradypus (Fig. 5D). The longest and most complete trackway (specimen NBMG 14143, Fig. 5D) shows footprints oriented outward, and common digit drag marks oriented in the direction of locomotion. This trackway shows 6 consecutive pesmanus couples (L1-3, R1-3), preserved in convex hyporelief. The bestpreserved pes-manus couples (Fig. $5 \mathrm{E}-\mathrm{G}$ ) include poorly-preserved pes (grade 0.5-1.5) and more complete manus (grade 1.5). Tracks are ectaxonic and pentadactyl, and the palm/sole impressions are relatively short and show a well-impressed basal pad of digit I. The pes is markedly larger than the manus and shows an evident medial-lateral decrease in relief. The claw marks hypothesized by Falcon-Lang et al. (2007) are actually digit tip drag marks. These features are consistent with the ichnotaxon Hylopus (see for comparison a similarlypreserved pes-manus couple in Fig. $5 \mathrm{H}$, specimen NMMNHNN 1, convex hyporelief), which is however attributed to an anthracosaur trackmaker (Fillmore et al., 2012). Therefore, the whole hypothesis of early amniote occurrence is based on relatively poorlypreserved material compared to an ichnotaphotaxon (Pseudobradypus). This material is instead assignable to a different ichnotaxon (Hylopus) attributed to anamniote trackmakers. 


\subsection{Permian}

11.2.1. cf. Hyloidichnus isp.

11.2.1.1. Material. USNM 11517, holotype of the ichnogenus Gilmoreichnus Haubold, 1971 and of the ichnospecies Gilmoreichnus hermitanus (Gilmore, 1927) (nomina dubia). Trackway with 7 tracks pertaining to 4 consecutive pes-manus couples (L1-2, R1-2), concave epirelief (Fig. 6A).

11.2.1.2 Stratigraphy and provenance. Hermit Shale, Cisuralian. Arizona, U.S.A.

11.2.1.3. Lithofacies and depositional environment. Reddish laminated mudstone with mud cracks, rain drops and ripple marks, distal floodplain environment (Gilmore, 1927).

11.2.1.4. Description. Footprints of a medium-sized quadruped, pentadactyl and ectaxonic with relatively short palm/sole impression, long and straight digit impressions with inwardly bent terminations, digit impression $V$ relatively short. Pes larger than the manus (pes length 3.0-3.7 cm, manus length $2.3-2.9 \mathrm{~cm}$ ). Broad trackway with irregular pattern and relatively low pace angulation $\left(74-102^{\circ}\right)$. Tracks turned inward or parallel to the midline.

11.2.1.5 $M$-preservation. The pes has a preservation grade of 1.5 , the manus of 0.5-1.5; footprints are generally incomplete and deformed (Fig. 6A). The best-preserved pes (RP2) is incomplete and the bestpreserved manus (RM1) is incomplete and has an unclear digit outline. Therefore, we consider Gilmoreichnus hermitanus a nomen dubium. This material is instead assignable to cf. Hyloidichnus isp. See for comparison Gilmore (1927) and Haubold et al. (1995).

11.2.1.6. Incorrect assignments. The ichnogenus Gilmoreichnus has been regarded as a pelycosaur track and used for faunal and biostratigraphic interpretations (e.g. Haubold et al., 1995; Haubold, 2000), although the probable trackmaker of the holotype was a captorhinid reptile according to Voigt (2005). Being based on poorly-preserved 


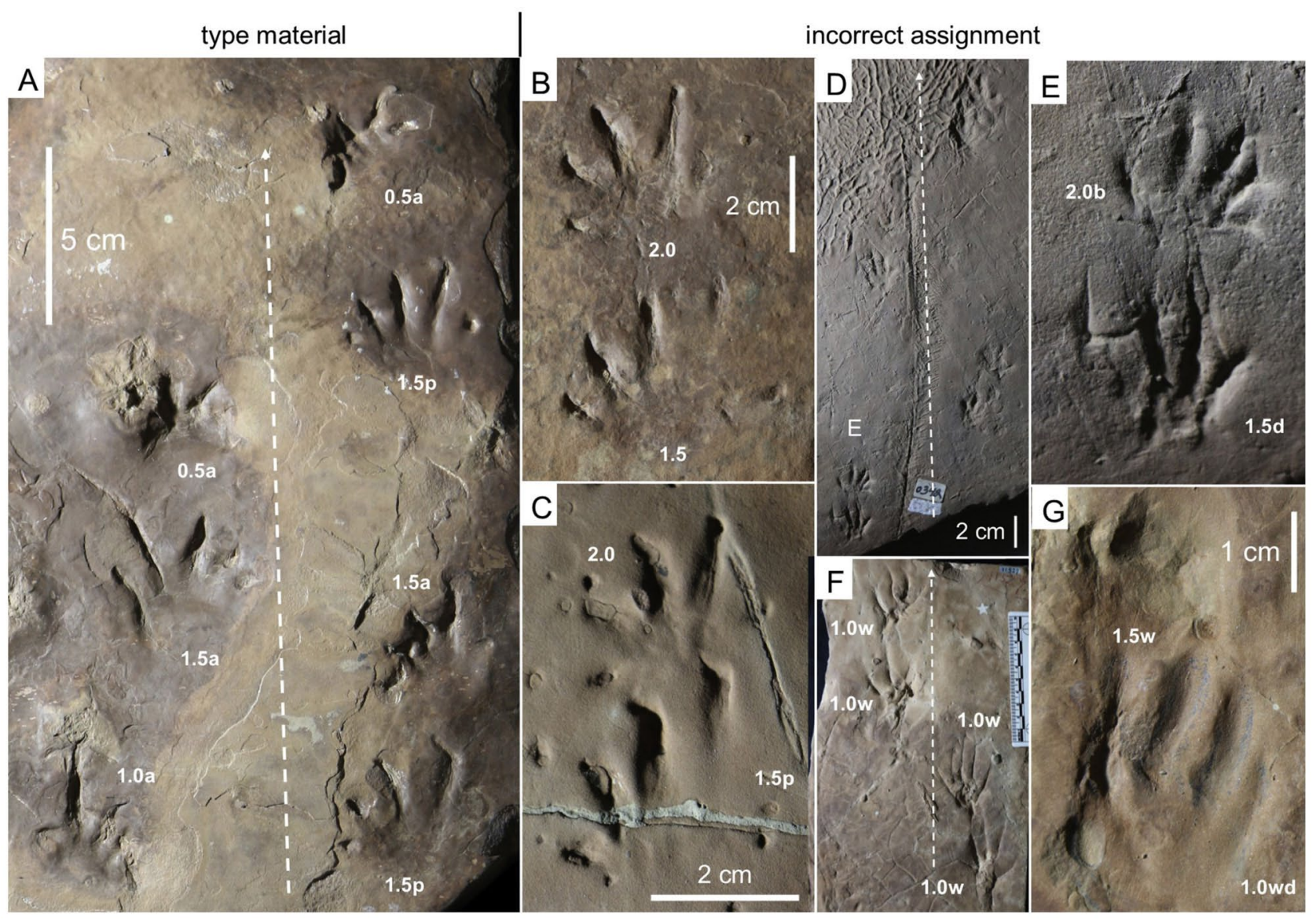

Fig. 6. Ichnotaphotaxa and incorrect assignments, Permian. A) USNM 11517. cf. Hyloidichnus isp. Holotype of Gilmoreichnus hermitanus (nomen dubium), trackway, concave hyporelief. Permian, Hermit Shale, Arizona. B-G) Specimens incorrectly assigned to Gilmoreichnus in Haubold et al. (1995). B) USNM 11711. Hyloidichnus isp., right pes-manus couple, concave epirelief. Permian, Hermit Shale, Arizona. C) YPM 304. Hyloidichnus isp., right pes-manus couple, concave epirelief. Permian, Hermit Shale, Arizona. D-E) NMMNH P-23424. Permian, Robledo Mountains Formation, New Mexico. D) Robledopus macdonaldi, trackway, concave epirelief. E) Enlargement of D, left pes-manus couple. F) USNM 11527. cf. Dimetropus isp., trackway, concave epirelief. Permian, Hermit Shale, Arizona. G) USNM 11563. Cf. Batrachichnus, right pes-manus couple, convex hyporelief. Permian, Hermit Shale, Arizona. Numbers and lower-case letters beside tracks indicate the preservation to our scale, arrows indicate the trackway midline and the direction of locomotion.

material, the ichnotaxon Gilmoreichnus was used to incorrectly assign poorly preserved specimens. For instance, in the revision of the Permian material from Arizona and New Mexico, Haubold et al. (1995) assigned to Gilmoreichnus specimens actually classifiable as 
Hyloidichnus (USNM 11711, Fig. 6B; YPM 304, Fig. 6C, concave epirelief), Robledopus macdonaldi (NMMNH P-23424, trackway with four consecutive pesmanus couples (L1-2, R1-2, concave epirelief, Fig. 6D-E), cf. Dimetropus (USNM 11527, incomplete step cycle, L1, R1, concave epirelief, Fig. 6F) and cf. Batrachichnus (USNM 11563, Fig. 6G, convex hyporelief). These footprints are attributed to captorhinid eureptiles, protorothyridid eureptiles, pelycosaur-grade synapsids and temnospondyl anamniotes, respectively (Voigt and Lucas, 2018). Therefore, the faunal interpretations based on this ichnotapohotaxon are misleading.

\subsection{Triassic}

\section{3. 1 Undetermined dinosauromorph track}

11.3.1.2 Material. IGF 5200, isolated pes, concave epirelief. (Fig. 7A-D), holotype of Coelurosaurichnus toscanus Huene, 1941 (nomen dubium) (Fig. 7A-D).

11.31..3 Stratigraphy and provenance. Quarziti di Monte Serra Formation, Late Triassic. Tuscany, Italy.

11.3.1.4 Lithofacies and depositional environment. The track-bearing Monte Serra Quartzites Formation consists of slightly metamorphic, partly fine-grained, well stratified arenites and finely laminated phyllites. Sedimentary features are mud cracks, ripple marks, flute casts, tool marks, groove casts, scour and fill structures, indicating a transitional terrestrial-to-marine deltaic depositional environment (Tongiorgi et al., 1977; Collareta and Farina, 2015).

11.3.1.5 Description. Relatively small (pes length $5.0 \mathrm{~cm}$, pes width 4.3 $\mathrm{cm}$ ) right tridactyl and mesaxonic pedal footprint, with relatively long and tapering digit impressions, longer and broader digit impression III and shorter, thinner, subequal digit impressions II-IV. Not very pronounced mesaxony $(\mathrm{Te} / \mathrm{PW}=0.67)$, total digit divarication $87^{\circ}$.

11.3.1.6 M-preservation. The footprint outline is rather undefined, as is the digit impression base and termination. Therefore, the 


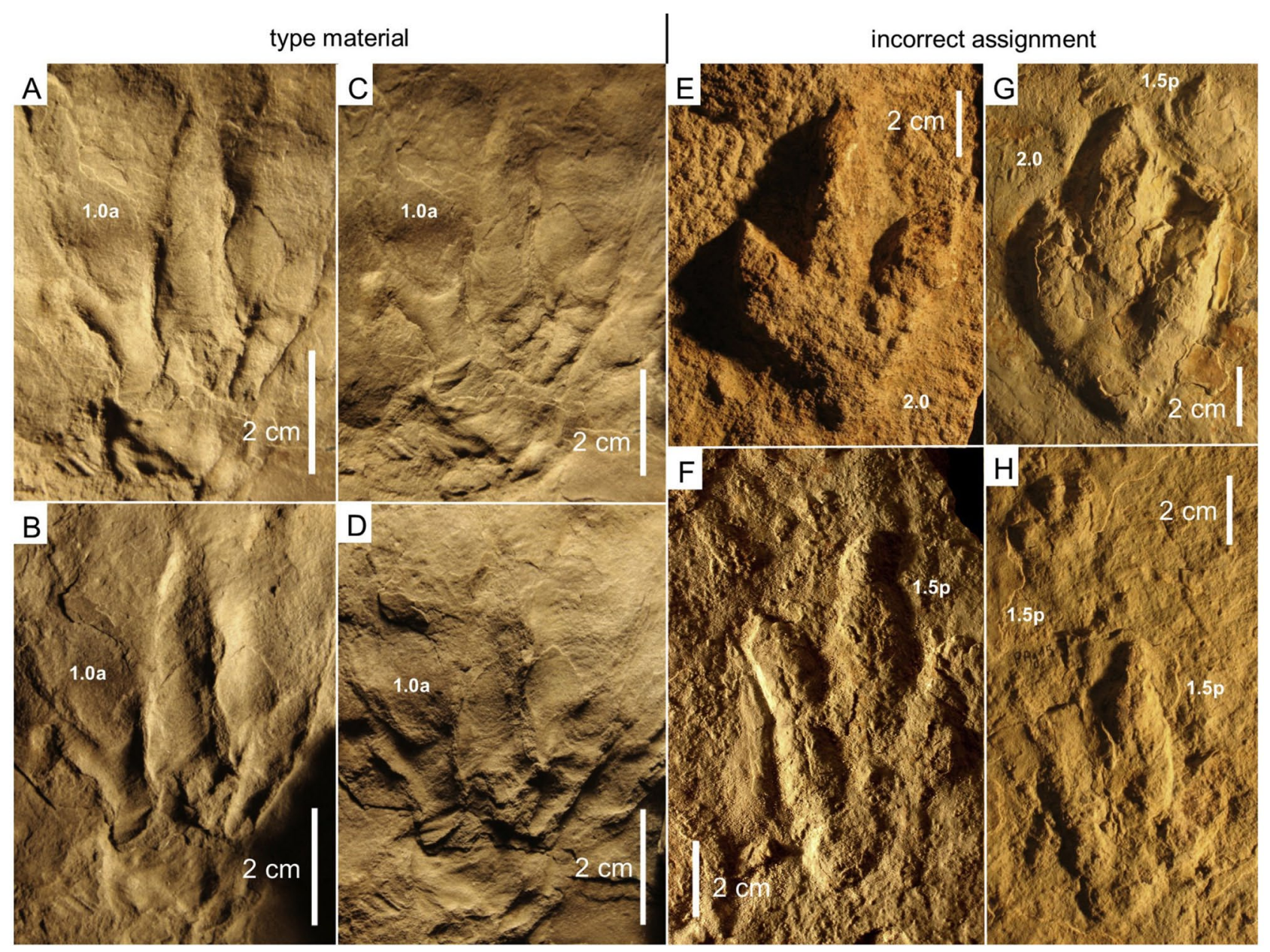

Fig. 7. Ichnotaphotaxa and incorrect assignments, Triassic. A-D) IGF 5200. Undetermined dinosauromorph track, holotype of Coelurosaurichnus toscanus (nomen dubium), pes imprint shown under different light, concave epirelief. Quarziti di Monte Serra Formation (Upper Triassic, Carnian), Tuscany, Italy. E-H) AtreipusGrallator plexus, convex hyporelief, specimens previously classified as Coelurosaurichnus perriauxi by Gand et al. (2005). Grès d'Antully Formation (Middle Triassic, Anisian-Ladinian), France. E) Holotype MHNA LP AF1. Pes imprint. La Pissoire locality. F) MHNA Pag 1. Pes imprint. Culles les Roches locality. G) MHNA Pag 50. Pes-manus couple. Pont d'Argent locality. H) MHNA Pag 15. Pes-manus couple. Pont d'Argent locality. Numbers and lower-case letters beside tracks indicate the preservation values and significant features according to our scale.

Mpreservation is low (grade 1.0) and Coelurosaurichnus toscanus is considered here a nomen dubium. The holotype is assignable to undetermined tracks of small bipedal or facultative bipedal dinosauromorphs. This follows the proposal of Leonardi and Lockley (1995), 
who proposed to abandon the name Coelurosaurichnus. However, we disagree on the assignment of this material to Grallator, because the specimens from the type locality (Lower Jurassic of Connecticut) differ significantly, being characterized by a higher mesaxony and a lower total divarication, as evidenced by Lockley (2009).

11.3.1.7 Incorrect assignments. Several other tridactyl footprints from the Middle-Upper Triassic of France have been associated with Coelurosaurichnus (Demathieu and Gand, 1972; Courel and Demathieu, 2000; Gand et al., 2005). Some were later revised and synonymized under Coelurosaurichnus perriauxi by Gand and Demathieu (2005). Following the revision by Haubold and Klein (2002), the French material is classifiable as Grallator-Atreipus plexus, whereas Grallator is characterized by tridactyl pes and absence of manus, (e.g., MHNA LP AF1, Fig. 7E and MHNA Pag 1, Fig. 7F), and Atreipus is characterized by tridactyl pes and presence of manus, (e.g. MHNA Pag 50, Fig. 7G and MHNA Pag 15, Fig. 7H). Some of them may also represent incomplete chirotheriid tracks, such as Sphingopus that are found on same surfaces. Sphingopus as well as the similar ichnotaxon Parachirotherium have pendadactyl but functionally tridactyl pes imprints and an associated manus imprint. All these morphologically similar ichnotaxa from the Triassic generally attributed to dinosauromorph trackmakers have been united in the plexus Sphingopus-ParachirotheriumAtreipus-Grallator (Haubold and Klein, 2002), and are distinguished mostly by the quadrupedal/bipedal stance and the number of digits in the pes. This variation can be due to 1) different trackmakers, 2) facultative bipedality of the same trackmaker (as documented in single trackways), 3) different posture of the pes, 4) different substrate conditions. Moreover, Grallator is presently distinguished from Eubrontes mostly by its smaller size and more gracile appearance but a higher anterior projection of digit III (more pronounced mesaxony) and a smaller digit divarication (Grallator-Eubrontes plexus, Lockley, 2009). Therefore, because the ichnotaxonomy of Triassic dinosauromorph tracks is so complex and gait-dependant, the use of well-preserved holotypes including trackways is a necessary requirement, which is certainly not matched by Coelurosaurichnus. 


\section{Examples of ichnotaxa/morphotypes}

In this section, we show several examples of different morphological preservation of selected and well-known ichnotaxa spanning from the Palaeozoic to the Quaternary, plus some recent neoichnological studies. An extensive tetrapod trace fossil record starts in the Carboniferous (e.g. Marsh, 1894; Matthew, 1903; Haubold and Sarjeant, 1973; Voigt and Ganzelewski, 2009). The Devonian also shows tetrapod footprints, but findings are fragmentary, often poorly-preserved and of dubious interpretation (e.g. Clack, 1997; Niedźwiedzki et al., 2010; Lucas, 2015); therefore we prefer not to include it and start instead from the Carboniferous. A number of two to three ichnotaxa or morphotypes per period are selected, an attempt to represent the diversity of the tetrapod groups, as far as possible. We consider to be of particular interest those specimens that display different morphological preservation of the footprints along the same trackway, evidencing morphological differences between footprints on the same side, between footprints on opposite sides of the trackway, between manus and pes in the same pesmanus couple, or between digits in the same footprint. Changes in trackmaker direction of travel, gait changes and trackways impressed on multiple layers are also of interest if linked to evident morphological changes.

\subsection{Carboniferous}

12.1.1 Anamniote tracks: Hylopus hardingi (Dawson, 1863) (Fig. 8)

12.1.1.1 Material. NMMNH-NN 1, trackway, five consecutive pesmanus couples (L1-3, R1-2), convex hyporelief.

12.1.1.2 Stratigraphy and provenance. Mauch Chunk Formation, Mississipian. Pennsylvania, U.S.A.

12.1.1.3 Lithofacies and depositional environment. Reddish mudstone/ siltstone/sandstone, common graded laminations, distal floodplain environment (Fillmore et al., 2012).

12.1.1.4Description. Pentadactyl, semiplantigrade, ectaxonic tracks of a medium-sized quadruped. Relatively long and straight digit 


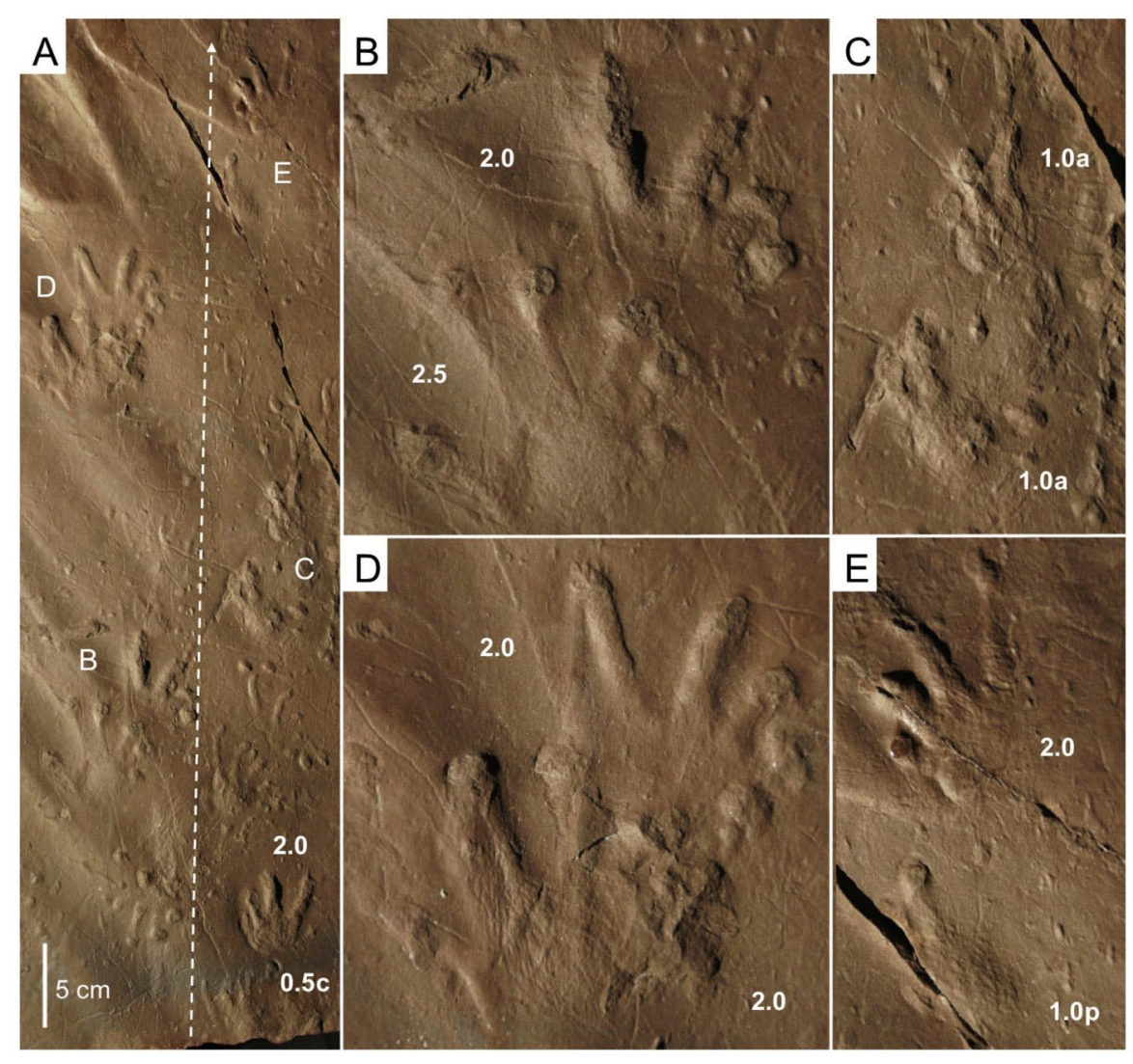

Fig. 8. Carboniferous, anamniote tracks. Hylopus hardingi. Mauch Chunk Formation, Pennsylvania, NMMNH-NN 1. A) Trackway, convex hyporelief. B, D) right pesmanus couples. C, E) left pes-manus couples. Numbers and lower-case letters beside tracks indicate the preservation values and significant features according to our scale, arrows indicate the trackway midline and the direction of locomotion.

impressions with rounded or enlarged terminations. Low divarication between digit impressions II-III in the manus and between digit impressions I-II in the pes. Digit impression V as long as digit impression I in the manus, as long as digit impression II in the pes and in a proximal position. Well-impressed and rounded basal pad of digit impression I. Medial-lateral decrease in relief, more evident in the pes. Pes larger than the manus (pes length 4.9-6.2 cm; manus length 3.6-5.0 cm). Relatively short sole/palm impression of elliptical shape and often not impressed. Simple alternating arrangement of pes-manus couples; footprints aligned to direction of locomotion or rotated outwards (pes) or inwards (manus). Relatively low pace angulation $\left(83-118^{\circ}\right)$. 
12.1.1.5 M-preservation. The trackway of specimen NMMNH-NN 1 shows a different M-preservation of the pedal tracks between the right (RP1-2, complete footprints, grade 2.0-2.5; Fig. 8B, D) and left side (LP1-3, only the medial side impressed, digits incompletely impressed or blurred, grade 0.5-1.0; Fig. 8A, C, E). The manual tracks are relatively well-preserved and display all five digits (RM2, Fig. 8D) except for the manus LM2 (only three deformed digits visible, grade 1.0; Fig. $8 \mathrm{C}$ ). Based on the morphologic features of the bestpreserved footprints (grade 2.0-2.5), this material is assignable to Hylopus hardingi (Dawson, 1872) and it is clearly pentadactyl as it is, although less well-preserved, its type material from the Carboniferous of Nova Scotia (Matthew, 1903). The shallow impression of digit $V$ may have brought incorrect interpretations in the past, with hypotheses of a tetradactyl manus (e.g. Fillmore et al., 2012).

12.1.2 Eureptile tracks: Notalacerta missouriensis Butts, 1891 (Fig. 9)

12.1.2.1. Material. NMMNH $\mathrm{P}-31746-7$, trackway with footprints pertaining to seven consecutive pes-manus couples (L1-4, R1-3) and continuous tail impression, convex hyporelief; NMMNH P-31749, trackway with footprints pertaining to five pes-manus couples (L13, R1-2) and continuous tail impression, convex hyporelief; NMMNH P31759-61, trackway with footprints pertaining to ten consecutive pesmanus couples (L1-5, R1-5) and continuous tail impression, convex hyporelief.

12.1.2.2. Stratigraphy and provenance. Keota Sandstone Member, McAlester Formation, Pennsylvanian. Oklahoma, U.S.A.

12.1.2.3. Lithofacies and depositional environment. Light olive grey to olive grey fine-grained micaceous litharenite that is thinly laminated and ripple laminated, with rain drops, gastropod impressions and plant remains; tidal flat environment (Lucas et al., 2004).

12.1.2.4. Description. Small, pentadactyl, ectaxonic, semiplantigrade to semidigitigrade footprints of a quadruped. Long, slender and tapering digit impressions ending in enlarged or bifurcated terminations. Digit impression V as long as digit impression III in the pes and as long as digit impression II in the manus. Digit impressions commonly 

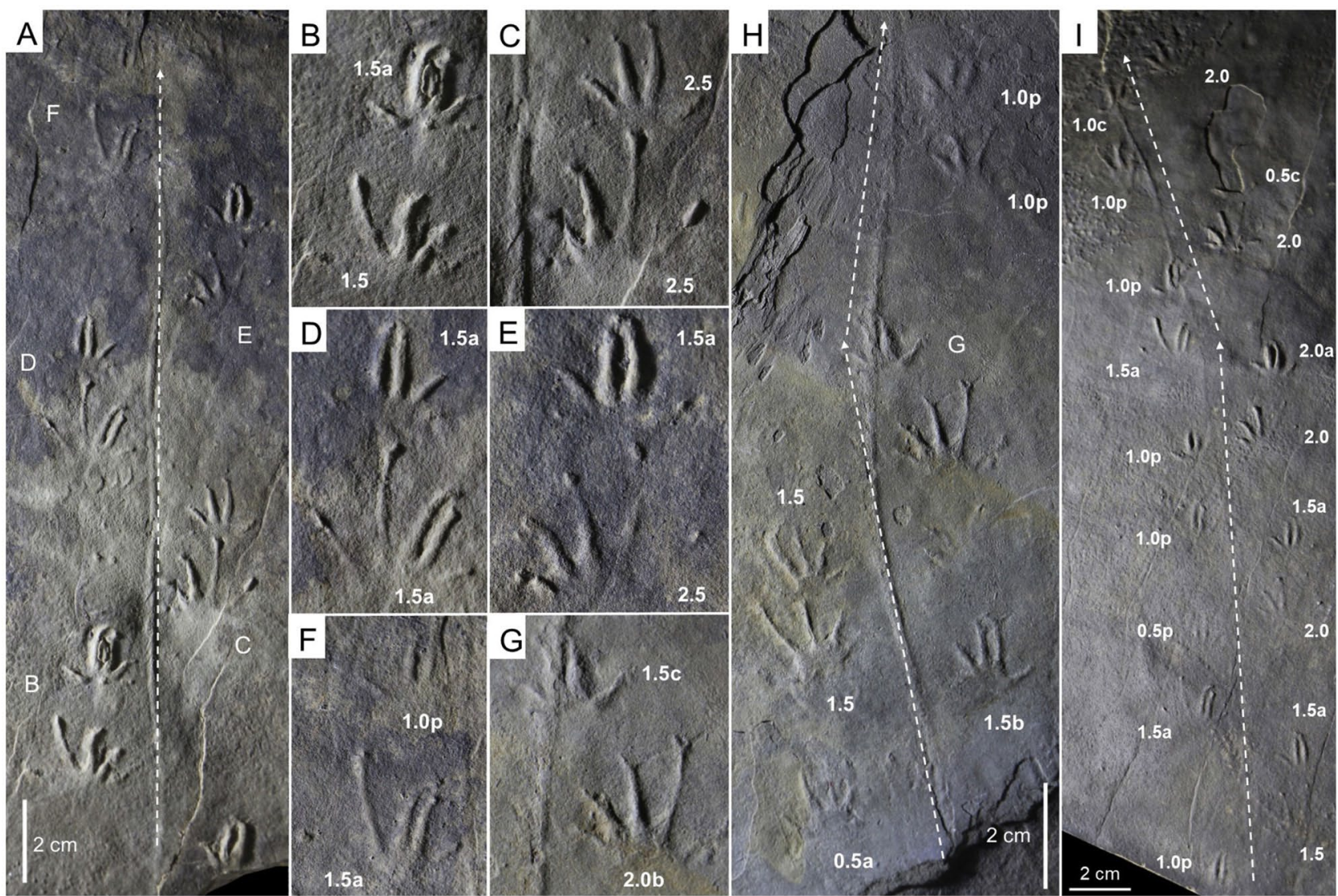

Fig. 9. Carboniferous, eureptile tracks. Notalacerta missouriensis. McAlester Formation, Oklahoma. A-F) NMMNH P-31746-7. A) Trackway and continuous tail impression, convex hyporelief. B, D, F) Right pes-manus couples. C, E) Left pes-manus couples. G-H) NMMNH P-31749. G) Left pes-manus couple. H) Trackway and continuous tail impression, convex hyporelief. I) NMMNH P-31759-61. Trackway and shallow tail impression, convex hyporelief. Numbers and lower-case letters beside tracks indicate the preservation values and significant features according to our scale, arrows indicate the trackway midline and the direction of locomotion.

inwards or outwards bent diastally, digit impressions II-III in the pes and III-IV in the manus can be parallel. Relatively high digit divarication. Pes larger than manus (pes length $1.5^{-1.9} \mathrm{~cm}$; manus length 1.2$1.5 \mathrm{~cm}$ ) and with a medial-lateral decrease in relief. Very short sole/ palm impressions with a straight to convex proximal margin, often not impressed. Simple alternating arrangement of pes-manus couples in broad trackways with relatively low pace angulation $\left(73^{-116^{\circ}}\right)$ and common, continuous and straight tail impression. Footprints are variably oriented and positioned. 
12.1.2.5. M-preservation. NMMNH P-31746-7 (Fig. 9A) includes a preserved trackway showing different ichnotaphonomic effects. The left pedal tracks are well-preserved (grade 2.5; Fig. 9C, E), whereas the right pedal tracks have a lower M-preservation because of the parallel digits II-III (grade 1.5; Fig. 9D, F) and a more indistinct outline (grade 1.5; Fig. 9B). The best-preserved manual tracks is the manus LM2 (grade 2.5; Fig. 9C); the other manus imprints show parallel digits IIIIV (grade 1.5; Fig. 9B, D, E) or are incompletely impressed (grade 1.0; Fig. 9F). NMMNH P-31749 (Fig. 9H) shows an overall poorer Mpreservation, with very incomplete ( $\mathrm{LP}_{3}$, grade 1.0), incomplete ( $\mathrm{RP} 2$, grade 1.5) or complete pes with bifuraction of the digit tip impression (LP2, grade 2.0; Fig. 9H). Manus imprints are very incomplete and 0.5-1.0) or incomplete, superimposed by the tail impression and with bifurcated digit impressions (grade 1.5; Fig. 9H-G). The trackway of specimen NMMNH P-31759-61 (Fig. 9I) shows footprints differently preserved on the two sides and progressively more deeply impressed along its course. The right manual tracks are very incomplete and show parallel digits III-IV (grade 0.5-1.0), the left manual tracks are truncated (grade 0.5 ), are incomplete and show parallel digits III-IV (grade 1.5), or are complete with parallel digits III-IV (grade 2.0). The right pedal tracks are incomplete and show parallel digits II-III (grade 1.0-1.5); the left pedal tracks are more complete and do not show digit parallelism (grade 1.5-2.0). Based on the morphologic features of the bestpreserved footprints (grade 2.0-2.5), this material is assignable to Notalacerta missouriensis Butts, 1891, according to the indications of Chesnut et al. (1994) and Lucas et al. (2004).

\subsection{Permian}

12.2.1 Anamniote tracks: Ichniotherium sphaerodactlylum (Pabst, 1895) (Fig. 10)

12.2.1.1. Material. MNG 10072, trackway with 13 consecutive pesmanus couples (L1-6, R1-7) overprinted by mud cracks, convex hypo relief. MB.1969.54.257, three pes-manus couples and partial pedal track of an incomplete step cycle, convex hyporelief.

12.2.1.2. Stratigraphy and provenance. Tambach Sandstone Member, Tambach Formation, Cisuralian. Thuringia, Germany. 

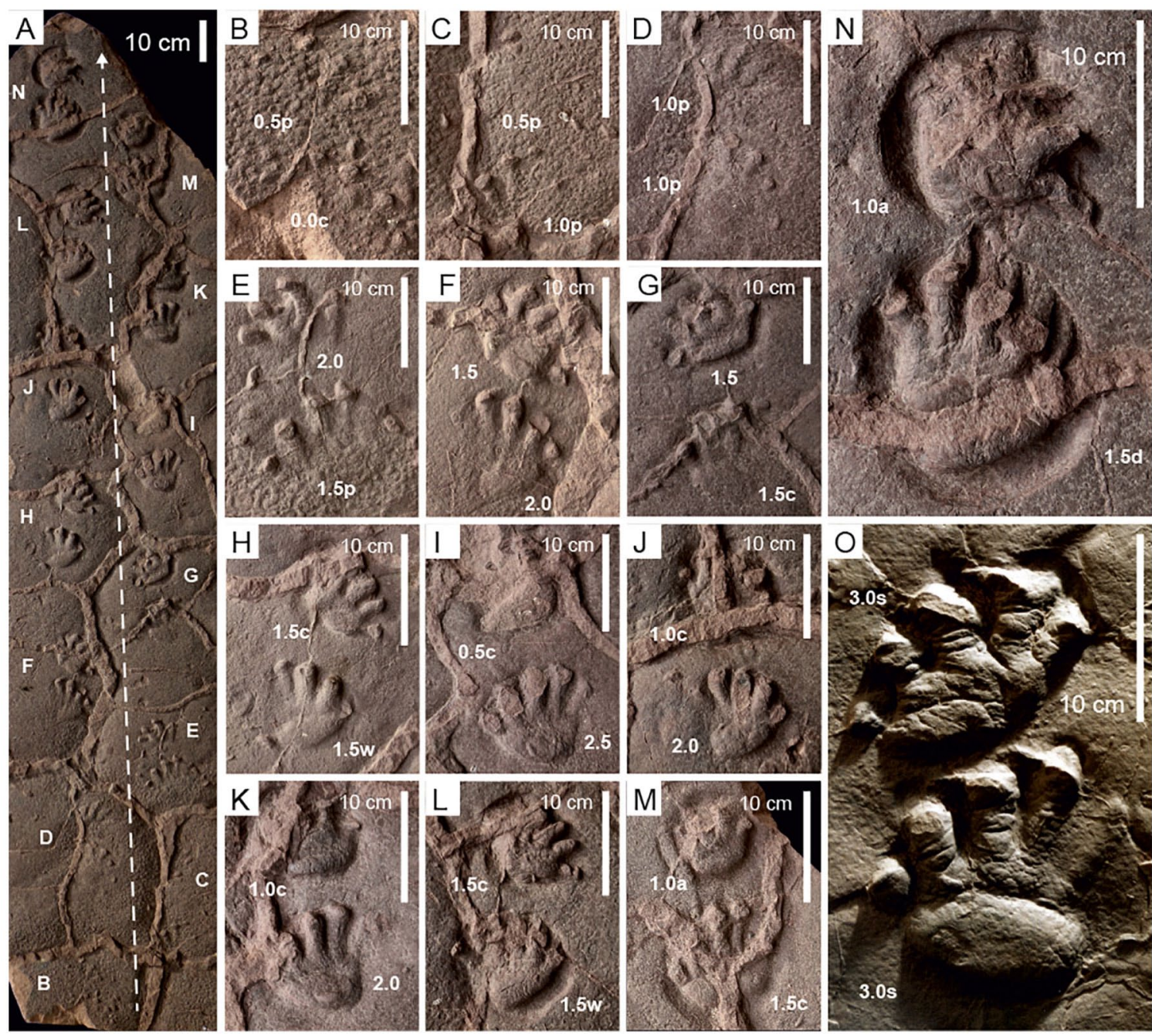

Fig. 10. Permian, anamniote tracks. Ichniotherium sphaerodactylum, Tambach Formation, Germany. A-N) MNG 10072. A) Trackway, convex hyporelief. B-N) Left and right pes-manus couples. O) MB.1969.54.257, left pes-manus couple, convex hyporelief. Numbers and lower-case letters beside tracks indicate the preservation values and significant features according to our scale, arrows indicate the trackway midline and the direction of locomotion.

12.2.1.3. Lithofacies and depositional environment. Reddish-brown, fineto medium-grained horizontally-laminated sandstones with mud cracks, raindrop marks, invertebrate trace fossils and hydromedusae; proximal floodplain environment (Eberth et al., 2000).

12.2.1.4. Description. Mediumto large-sized $(8.0-13.0 \mathrm{~cm})$, ectaxonic, pentadactyl, plantigrade footprints of quadrupeds. Pes about as 
long as wide, manus wider than long, pes about one fourth longer than manus. Digit impressions I-IV of manus and pes imprints with sequential increase in length, $\mathrm{V}$ about four-fifths the length of IV. Pedal digit impressions straight with expanded, rounded terminations (=drumstick-like outline). Manual digit impressions II-IV inwardly bent. Imprints with mediolaterally expanded, oval sole/palm impression, larger and more clearly separated from the digit imrpessions in pes than manus. Proximal part of digit imrpessions transversely segmented by short, narrow, and slightly irregularly curved creases. Manus always in front of the pes; typically alternating arrangement of coupled pes-manus imprints along trackway. Relatively low pace angulation $\left(73-104^{\circ}\right)$. Both imprints turned toward trackway midline, manus more deeply impressed than pes.

12.2.1.5. M-preservation. Specimen MNG 10072 (Fig. 10A-N) shows a trackway where pes and manus imprints gradually change morphological preservation from very shallow to very deeply impressed footprints along the direction of locomotion. Imprints of the couples R1-2 and L1 (Fig. 10B-D) have very low preservation grade (0.0 to 1.0), as digit impressions are incomplete and pes and manus are distinguishable mainly by size. Imprints of couples R3-5 and L2-5 (Fig. $10 \mathrm{E}-\mathrm{K})$ demonstrate increasingly complete digit impressions and shallow to almost complete outlines of the proximal part of footprints, demonstrating distinctiveness of pes and manus. Preservation grade range between 1.5 and 2.5 , with a few lower values due to mud crack overprinting. Most informative imprints regarding anatomical details of the trackmaker's autopods (e.g., proportions of all five digits and shape of sole and palm) are pes LP4 (grade 2.5; Fig. 10I) and manus LM2 (grade 2.0; Fig. 10E). Imprints of couples R6-7 and L6 (Fig. 10L$\mathrm{N}$ ) have reduced preservation grade (1.0 to 1.5) because of too deep impression and mud crack overprinting. Based on the morphologic features of the best-preserved footprints (grade 2.0-2.5), this material is assignable to Ichniotherium sphaerodactylum (Pabst, 1895), following the indications of Voigt (2005). Best preserved tracks of Ichniotherium sphaerodactylum not only reflect proportions of all digits, complete outlines, and different oval shapes of sole and palm proximal pads, but also include transverse segmentation of digit impressions (Fig. 10O) (Voigt, 2005; Voigt et al., 2007). 


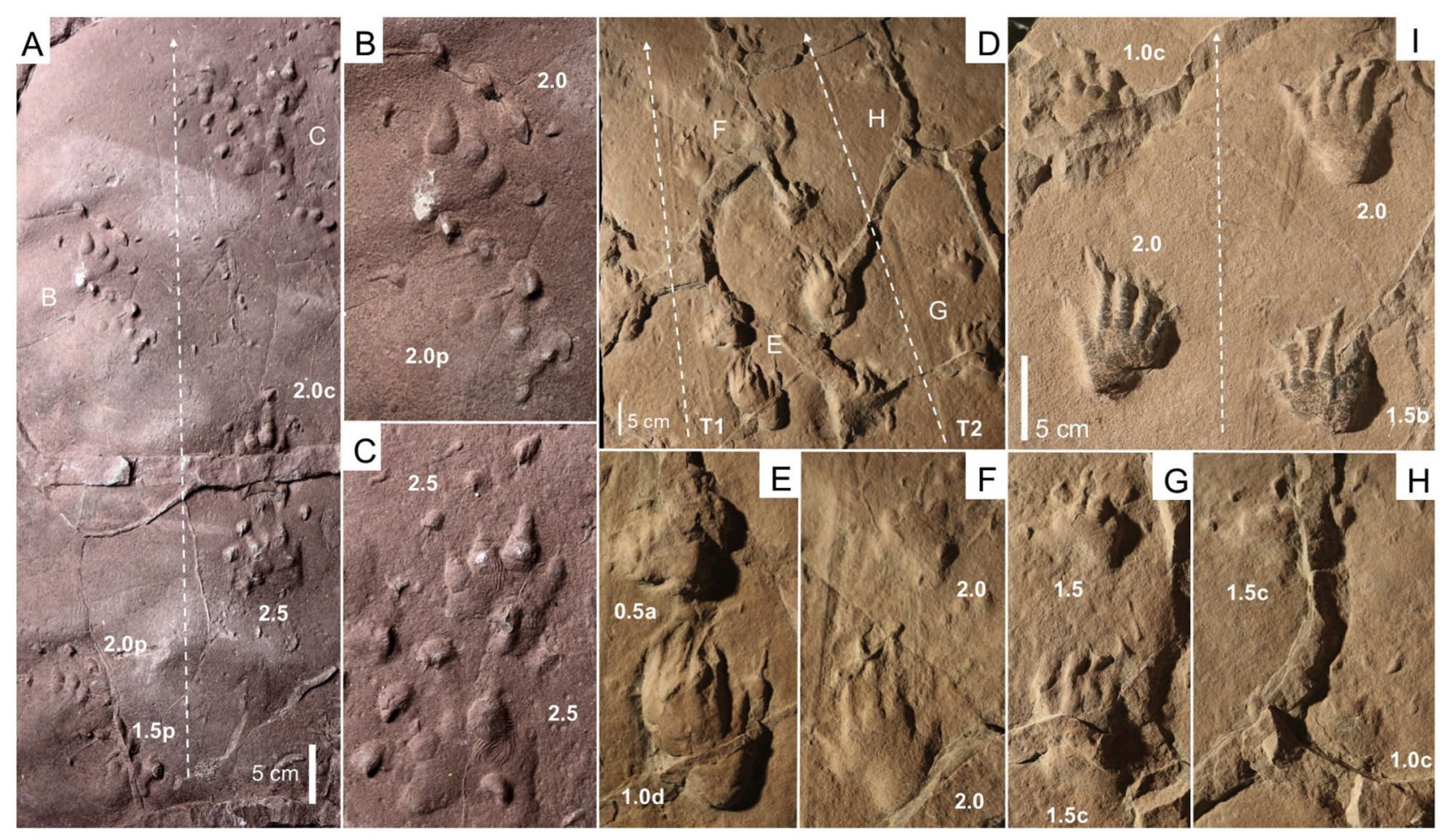

Fig. 11. Permian, synapsid tracks. Dimetropus leisnerianus, Tambach Formation, Germany. A-C) MNG-NN 1. A) Trackway, convex hyporelief. B) Right pes-manus couple. C) Left pes-manus couple. D-H) MNG 1823. D) Two parallel trackways (T 1-2) with continuous shallow tail impression. E-F) Left pes-manus couples of T 1. G-H) Left pes-manus couples of T 2. I) MNG 1762. Part of a trackway, convex hyporelief. Numbers and lower-case letters beside tracks indicate the preservation values and significant features according to our scale, arrows indicate the trackway midline and the direction of locomotion.

12.2.2. Synapsid tracks: Dimetropus leisnerianus (Geinitz, 1863) (Fig. 11)

12.2.2.1. Material. MNG-NN 1, trackway with seven consecutive pesmanus couples (L1-4, R1-3) cut by mud cracks, convex hyporelief; MNG 1823, two parallel trackways (T1 with 10 consecutive pes-manus couples, L1-5, R1-5 and T2 with 9 consecutive pes-manus couples, L14, R1-5) with straight shallow tail impression and cut by mud cracks, convex hyporelief; MNG 1762, trackway with footprints pertaining to six consecutive pes-manus couples (L1-3, R1-3) cut by mud cracks, convex hyporelief. 
12.2.2.2 Stratigraphy and provenance. Tambach Sandstone Member, Tambach Formation, Cisuralian. Thuringia, Germany.

12.2.2.3. Lithofacies and depositional environment. Reddish-brown, fineto medium-grained horizontally-laminated sandstones with mud cracks, raindrop marks, invertebrate trace fossils and hydromedusae; proximal floodplain environment (Eberth et al., 2000).

12.2.2.4. Description. Relatively large, ectaxonic, plantigrade to semiplantigrade footprints of quadrupeds. Relatively straight and parallel digit impressions, well-impressed in the proximal and distal part. Basal digital pad impressions rounded, well-impressed and aligned in a semicircle. Impressions of the digit terminations enlarged or bifurcated. Relatively large palm and sole impressions, with convex proximal margin. The sole impression is commonly elongated proximolaterally. Pes larger than the manus (pes length 6.3-9.0 cm; manus length $6.3-7.7 \mathrm{~cm}$ ), medial-lateral increase in relief. Broad trackways in a simple alternating arrangement, with variable pace angulation, from very low to low $\left(52-113^{\circ}\right)$. Possible occurrence of a straight and continuous but faint tail impression. Footprints generally aligned to the midline, manus in front of the pes and variably positioned.

12.2.2.5. $M$-preservation. The trackway of specimen MNG-NN 1 (Fig. 11A) shows a different M-preservation between the left and right sides of the trackway. The left pes-manus couples are more clearly impressed and have higher preservation grade (pes 2.5, manus 2.02.5). The right couples are more incomplete and have a lower grade (pes 1.5-2.0, manus 2.0). The pes RP2 and the manus LM3 are cut by a mud crack, and therefore show relatively lower grade ( 1.5 and 2.0, respectively) compared to pes and manus on the same side (RP 3 and LM 4; 2.0. and 2.5, respectively; Fig. 11B, C). MNG 1823 includes two parallel trackways (T1-2) that change morphological preservation along their course, becoming progressively less deeply impressed. T1 shows a poorly-preserved couple L3 with large palm/sole impression and completely blurred digits (pes grade 1.0, manus grade 0.5; Fig. $11 \mathrm{E}$ ) and a well-preserved couple $\mathrm{L} 4$, with recognizable outline and digits (grade 2.0; Fig. 11F). Conversely, T2 shows a couple L2 relatively complete, although cut by a mud crack (grade 1.5, Fig. 11G) and a more incomplete L3, also cut by a mud crack (pes grade 1.0, manus grade 
1.5; Fig. 11H). MNG 1762 (Fig. 11I) shows a relatively well-preserved trackway, with scale impressions and digit tip bifurcation (pes grade 2.0, manus grade 1.0-1.5). The poorer Mpreservation of the manus is due to the mud crack superimposition. Based on the morphologic features of the best-preserved footprints (grade 2.0-2.5), this material is assignable to Dimetropus leisnerianus (Geinitz, 1863), following the indications of Voigt (2005).

12.2.3. Parareptile tracks: Erpetopus willistoni Moodie, 1929 (Fig. 12)

12.2.3.1. Material. HF 197, two trackways (T1 with three consecutive pes-manus couples, L1, R1-2 and T2 with four consecutive pes-manus couples, L1-2, R1-2), concave epirelief; MNA-V 9148; trackway with footprints pertaining to nine consecutive pes-manus couples (L1-5, R1-4) and tail impression, concave epirelief; UGKU 1803, trackway with footprints pertaining to seven consecutive pes-manus couples (L1-3, R14), concave epirelief. MNA-V 3385; trackway with footprints pertaining to 13 pes-manus couples (figured L6-7, R4-5), concave epirelief. USNM 11151; left pes imprint, convex hyporelief.

12.2.3.2 Stratigraphy and provenance. Choza Formation, Cisuralian, Texas, U.S.A. (HF 197, MNA-V 9148, UGKU 1803) and Coconino Formation, Cisuralian, Arizona, U.S.A. (MNA-V 3385, USNM 11151).

12.2.3.3. Lithofacies and depositional environment. Choza Formation: the track-bearing horizon is an approximately $0.2 \mathrm{~m}$ thick ledge of ripplelaminated calcareous siltstone with mud cracks and invertebrate trace fossils. It is interpreted as a lacustrine (playa) siltstone encased in floodplain mudrock (Haubold and Lucas, 2003). The Choza Formation is interpreted as fluvial and lacustrine red beds interbedded with thin dolomites of marine origin (Presley and McGillis, 1982). Coconino Formation: the footprint-bearing lithofacies are mediumto finegrained well-sorted sandstones of aeolian origin, showing large-scale crossstratification (Blakey and Knepp, 1989). The trampled surfaces are interpreted as foreset dune surfaces (Marchetti et al., 2019).

12.2.3.4. Description. Small, semiplantigrade, pentadactyl and ectaxonic footprints (foot lenght 10-15 mm) of a quadruped with long, slender, tapering digit impressions terminating in sharp and thin 

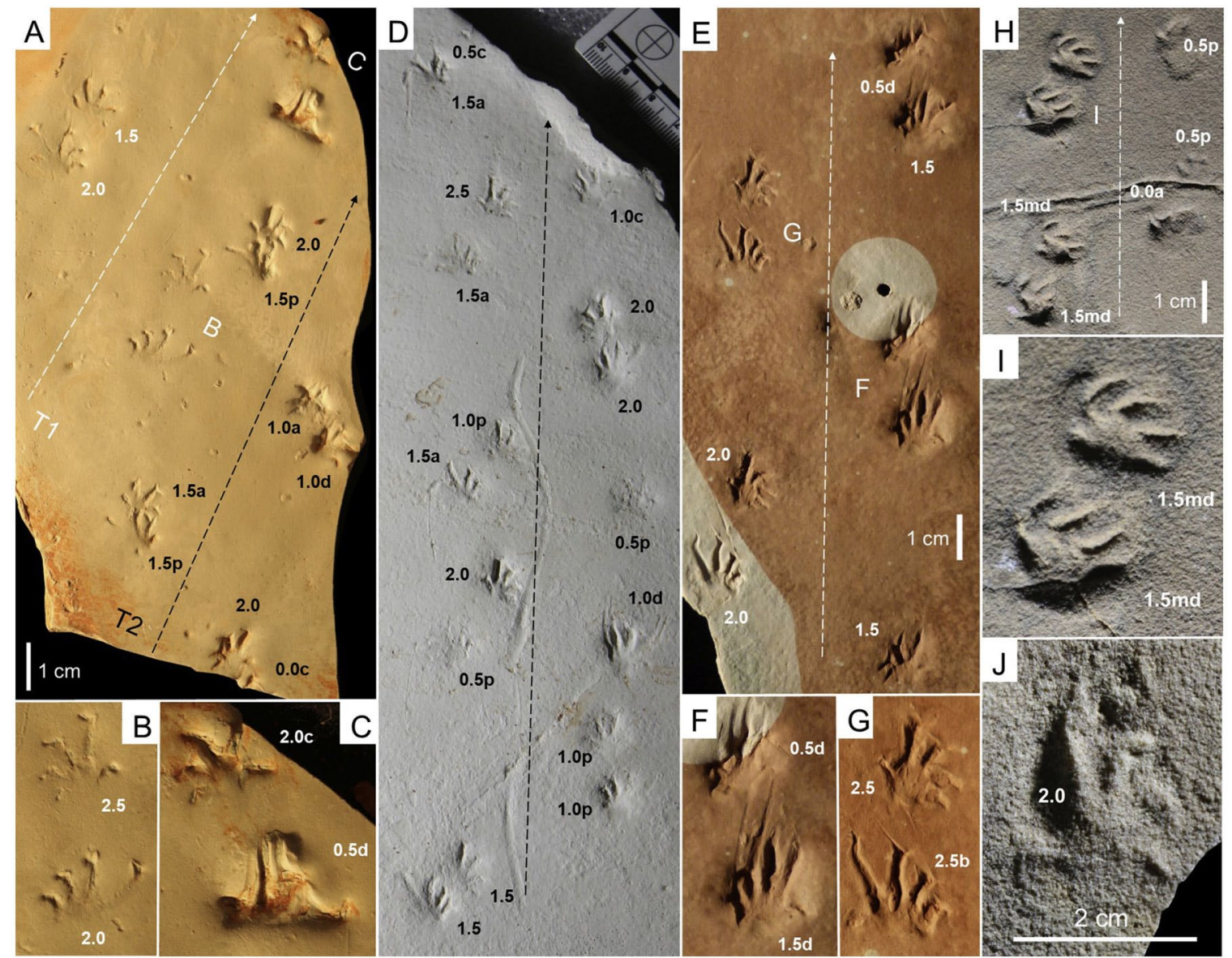

Fig. 12. Permian, parareptile tracks. Erpetopus willistoni. A-G) Choza Formation, Cisuralian, Texas. A) HF 197, two trackways ( 11 and T 2), concave epirelief. B-C) pes-manus couples, enlargements of A. D) MNA-V 9148; trackway with tail impression, concave epirelief E) UGKU 1803, trackway, concave epirelief. F-G) pes-manus couples, enlargements of E. H-J) Coconino Formation, Cisuralian, Arizona. H) MNA-V 3385; trackway, concave epirelief. I) Pes-manus couple, enlargements of $\mathrm{H}$. J) USNM 11151; left pes imprint, convex hyporelief. Numbers and lower-case letters beside tracks indicate the preservation values and significant features according to our scale, arrows indicate the trackway midline and the direction of locomotion.

claw impressions. Digits impressions I-IV distally bent inwards, digit impression V distally bent outwards. Digit impression proportions: I $<$ V $<$ II < III < IV. Relatively low digit divarication with tightlypacked digit base impressions. Digit impression V in a proximal position. Footprints about as long as wide, with short to very short palm/sole impressions. Pes and manus with similar morphology, pes slightly larger than manus and characterized by a marked medianlateral 
decrease in relief. Simple alternating arrangement of distinct pesmanus couples in broad trackways, with very low to low pace angulation $\left(40-105^{\circ}\right)$. Pes parallel to the midline or outward-bent, manus usually more medial and inward-bent. Possible partial primary overlap of the pes on the manus. Possible occurrence of sinusoidal tail impression.

12.2.3.5 M-preservation. HF 197 (Fig. 12A-C) includes two trackways, $\mathrm{T} 1$ and $\mathrm{T} 2$. T1 is characterized by a preservation grade of $0.5-2.5$. The pes imprints RP1 and LP1 are well-preserved (grade 2.0) and were used for the assignment. RP2 (grade 0.5) is instead completely deformed by the digit drag marks, so it was excluded. The manus imprints RM1 (grade 2.5) and RM2 (grade 2.0) are well-preserved and were used for the assignment, although the second has a digit IV impression distally truncated. LM1 (grade 1.5) is more unclear in the morphological preservation of the digit tip impressions. T2 is characterized by a preservation grade of 0.0-2.0. The pes imprints LP1 and LP2 (grade 1.5) were used for the assignment as regards the pedal digit impressions I-IV. RP2, although completely deformed in the digit impressions I-IV because of digit drag marks (grade 1.0), preserves a clear digit impression $\mathrm{V}$, which was therefore used in the assignment. $\mathrm{RP} 1$ is truncated, only two digit tip impressions are visible (grade o.o). The manus imprints RM1 and LM2 are well-preserved (grade 2.0) and were used for the assignment. LM1 (grade 1.5) is partially overlapped by the pes and shows a distally deformed digit impression IV and RM2 (grade 1.0) is deformed and only digit impressions I-III are recognizable. MNA-V 9148 (Fig. 12D) includes a trackway with preservation grade of $0.5^{-2.5}$. The pes imprints $\mathrm{LP}_{1}, \mathrm{LP}_{4}$ and $\mathrm{RP}_{3}$ were used for the assignment (grade 1.5-2.0). LP3, LP4 and LP5 (grade 1.5) show an anomalous outward-bending of digit impression IV, this was considered a taphonomic feature. RP1 is incompletely-impressed, RP2 is deformed by digit drag marks and RP4 is truncated (grade 1.0). LP2 is very shallow and almost non visible (grade 0.5 ). The manus imprints LM2, LM4 and RM3 are well-preserved (grade 2.0-2.5) and were used for the assignment. LM1, RM1 and RM2 are shallow and incompletelyimpressed (grade 0.5-1.5). LM 5 is truncated (grade 0.5). UGKU 1803 (Fig. 12E-G) includes a trackway more deformed on the right side. The preservation grade is $0.5^{-2.5}$. The pes-manus couples L1-2 
are well-preserved (grade 2.0-2.5) and were used for the assignment. RP2-3 (grade 1.5) are complete but deformed by the digit drags. RM1 (grade 1.5) shows a bifurcation of digit tips in digit impressions II and III, this is considered a taphonomic effect. RM2-3 are completely deformed by the digit drag marks (grade 0.5). MNA-V 3385 (Fig. 12HI) includes a trackway with a different M-preservation on the left (grade 1.5) and right (grade 0.0-0.5) side. This is likely due to the direction of progression that was perpendicular to the dip direction. The digit tip impressions of the left side are elongated laterally, due to the lateral sliding of the trackmaker on the inclined surface. USNM 11151 (Fig. 12J) includes a pes imprint that is relatively well-preserved (grade 2.0) although in aeolian lithofacies. Based on the morphologic features of the best-preserved footprints (grade 2.0-2.5), this material is assignable to Erpetopus willistoni, following the indications of Haubold and Lucas (2003).

\subsection{Triassic}

12.3.1 Archosauromorph tracks: Synaptichnium pseudosuchoides Nopcsa, 1923 (Fig. 13)

12.3.1.1. Material. SKF UMBD 7, left pes-manus couple; SKF UMBD 13 right pes-manus couple; SKF UMBD 20, left pes-manus couple; SKF UMBD 15, left pes-manus couple; isolated, convex hyporelief.

12.3.1.2 Stratigraphy and provenance. Eschenbach Formation, Middle Triassic, Anisian. Bavaria, Germany.

12.3.1.3. Lithofacies and depositional environment. Siliciclastic marginal facies of the Muschelkalk. Fineto medium-grained arcosic sandstone, siltstone and clay. Characteristic features are cross-bedding, parallel lamination, asymmetric current ripples, scour marks, tool marks, claystone clasts, invertebrate traces, and plant remains. The lack of mud cracks and the abundance of preserved skin texture suggests a continuously moisture substrate with high plasticity. The depositional environment can be characterized as fluvial, possibly alluvial fan with occasional sheet floods (Klein and Lucas, 2018). 

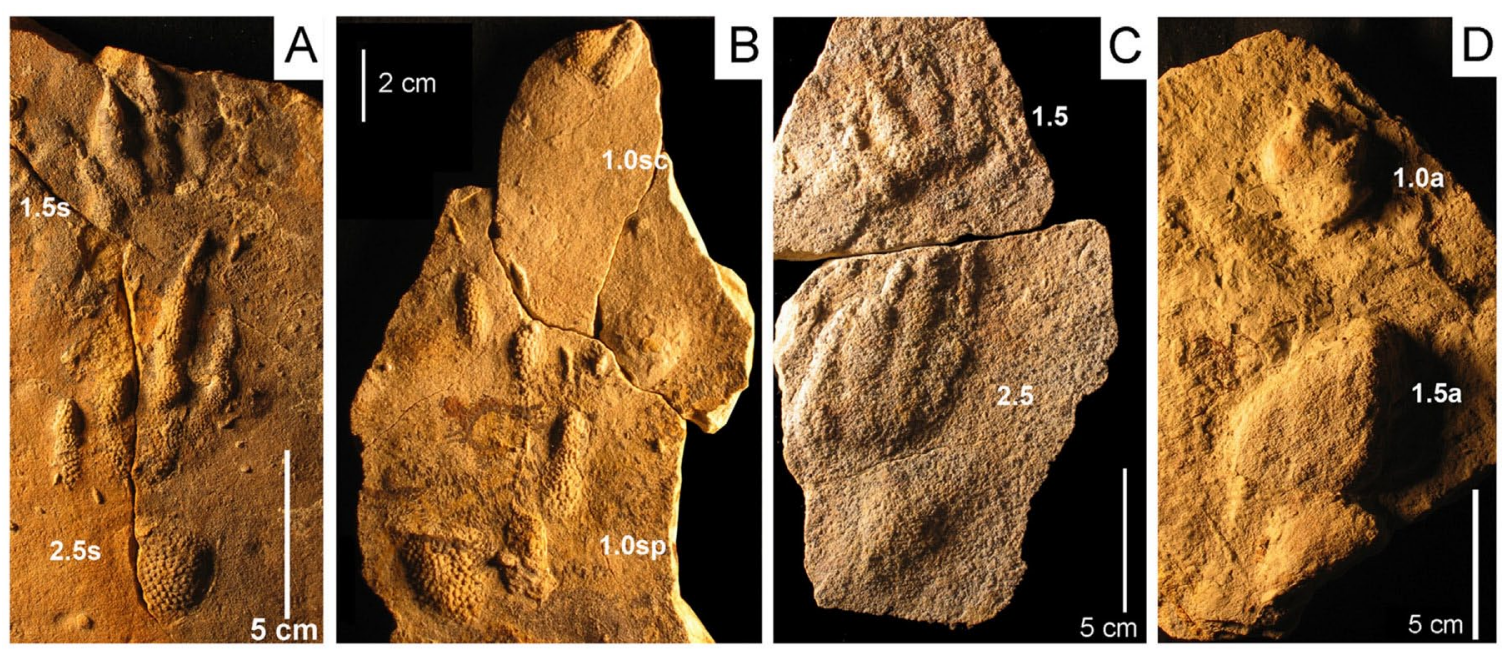

Fig. 13. Triassic, archosauromorph tracks. Chirotheriid footprints with different M-preservation. Synaptichnium pseudosuchoides, convex hyporelief. Eschenbach Formation (Middle Triassic, Anisian), northeastern Bavaria, Germany. A) SKF UMBD 7. Left pes-manus couple. B) SKF UMBD 13. Right pes-manus couple. C) SKF UMBD 20. Left pes-manus couple. D) SKF UMBD 15. Left pes-manus couple. From Klein and Lucas (2018). Numbers and lower-case letters beside tracks indicate the preservation values and significant features according to our scale.

12.3.1.4. Description. All pes imprints are of similar size, about 10 $\mathrm{cm}$ in length and $5 \mathrm{~cm}$ in width. SKF UMBD 7 (Fig. 13A) has a pentadactyl, semiplantigrade pes imprint. Digit impressions increase in length from I-IV, with digit IV being subequal in length with digit III. Digit impression $\mathrm{V}$ is preserved posteriorly as an oval basal pad and lacks the phalangeal portion. Claw impressions are sharp, in digit impressions I and IV, occasionally separated from digit impressions by a larger interspace and often elongated as drag marks. The smaller manus (manus length: pes length $=1: 3$ ) which is positioned anterior to the pes, shows four digit impressions (I-IV), with digit III being the longest. The posterior margin with digit impression $\mathrm{V}$ is apparently overstepped by the pes, the latter being rotated outward relative to the manus. Welldeveloped rounded phalangeal and metatarsophalangeal pad impressions are visible. Skin texture with polygonal scale impressions cover entire digit and sole impressions in the pes, and are partly also present, but mostly less distinct in the manus. SKF UMBD 13 (Fig. 13B) shows four digit impressions in the pes (I-III and V). Digits impressions II and III are preserved at their distal ends only. 
Digit impressions I-III have elongated claw drag marks that are separated from the rest of the digits and directed outward. There is no impression of the sole. The manus is incomplete, consisting of three partial digit impressions only. All digit impressions have skin texture similar to SKF UMBD 7. UMBD 20 (Fig. 13C) is a pes-manus couple of similar morphology as SKF UMBD 7, but lacks skin texture. Digit V of the manus is preserved as a faint, short impression. SKF UMBD 15 (Fig. 13D) shows a complete pes and an incomplete manus imprint, but without distinct borders between digit impressions.

12.3.1.5. M-preservation. SKF UMBD 7 (Fig. 13A) displays different morphological preservation of pes and manus imprints. The pes shows all digit impressions with well-defined margins, but with pad impressions being less complete, and is given a preservation grade of 2.5. In the manus the number of digit impressions is incomplete, digit V is missing and digit IV is slightly deformed. It has a grade of 1.5. SKF UMBD 13 (Fig. 13B) lacks pedal digit impression IV, digit impressions II-III are preserved with their distal ends only, but with perfect scale impressions. The sole impression is not visible, and it seems that only distal digits penetrated the substrate and reached the footprint-bearing sediment layer, while the rest of the foot remained obscured. An alternative explanation may be a laterally different substrate consistency. The fragmentary manus has three digit impressions only. A grade of 1.0 is given here for both. SKF UMBD 20 (Fig. 13C) consists of a complete well-preserved pes with almost clearly defined digit, pad and claw impressions (grade 2.5) and a nearly complete, less well-preserved manus (grade 1.5). SKF UMBD 15 (Fig. 13D) has a complete pes imprint, but with poorly defined margins of digit impressions and with a flattened sole surface, possibly being an undertrack (grade 1.5). The manus imprint shows a similar morphological preservation, moreover digit impression III is incomplete (grade 1.0). Based on the morphologic features of the best-preserved footprints (grade 2.0-2.5), this material is assignable to Synaptichnium pseudosuchoides Nopcsa, 1923 following the indications of Klein and Lucas (2018). 


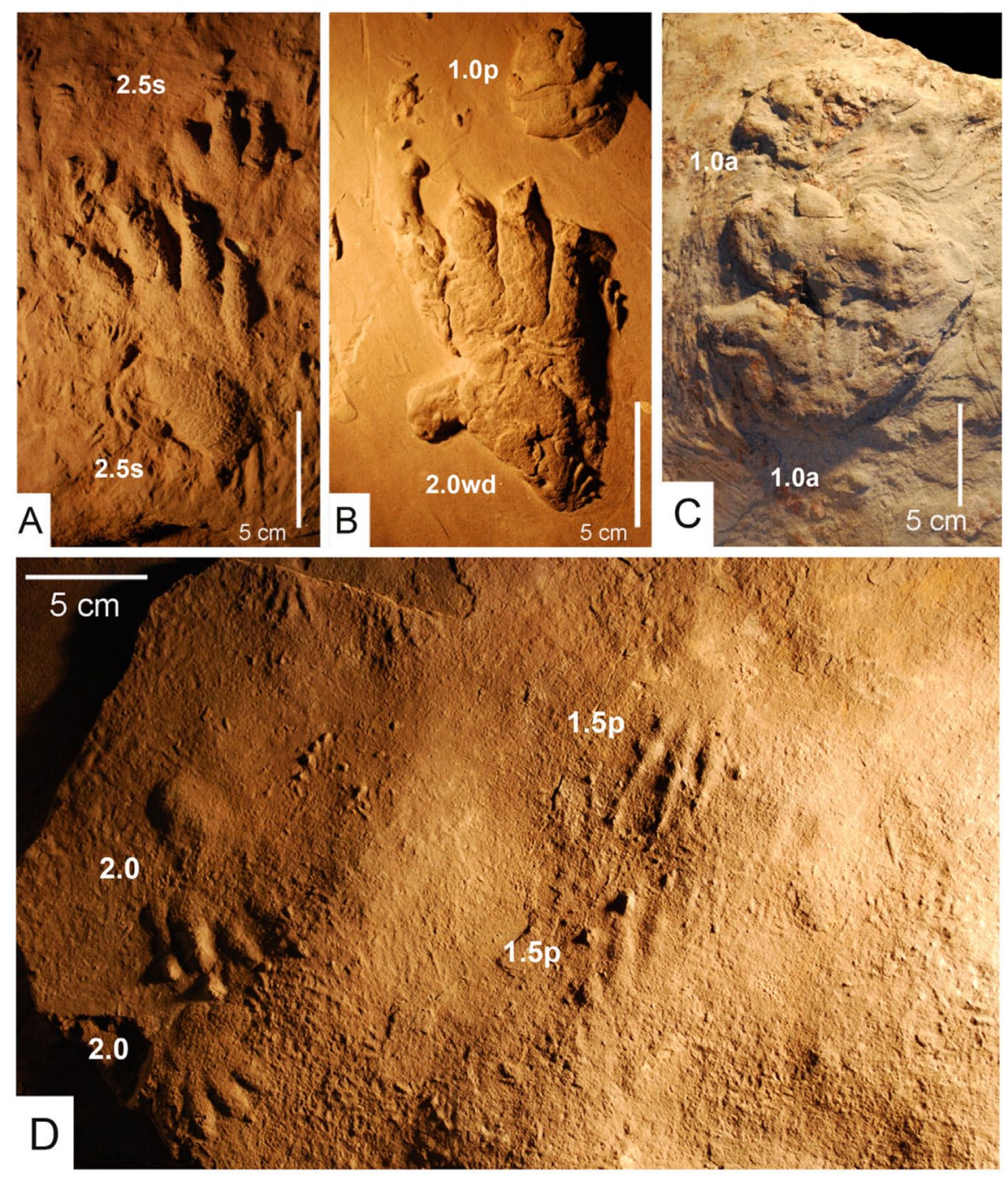

Fig. 14. Triassic, archosauromorph tracks. Chirotheriid footprints with different M-preservation. Protochirotherium hauboldi convex hyporelief. Wióry Formation (Lower Triassic, Olenekian), Wióry, Holy Cross Mountains, Poland. Note Procolophonichnium and other small footprints cooccurring. A) MPT. P. W3. Right pesmanus couple. B) MPT. P. W5. Right pes-manus couple. C) MPT. P. W32. Right pesmanus couple. D) MPT. P. W43. Right pes-manus couple and two left pes imprints, isolated. From Klein and Niedzwiedzki (2012). Numbers and lower-case letters beside tracks indicate the preservation values and significant features according to our scale.

\subsubsection{Archosauromorph tracks: Protochirotherium hauboldi (Ptaszyński in Fuglewicz et al., 1990) (Fig. 14)}

12.3.2.1. Material. MPT. P. W3, right pes-manus couple of a trackway; MPT. P. W5, right pes-manus couple, isolated; MPT. P. W32, right 
pesmanus couple, isolated; MPT. P. W43, slab with one right pesmanus couple and two left pes imprints, isolated; convex hyporelief.

12.3.2.2. Stratigraphy and provenance. Wióry Formation, Lower Triassic, Olenekian. Wióry, Holy Cross Mountains, Poland.

12.3.2.3. Lithofacies and depositional environment. Fineto mediumgrained sandstone and siltstone. Depositional environment can be characterized as braided river. Fluvial fining upward cycles with channel deposits overlain by floodplain sediments with crevasse-splay intercalations. Features are mud cracks, current ripples, vertebrate bone remains, conchostracans, plant remains and invertebrate traces (Klein and Niedzwiedzki, 2012).

12.3.2.4. Description. All pes imprints are subequal in size and about 11-12 cm in length and 7-9 cm in width. MPT. P. W3 (Fig. 14A) has a pentadactyl, semiplantigrade pes imprint with digit impression III being the longest, followed by digit impressions IV, II and I. Digit impression $\mathrm{V}$ is preserved with a massive, elongated oval impression, posterolaterally to digit impressions I-IV. Digit impression IV is slightly laterally spread. The smaller manus ( $6 \mathrm{~cm}$ long, $5.5 \mathrm{~cm}$ wide) is positioned antero-medially to the pes, pentadactyl, and with digit impression III being the longest. Digit impression V is partly overstepped by the pes. The pes is rotated slightly more outward relative to the manus. Robust triangular claw impressions and indistinct pad impressions are visible. Polygonal scales of the skin are covering all digit and the sole impressions. MPTP. W5 (Fig. 14B) is a deformed pesmanus couple preserved as deep impressions, with broad digit impressions lacking distinct pad and skin texture impressions. Pedal digit impression IV shows a drag mark distally. Pedal digit impression $\mathrm{V}$ has a recurved distal ?phalangeal portion and is elongated posteriorly into a massive "heel" impression. In the manus only digit impressions III-V are more distinct. MPT. P. W32 (Fig. 14C) is a deeply impressed pes-manus couple with short, broad digit impressions lacking claw marks. The broad pes imprint is pentadactyl with a massive, distally recurved digit impression $\mathrm{V}$, whereas the manus imprint lacks digit impression V. MPT. P. W43 (Fig. 14D) are isolated impressions with a pes-manus couple and two isolated faint pes imprints. While 
the couple is more deeply impressed, with distinct triangular claw marks, but lacks clear pad impressions, the faint pes imprints have distinct pad and claw marks on some digit impressions, but otherwise have poorly defined outlines.

12.3.2.5. M-preservation. MPT. P. W3 (Fig. 14A) is nearly perfect in morphological preservation; only some claw marks are less welldefined (grade 2.5). MPT. P. W5 (Fig. 14B) shows a pes imprint with relatively broad digit impressions due to the deep substrate (grade 2.0). The manus is deformed and incomplete (grade 1.0). MPT. P. W32 (Fig. 14C) is an extremely deformed pes-manus couple with very short and thick digit impressions that lack any details, indicating the substrate was probably more soft and deep (grade 1.o). MPT. P. W43 (Fig. 14D) shows both deeper impressions of pes and manus imprints with complete and well-defined digit and claw mark impressions (grade 2.0), as well as very faint pes imprints displaying a poor general outline, but with digital pad impressions (grade 1.5). The different M-preservation on a single surface suggests varying water contents of the substrate, with the faint impressions reflecting registration under drier conditions, but with enough moisture to leave some details such as the phalangeal pad impressions. Based on the morphologic features of the best-preserved footprints (grade 2.0-2.5), this material is assignable to Protochirotherium hauboldi (Ptaszyński in Fuglewicz et al., 1990) following the indications of Klein and Niedzwiedzki (2012).

12.3.3. Archosauromorph tracks: Rotodactylus cursorius Peabody, 1948 (Fig. 15)

12.3.3.1. Material. Slab with two complete trackways UCMP 38022 (figured L2, R1-2) and UCMP 38023 (figured L1, R1-2); convex hyporelief.

12.3.3.2. Stratigraphy and provenance. Moenkopi Group ("upper red formation”), Middle Triassic, Anisian. Near Hurricane, Utah, U.S.A. (Peabody, 1948; Klein and Lucas, 2010b).

12.3.3.3. Lithofacies and depositional environment. Fine-grained sandstone-siltstone. Footprints come from a facies that suggests 


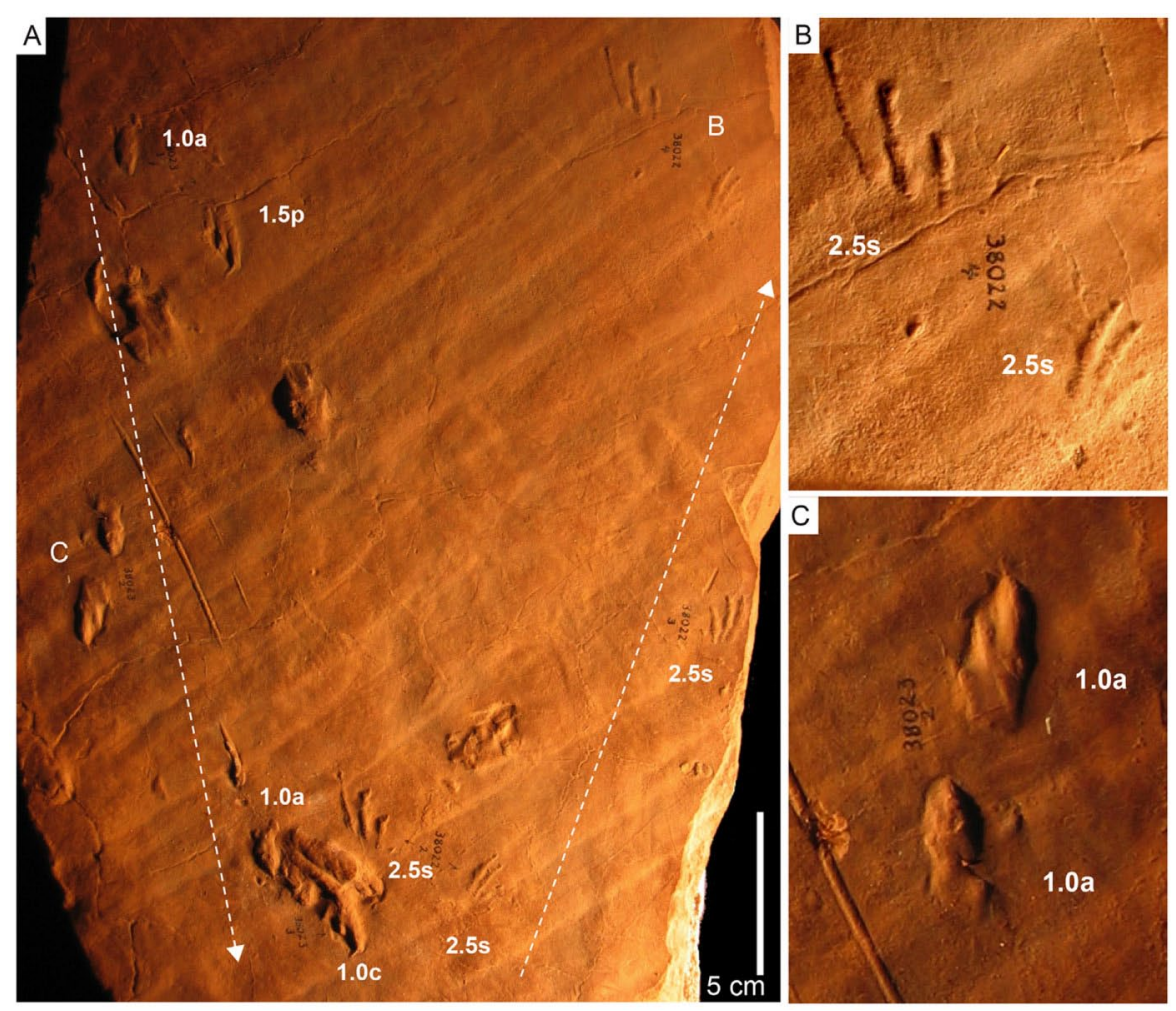

Fig. 15. Triassic, archosauromorph tracks. Slab with two trackways of Rotodactylus cursorius UCMP 38022 and 38,023 in different M-preservation, convex hyporelief. Moenkopi Formation, Arizona. A) Overview. B) Enlargement of A. Right pes-manus couple of trackway UCMP 38022. C) Enlargement of A. Left pes-manus couple of trackway UCMP 38023 . Note the complete primary overstep of the pes on the manus. From Klein and Lucas (2010b). Numbers and lower-case letters beside tracks indicate the preservation values and significant features according to our scale, arrows indicate the trackway midline and the direction of locomotion.

unchannelized flow events on river floodplains or tidal flats. Features are mudcracks and ripple lamination. Accompanying fossils are invertebrate traces indicating the Scoyenia ichnofacies. A diverse vertebrate fauna with abundant skeletal remains is known from adjacent channel layers in the Moenkopi Formation (Klein and Lucas, 2010b).

12.3.3.4. Description. The slab with UCMP 38022 and UCMP 38023 (Fig. 15A) is part of longer trackways consisting of numerous digitigrade to semi-plantigrade, pentadactyl pes-manus couples. The pes is about $3.5 \mathrm{~cm}$ in length and the manus about $1.9 \mathrm{~cm}$ in length. Digit impressions are thin and slightly curved inward, with small sharp claw marks. They increase in length from I to IV, digit impression 
IV is the longest. Digit impression V is preserved far posterior to the main digit group by a punctiform impression and positioned in line with digit impression IV. In the pes, the distance of digit impression $\mathrm{V}$ from the posterior end of digit impression IV corresponds to the length of digit impression IV; in the manus it is shorter. Trackways show long strides with lateral primary overstep of the manus by the pes. Relatively high pace angulation $\left(123-152^{\circ}\right)$. The pes is outwardly, the manus inwardly rotated relative to the midline. UCMP 38022 has imprints with distinct pad, claw traces and transverse scale impressions (couple R2, Fig. 15B). UCMP 38023 shows only indistinct borders of digits in most imprints; only in one pes imprint digits are more clearly defined (couple L1, Fig. 15A).

12.3.3.5. M-preservation. UCMP 38022 and UCMP 38023 (Fig. 15A) are differently preserved trackways on the same surface. While UCMP 38022 is nearly perfect with well-defined digit, pad, scale impressions (e.g., couple R2, grade 2.5; Fig. 15B), UCMP 38023 shows only few details. The best-preserved imprint is a pes with well-defined digit margins and claw traces (RP1, grade 1.5), whereas the corresponding manus imprint shows no defined digit impressions (RM1, grade 1.0) (Fig. 15A). Other pes and manus imprints of this trackway take a 1.0 grade, characterizing a morphology with incomplete, poorly defined and blurred digit impressions (couple L1, Fig. 15C). The different Mpreservation of these trackways on a relatively small surface is due to different moisture contents of the substrate. This suggests that trackmakers, probably small dinosauromorphs, left their footprints here at different times. Based on the morphologic features of the bestpreserved footprints (grade 2.0-2.5), this material is assignable to Rotodactylus cursorius Peabody, 1948 following the indications of Klein and Lucas, 2010b).

\subsection{Jurassic}

12.4.1. Theropod dinosaur track: Megalosauripus transjuranicus Razzolini et al., 2017 (Fig. 16)

12.4.1.1. Material. Trackway BSY1040-T1 (figured pes imprints L2-3, R1-2), with R1 being a paratype and L2, R2, L3 referred specimens (see also S14 of Razzolini et al., 2017), concave epirelief. 

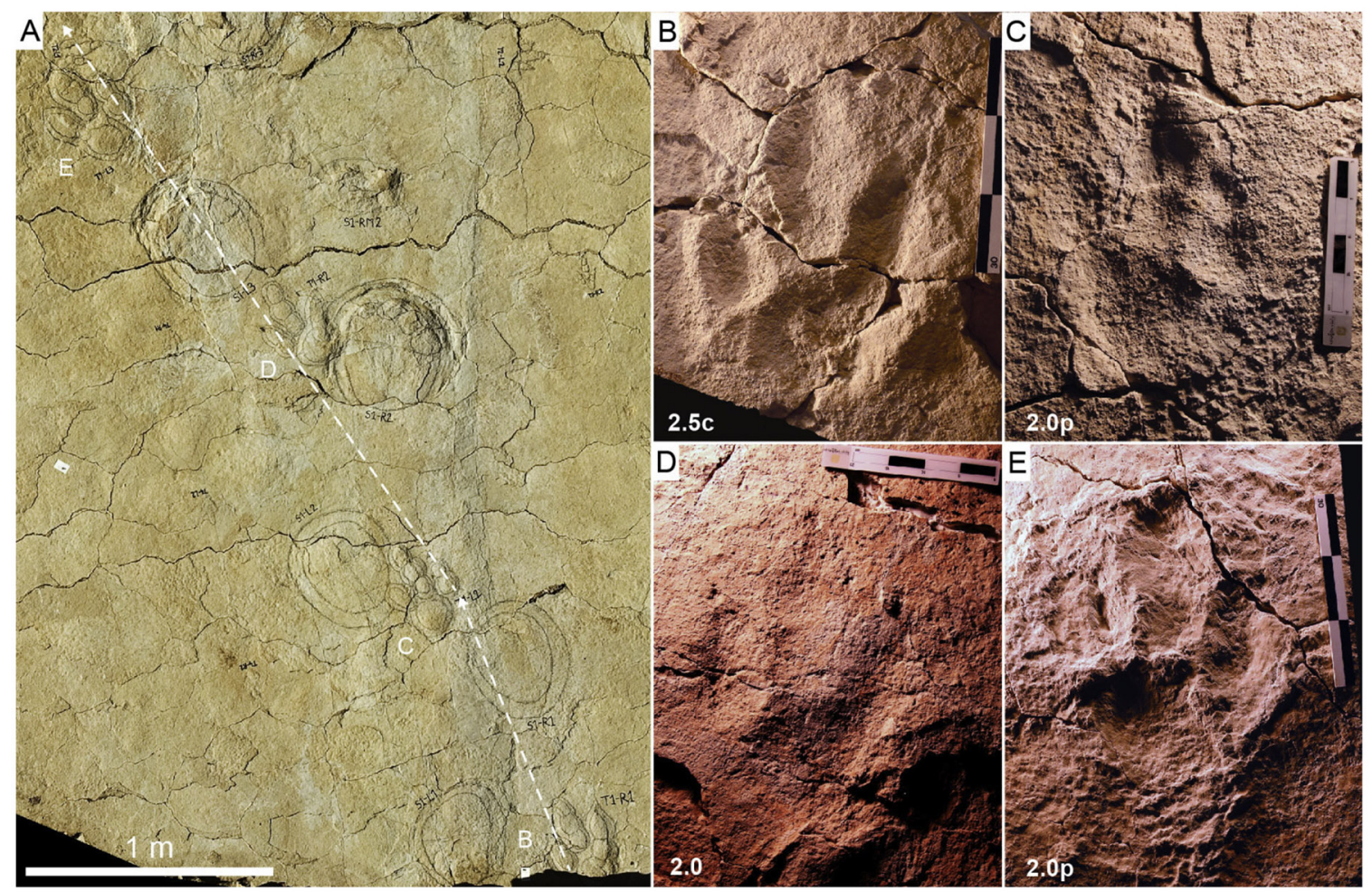

Fig. 16. Jurassic, theropod tracks. Reuchenette Formation, Bois-des-Sylleux tracksite (Courtedoux, Switzerland) (Paratte et al., 2017a). A) Orthophoto of a segment of trackway BSY1040-T1 (from R1 to L3) crossing sauropod trackway BSY140-S1, concave epirelief. B) BSY1040-T1-R1. Paratype of Megalosauripus transjuranicus (Razzolini et al., 2017). Despite fractures during collection of the slab from the field, the track preserves the best morphological details of the trackway. C) BSY104OT1L2. This print shows good M-preservation of digital pad impressions of digit II, but poorer M-preservation of the other toe impressions. D) BSY104O-T1-R2. This is the shallowest track of the trackway, but nevertheless retains good details, especially of digit impression II and all three claw impressions. E) BSY1040-T1-L3. This is the deepest track of the trackway. It preserves details of digital pads in digits II and III, but the internal morphology of digit IV is obliterated Numbers and lower-case letters beside tracks indicate the preservation values and significant features according to our scale, arrows indicate the trackway midline and the direction of locomotion.

12.4.1.2 Stratigraphy and provenance. Reuchenette Formation (Thalmann, 1966; Gygi, 2000), deposited during the early Late Kimmeridgian (152.7-150.1 Ma) (Jank et al., 2006a, 2006b; Comment et al., 2011, 2015). All Jurassic tracks described here are from the Swiss Jura Mountains. 
12.4.1.3 Lithofacies and depositional environment. Laminated limestone from a vast and complex carbonate platform (Stampfli and Borel, 2002) on the northern margin of the oceanic Ligurian Tethys (palaeolatitude around $30^{\circ} \mathrm{N}$ ) (Jank et al., 2006a).

12.4.1.4 Description. Trackway BSY1040-T1 (Fig. 16A) is composed of seven consecutive tracks and has a total length of $8.2 \mathrm{~m}$. Mean pes length is $40.5 \mathrm{~cm}$ and mean pes width is $24 \mathrm{~cm}$. Tracks are very elongate and narrow, with a moderate mesaxony. A clear phalangeal pad configuration 2-3-4 can be identified for digit impressions II-III-IV of most of the tracks. Claw marks are preserved on digit impression IV of track R1 (paratype specimen number MJSN-BSYoo8-339) and R4, and on digit impression II of track R2. All tracks display the wide pes digit IV pad impression typical of $M$. transjuranicus. The trackway configuration is quite regular, with a slight 'zig-zag' pattern and a marked outward rotation for both right $\left(10^{\circ}\right)$ and left $\left(6^{\circ}\right)$ tracks. Pace lengths do not display any significant difference between the right and left sides $(129.7 \mathrm{~cm}$ for left-to-right pace and $131 \mathrm{~cm}$ for right-toleft pace). Average stride length is $258 \mathrm{~cm}$, and average pace angulation $167^{\circ}$. The narrow trackways suggest a trackmaker with a moderately narrow posture.

BSY1040-T1-R1 (paratype, Fig. 16B). Very shallow, tridactyl, asymmetrical right pes track with slender and well-separated digit impressions. Discenible phalangeal pad impressions. Claw marks are slender and comparatively short. Presence of a pronounced posteromedial indentation proximal to digit impression II. Narrow track with asymmetric and low interdigital angles ( $5^{\circ}$ for II-III and $14^{\circ}$ for III-IV). The track is longer than wide (pes length/pes width ratio $=1.8$ ), and the mesaxonic index is not extremely pronounced (ratio $\mathrm{Te} / \mathrm{PW}=0.6$ ).

12.4.1.5. M-preservation. The ichnotaxon was erected on a large set of tracks showing a complete range of morphological preservation. Type specimens include the holotype (TCH1030-T6-L1) and 6 paratypes (BSY1035-T6-L2, BSY1040-T1-R1, TCH1O25-T2-L1, TCH1O3O-T2-R2, TCH1030-T2-L3, TCH1030-T7-L2), to which more referred material was added (Razzolini et al., 2017).

M-preservation of the trackway BSY1040-T1 varies from good to very good, with preservation grade ranging from 2.0 to 2.5. All the 
tracks have clear digit impressions with well-defined walls, and often display digital pad impressions in most of the digits, although claw marks are not present in all specimens. Variability along the trackway is mostly related to different depths of the tracks, with some tracks (R1, L2, R2; Fig. 16B-D) around $10 \mathrm{~cm}$ deep and others that could reach more than $13.5 \mathrm{~cm}$ (L3; Fig. 16E). This affects the overall quality of the tracks, which, however, is unrelated to the depth of the footprint: the best-preserved track (R1, grade 2.5; Fig. 16B) is the track with the intermediate depth, while shallower (L2, R2; Fig. 16CD) and deeper (L3; Fig. 16E) tracks present slightly less details, especially by having less defined phalangeal pad impression or claw marks.

All the specimens used in describing $M$. transjuranicus variability can be accessed in Razzolini et al., 2017 and in its supplementary materials (including 3D models).

12.4.2 Sauropod dinosaur tracks: Parabrontopodus-type sensu Marty et al. (2010) (Fig. 17)

12.4.2.1. Material. Trackway TCH1055-S4 composed of 16 pes and 19 manus tracks (figured couples L4-6, R4-6), concave epirelief. Sauropod trackway, temporarily assigned to Parabrontopodus-type (Marty et al., 2010). Ichnotaxonomical revision of the sauropod tracks of the Ajoie ichnoassemblage (Marty et al., 2010) is undergoing.

12.4.2.2 Stratigraphy and provenance. Reuchenette Formation (Thalmann, 1966; Gygi, 2000), deposited during the early Late Kimmeridgian (152.7-15.01 Ma) (Jank et al., 2006a, 2006b, Comment et al., 2011, 2015). All Jurassic tracks described hare $m$ the Swiss Jura Mountains.

12.4.2.3 Lithofacies and depositional environment. Laminated limestone from a vast and complex carbonate platform (Stampfli and Borel, 2002) on the northern margin of the oceanic Ligurian Tethys (palaeolatitude around $30^{\circ} \mathrm{N}$ ) (Jank et al., 2006a).

12.4.2.4 Description. This is a $14 \mathrm{~m}$-long, straight, discontinuous trackway (Fig. 17A). All tracks are rather shallow, with small displacement rims. Pes tracks have a subcircular to oval shape and are rounded posteriorly and longer (pes length $36.0 \mathrm{~cm}$ ) than wide (pes width 27.1 $\mathrm{cm}$ ) with the greatest width located in the anterior part of the pedal 

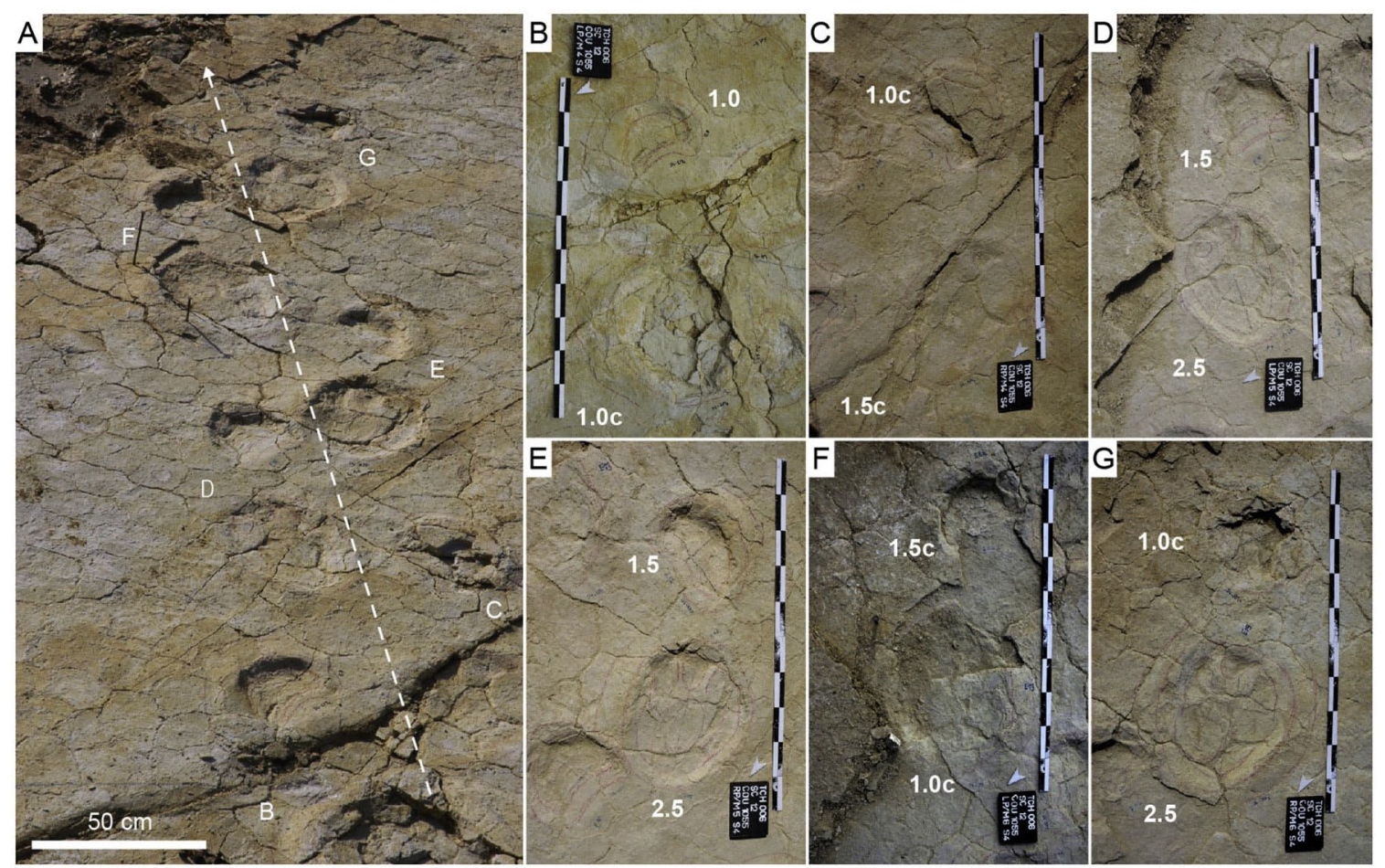

Fig. 17. Jurassic, sauropod tracks. Reuchenette Formation, Tchâfouè tracksite (Courtedoux, Switzerland) (Paratte et al., 2017b). A) Oblique photograph of a segment of trackway TCH1055-S4 (LP4, LM4 to RP6, RM6), concave epirelief. See also Marty et al., 2010, (Fig. 5C). B) TCH1055-S4-LP4, LM4. Poorly preserved pes track due to cracks and fractures that obliterate the morphology. Manus track clear but lacking details. Scale $1 \mathrm{~m}$. C) TCH1055-S4-RP4, RM4. Fairly poorly-preserved manuspes couple. The pes shows only a claw mark on digit impression I. Manus morphology is obliterated by the infilling that still is in place. Claw marks present in digit impressions I and IV, but those are the only details visible. Scale $1 \mathrm{~m}$. D) TCH1055-S4-LP5, LM5. Best preserved manus-pes couple. Internal details of the manus are less often preserved than in the pes, but in this case it is possible to observe the claw mark on digit impression I. Scale $1 \mathrm{~m}$. E) TCH1055-S4-RP5, RM5. Very well-preserved pes, with digit, internal pad and claw impressions preserved. Good manus M-preservation with a faint claw mark in digit impression I. Scale 1m. F) TCH1055-S4-LP6, LM6. Poorly preserved partial (broken) manus and pes. Scale 1 m. G) TCH1O55S4-RP6, RM6. Very good pes track, with internal pad and claw impressions preserved, and very poor, broken manus impression. Numbers and lower-case letters beside tracks indicate the preservation values and significant features according to our scale, arrows indicate the trackway midline and the direction of locomotion.

long axis, but not very far away from its midpoint. The bestpreserved tracks show three digit impressions (digits I-III; decreasing in size) and two triangular claw impressions, on digit impressions I and II. Manus tracks are never overprinted, and are semicircular to crescent 
shaped and convex forward, wider (manus width $23.1 \mathrm{~cm}$ ) than long (manus length $13.3 \mathrm{~cm}$ ), and have a track bottom inclined toward the anterior part of the track. This quadrupedal trackway has a very narrow gauge and a regular configuration, with both manus and pes tracks located close to the trackway midline. Relatively low pace angulation $\left(65-96^{\circ}\right)$.

Both pes and manus tracks are rotated outwards, and the rotation is much higher for the manus than for the pes tracks, reaching up to $107^{\circ}$ (LM12). Some manus tracks are located well in front of the pes tracks, closer to the following opposite pes track than to the preceding pes track from the same side (e.g. $\mathrm{LM}_{5}$ closer to $\mathrm{RP}_{5}$ than to $\mathrm{LP}_{5}$; Fig. 17A).

12.4.2.5 M-preservation. TCH1055-S4 is one of the trackways with the best-preserved pes tracks (digit and claw impressions clearly discernible) of the Ajoie ichnoassemblages (Marty et al., 2010). After track registration a network of mud cracks with a diameter of $10-20 \mathrm{~cm}$ was formed. Pes quality ranges from grade 1.0, where the overall oval shape is barely recognizable (Fig. $17 \mathrm{~B}, \mathrm{~F}$ ), to grade 2.5 , where pad and claw impressions are clearly discernible (Fig. 17D, E, F), except that digit impression IV is faint, and therefore the tracks are not suitable for a grade 3.o. Manus are generally less well preserved than pes imprints, with a preservation grade ranging from 1.0 to 1.5 . It is worth noticing that manus and pes morphological preservation are independent.

\subsection{Cretaceous}

12.5.1. Ornithopod dinosaur tracks: Iguanodontipus? oncalensis (Moratalla García, 1993) after Castanera et al. (2013b) (Fig. 18)

12.5.1.1. Material. LP3, trackway with 8 pes imprints (L1-4, R1-4) preserved in concave epirelief, in situ (Castanera et al., 2013b).

12.5.1.2 Stratigraphy and provenance. Huérteles Formation, Berriasian. La Peña tracksite, Bretún, Soria, Spain.

12.5.1.3. Lithofacies and depositional environment. Fine grained sandstone deposited in siliciclastic tidal flats traversed by meandering channels (Quijada et al., 2013, 2016). 


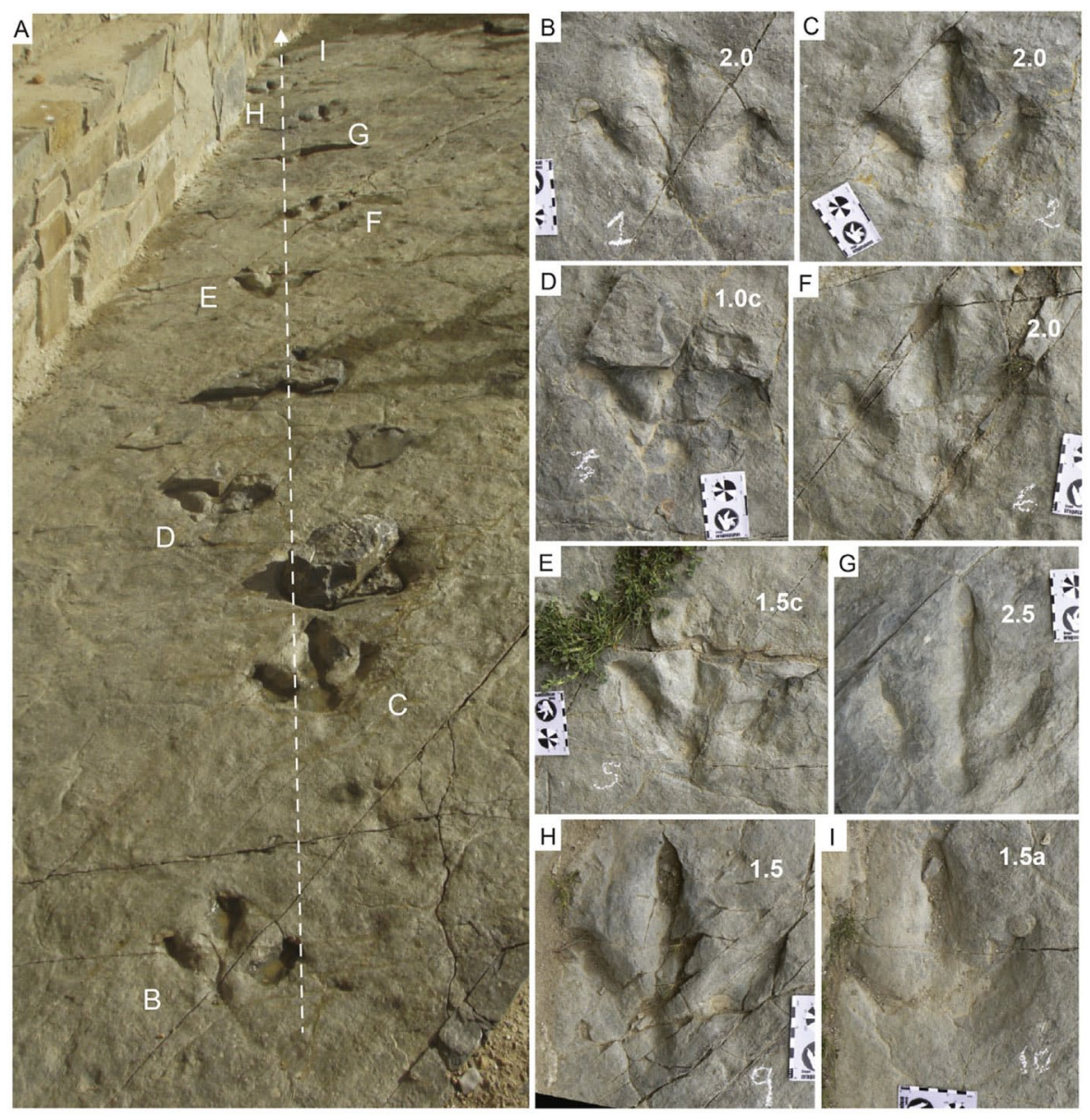

Fig. 18. Cretaceous, ornithopod tracks. Trackway LP3, Iguanodontipus? oncalensis, concave epirelief. Huérteles Formation, La Peña tracksite (Bretún, Spain). A) Oblique photograph of the whole trackway. B, D, E, H) Left pes imprints. C, F, G, I) Right pes imprints. Scale $8 \mathrm{~cm}$. Numbers and lower-case letters beside tracks indicate the preservation values and significant features according to our scale, arrows indicate the trackway midline and the direction of locomotion.

12.5.1.4. Description. LP3 (Fig. 18A) is a trackway composed of medium-sized (mean pes length $21.9 \mathrm{~cm}$ ) tridactyl tracks, slightly longer than wide (mean pes length/pes width ratio 1.06) with low mesaxony (Te/PW ratio 0.46 ). They are characterized by a rounded heel pad impression with a lateral and medial notch, the track being symmetrical. The digit impressions are robust, digit III being the longest (mean $21.9 \mathrm{~cm}$ ) and digits II and IV almost equal in length (about $15 \mathrm{~cm}$ ). The hypexes are also fairly symmetrical. There seem to be no discrete phalangeal pad impressions, but some tracks (e.g.: pes imprint R3, Fig. 18G) show constrictions in the digit impressions, so this absence 
could be a preservation bias. The distal end of the digit impressions is rounded, and there is no evidence of sharp claw marks, though some tracks (e.g.: pes imprint R3, Fig. 18G) apparently show evidence of blunt claw marks. The interdigital angle II-IV varies from $72^{\circ}$ to $81^{\circ}$, interdigital angle II-III (mean $42^{\circ}$ ) being slightly greater than interdigital angle III-IV (mean $34^{\circ}$ ). Mean pace length and stride length values are $58 \mathrm{~cm}$ and $114 \mathrm{~cm}$, respectively. The mean pace angulation is $155^{\circ}$ and the trackway width is about $38 \mathrm{~cm}$, the trackway being rather narrow. The tracks have a slightly outward orientation (mean $9^{\circ}$ ).

12.5.1.5. M-preservation. LP3 (Fig. 18A) is composed of 10 footprints. It is characterized by a preservation grade that varies from 1.0 to 2.5 . Pes imprint R3 (Fig. 18G) is the one with the highest grade (2.5) and the best one for the assignment. L1, R2, R3 (Fig. 18B, C, F) have a slightly lower grade (2.0) and can be also used for ichnotaxonomic assignment. The other tracks have lower preservation grade as some of the digit impressions are recognizable but incomplete (e.g. L2, grade 1.0; Fig. 18D). It should be noted that many of the tracks in this trackway are probably preserved as shallow undertracks, this being the reason why there are no footprints with preservation grade of 3.0.

12.5.2 Theropod dinosaur tracks: Eubrontes-type sensu Xing et al. (2018) (Fig. 19)

12.5.2.1 Material. LJ-T7, trackway with seven consecutive tracks (figured pes imprints L1-2, R2), concave epirelief, in situ (Xing et al., 2018).

12.5.2.2 Stratigraphy and provenance. Jiaguan Formation, Lower Cretaceous. Linjiang tracksite, Linjiang region, Guizhou Province, China.

12.5.2.3. Lithofacies and depositional environment. Mediumto verythick feldspar-clastic sandstone interbedded with thin mudstone (Liu and Luo, 2015). The area from Xishui (Guizhou Province) to Hejiang of Luzhou City was predominantly a braided river deposit in the Cretaceous (Geng, 2011). The Linjiang site reveals dense invertebrate traces dominated by vertical burrows. These traces appear in the interbedded sandstone and mudstone of alternating lakeshore and upper shallow lake environments ( $\mathrm{Hu}$ et al., 2014). 


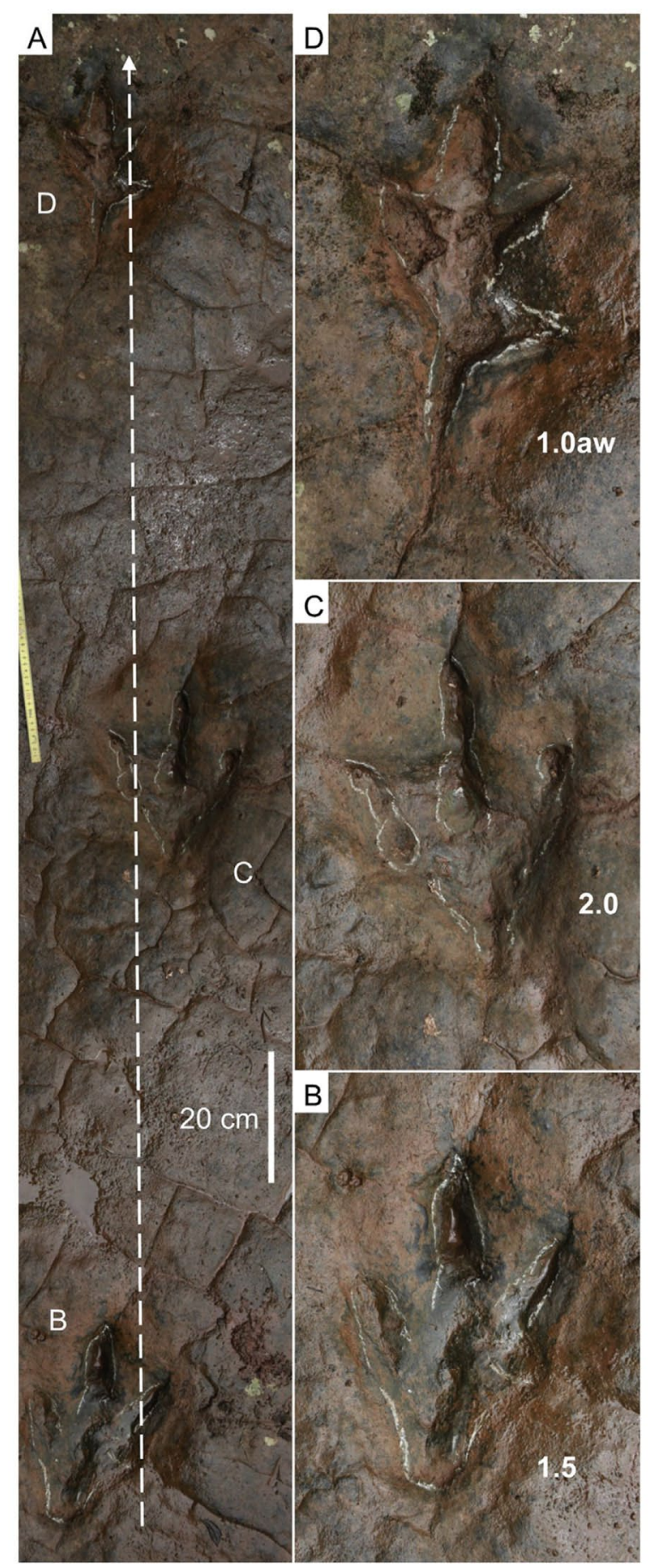

Fig. 19. Cretaceous, theropod tracks. Eubrontes-type sensu Xing et al. (2018). A) Photomosaic of trackway LJ-T7, concave epirelief. Jiaguan Formation, Linjiang tracksite, Linjiang region, Guizhou Province, China. B-D) enlargements of A, pes imprints. B) LJ-T7-L1, C) LJT7-R2, C) LJ-T7-L2. Numbers and lower-case letters beside tracks indicate the preservation values and significant features according to our scale, arrows indicate the trackway midline and the direction of locomotion.

12.5.2.4. Description. LJ-T7 (Fig. 19A) is relatively well preserved, and includes 7 tridactyl tracks with a mean pes length/pes width ratio of 1.4, and low mesaxony (Te/PW ratio $0.46-0.55$, average 0.49 ). In well-preserved T7-R2 (Fig. 19C), digit impression II has 2 digit pads, digit impression III has 3 digit pads, while digit impression IV does 
not have any identifiable digit pads. T7-L2 (Fig. 19D) is the print following $\mathrm{T} 7 \mathrm{R} 2$, in the emplacement of which the animal encountered much softer sediment. At this point the trackmaker left impressions of an incomplete metatarsal pad and digit I when its foot sank more deeply into the sediment. Pulling out its foot caused mud collapse effects that shrank the track size. Therefore, L2 is only $13.7 \mathrm{~cm}$ long compared with R2 $(27.2 \mathrm{~cm}$ in length), or $24.9 \mathrm{~cm}$ when including the incomplete metatarsal pad impression. Digit impression shortening also enlarges the divarication angle between digits II and IV from $57^{\circ}$ in R2 to $79^{\circ}$ in L2. Narrow trackway with high pace angulation $\left(166^{\circ}\right)$.

12.5.2.5. $M$-preservation. Some penecontemporaneous infilling indicates that the substrate was locally high in water content and fluidity. Such morphological preservation, which has also been reported from other track localities like the Nanguzhai site with theropod and sauropod tracks (Xing et al., 2010), significantly influenced the track mophology. Substrate consistency of the exposed area at the Linjiang site was uneven. Therefore, both well-preserved tridactyl tracks, such as T7-R2 (preservation grade 2.0; Fig. 19C), and others, with incomplete digit traces or very long metatarsal pad impressions such as in T7-L2 (preservation grade 1.0; Fig. 19D), can be seen in the same trackway. Well-developed metatarsal pad traces may be seen in theropod tracks and may indicate a trackmaker resting or crouching when its metatarsals contacted the ground, depending on track depth and trackway pattern (e.g., Kuban, 1989; Gatesy et al., 1999; Milner et al., 2009; Lockley et al., 2003; Xing et al., 2015). Xing et al. (2015) suggested that this distinctive gait did not significantly slow its speed, despite a close relationship between the registration of metatarsal pad traces and deep and soft sediments (in agreement with other works such as Farlow et al., 2015). In fact, LJ-T7 shows metatarsal impressions and high pace angulation $\left(166^{\circ}\right)$. Among the theropod tracks from the Jiaguan Formation, many have welldeveloped metatarsal pad traces, like cf. Irenesauripus isp. Tracks from the Baoyuan tracksite (Xing et al., 2011a), and the Eubrontes morphotype tracks from the Hanxi tracksite (Xing et al., 2015). Theropod tracks from the Baoyuan tracksite share the same Mpreservation pattern with those from the Linjiang site. Metatarsal pads and hallux traces can be found in some tracks. In LJ-T7-L2, the divarication angle between digit I and II is $54^{\circ}$, 
different from Baoyuan specimens $\left(30^{\circ}-45^{\circ}\right)$. However, these parameters may be affected by extramorphological changes.

\subsection{Palaeogene}

12.6.1. Artiodactyl mammal tracks: Anoplotheriipus cf. lavocati Ellenberger, 1980 (Fig. 20)

12.6.1.1Material. $A B$ 1.1, 1.2, isolated tracks; $A B$ 2.1, isolated track; $A B$ 1-t1 trackway (figured couples L1, R1-2) and AB 1.3 isolated track; concave epirelief, in situ.

12.6.1.2. Stratigraphy and provenance. Peraltilla Formation (Peraltilla Limestones), early Oligocene. Fondota tracksite, Abiego, Huesca, Spain. This tracksite is currently under evaluation. A preliminary description was made by Canudo et al. (2007), who identified more than 1000 artiodactyl tracks and distinguished 3 different morphotypes. Here
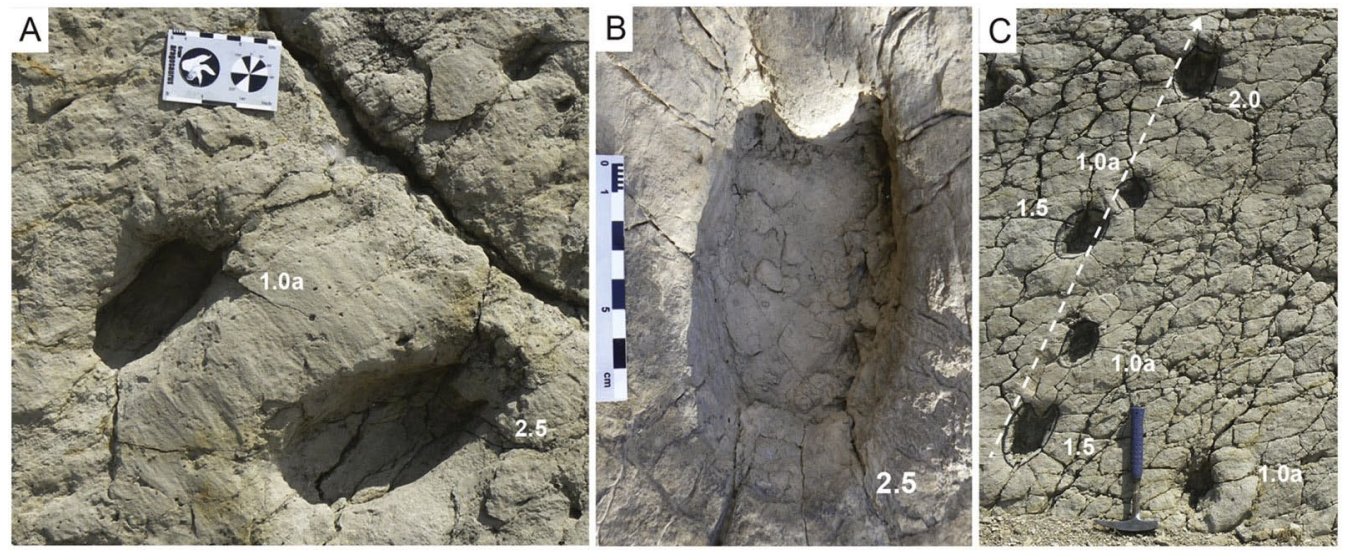

Fig. 2o. Paleogene, mammal tracks. Artiodactyl tracks, Anoplotheriipus cf. lavocati, concave epirelief. Peraltilla Formation, Oligocene, Fondota tracksite (Abiego, Spain). A) Two isolated tracks ( $\mathrm{AB}$ 1.1, $\mathrm{AB}$ 1.2) with different values of the preservation scale. Note the difference in the anterior part as to whether or not the print shows hoof marks. B) Track (AB 2.1) with the highest preservation scale grade (2.5). C) Trackway ( $A B$ 1-t1) showing two manus-pes sets, an isolated pes print ( $A B$ 1.3), and an isolated track located in the left side. Note that the outline of the footprints drawn in black does not correspond with the real morphology (it is just an approximation). Scale $8 \mathrm{~cm}$. Numbers and lower-case letters beside tracks indicate the preservation values and significant features according to our scale, arrows indicate the trackway midline and the direction of locomotion. 
we illustrate examples of the tracks belonging to the largest morphotype, the one described as Anoplotheriipus cf. lavocati by Canudo et al. (2007).

12.6.1.3. Lithofacies and depositional environment. Limestones deposited in a shallow carbonate lacustrine system (Luzón, 2005; RabalGarcés et al., 2018).

12.6.1.4. Description. Tracks having an oval-subelliptical morphology. Pes imprints are didactyl and clearly longer (around $15^{-16} \mathrm{~cm}$ ) than wide (around 7-8 cm), the maximum width occurring in the central part of the footprint. Two hoof marks only are visible in the anterior part of the footprint. They are subtriangular in morphology, with sharp to blunt distal ends. The distance between both hoof impressions is $2-3 \mathrm{~cm}$, and the divarication angle $17^{\circ}$. The posterior part of the footprint is subrounded in morphology. Manus prints (when preserved) are oval depressions, slightly longer than wide, located anteriorly to the pes imprints. High pace angulation $\left(160^{\circ}\right)$.

12.6.1.5. $M$-preservation. In the pes tracks with preservation grade of 2.0-2.5 (AB 1.2; AB 2.1) two hoof marks can easily be distinguished in the anterior part (Fig. 2OA-B). These tracks are good for ichnotaxonomic assignment, although the artiodactyl ichnotaxonomy is quite confusing (see Costeur et al., 2009). When the preservation grade is 1.5-2.o (pes of AB 1-t1; Fig. 2OC), the presence of the two hooves can be distinguished, but the morphology of the track is not completely well defined. Imprints walls show deformation. These tracks can be used for ichnotaxonomic assignment, but with caution. When the preservation grade is 1.0 (manus of $A B$ 1-t1; Fig. 2OC), only subelliptical to rounded depressions can be distinguished because the sediment has collapsed into the footprint. Thus, these tracks are not good for ichnotaxonomic assignment, and it is even difficult to know whether the tracks were produced by an artiodactyl or by another animal when found isolated ( $A B$ 1.3; Fig. 20C). No tracks with a grade of 3.0 in the preservation scale have been preserved at the site, because the tracks are quite deep and imprint walls or the sole impressions are not perfectly defined. 

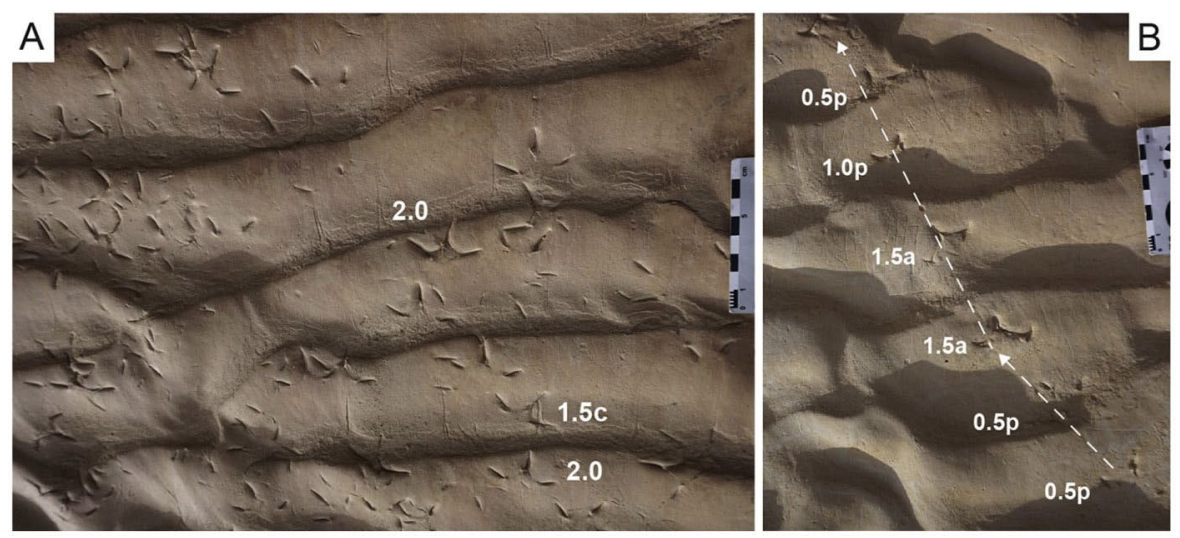

Fig. 21. Paleogene, bird footprints. Avipedidae, concave epirelief. Peralta Formation, Oligocene, Playa Fósil tracksite. A) Picture of the upper part of the site where the surface is heavily trampled but the tracks have higher M-preservation gradeand show more morphological features with the absence of the webb-like structure. B) Picture of the lower part of the site with trackway PF-t1 where the footprints show evidence of the webb-like structure interpreted as a sediment collapse. Thus, they have lower preservation grade. Scale $8 \mathrm{~cm}$. Numbers and lower-case letters beside tracks indicate the preservation values and significant features according to our scale, arrows indicate the trackway midline and the direction of locomotion.

12.6.2. Bird tracks: Avipedidae Sarjeant and Langston Jr, 1994

(Fig. 21)

12.6.2.1. Material. PF 1-3 isolated tracks, PF-t1 long trackway showing here seven consecutive pes imprints (L1-4, R1-3), concave epirelief, in situ.

12.6.2.2. Stratigraphy and provenance. Peralta Formation, early Oligocene. La playa fósil tracksite, Peralta de la Sal, Huesca, Spain. The tracksite is currently under evaluation. A preliminary identification was made by Hernández-Pacheco (1929).

12.6.2.3. Lithofacies and depositional environment. Sandstone deposited in a short, high-gradient alluvial fan passing laterally to the marginal part of a dominantly saline lake (Senz and Zamorano, 1992; RabalGarcés et al., 2018).

12.6.2.4. Description. Tridactyl footprints showing three digit impressions directed forward. Digit impression III is slightly longer (2.7-2.8 
$\mathrm{cm}$ ) than digit impressions II and IV, which are subequal in length $\left(2.2-2.3 \mathrm{~cm}\right.$ ). High divarication angle (around $125^{\circ}$ ). Webbing absent or limited to the proximal part of the footprint. No evidence of hallux mark. High pace angulation $\left(151-178^{\circ}\right)$.

12.6.2.5. $M$-preservation. La playa fósil tracksite is an excellent of example of how bird footprint morphology can change across the site, and even along the same trackway (PF-t1). Hernández-Pacheco (1929) identified two different types of bird footprint, the main differences being the absence or presence of webbing (see Fig. 21). The site is currently under evaluation and the working hypothesis is that the putative web-like structure seen in one of the morphotypes (PF-t1, Fig. 21B) is in fact an extramorphological feature produced by the footsediment interaction (Rabal-Garcés et al., 2018), such that a similar trackmaker might have produced the two types of footprints by walking in substrates of different consistency. The footprints of PF-t1 have low preservation grade (0.5-1.5). Thus, the two different morphotypes (see Fig. 21A and B) would be variants of one type of footprint, with different grades in the preservation scale. According to this hypothesis, the tracks that have the web-like structure are those with lower preservation grade (less than 2.0). Tracks with preservation grade 2.0 (PF 1-3, Fig. 21A) do not have this web-like structure and would be good for ichnotaxonomic assignment, at least at the ichnofamily level. Further work is needed in order to understand the M-preservation of these tracks and whether they can fit in the ichnogenus Avipeda or in any other related ichnotaxa, and so for the moment they are tentatively included in the ichnofamily Avipedidae (Sarjeant and Langston Jr, 1994).

\subsection{Neogene}

12.7.1. Bird tracks: Koreanaornis isp. (Fig. 22)

12.7.1.1. Material. $14 \mathrm{MPE}$, block with twenty-six tracks including a trackway with five consecutive tracks (14 MPE 3, pes imprints L1-2, R13), convex epirelief.

12.7.1.2. Stratigraphy and provenance. Transition between the Nájera and Haro Formations, Agenian European Land Mammal Age, lower Miocene. Cenicero, La Rioja, Spain. 


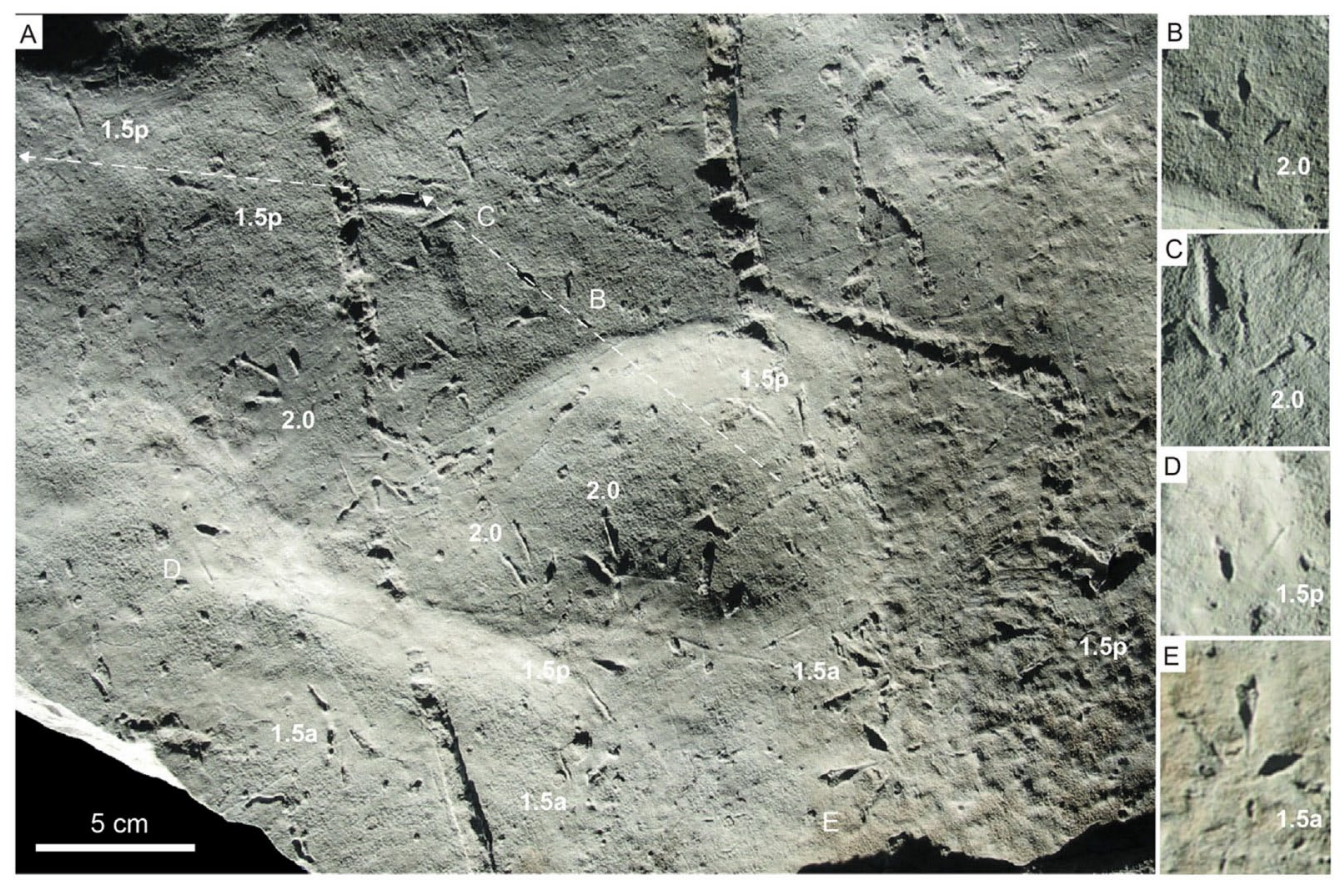

Fig. 22. Neogene, bird footprints. Koreanaornis isp. Transition between the Nájera and Haro Formations, Miocene, Cenicero, La Rioja, Spain. A) 14 MPE, block with twenty-six tracks, convex epirelief. B-E) Enlargements of A, pes imprints. Numbers and lower-case letters beside tracks indicate the preservation values and significant features according to our scale, arrows indicate the trackway midline and the direction of locomotion.

12.7.1.3. Lithofacies and depositional environment. The shorebird-like footprints are found in a fine-grained calcarenitic sandstone block with very thin lamination. Centimeter sized current ripples, wrinkle structures, and invertebrate traces can be seen on the same surface as the bird tracks. The palaeoenviroment is considered as ephemeral ponds in an alluvial or floodplain system (Díaz-Martínez et al., 2015c).

12.7.1.4. Description. The tracks are tridactyl or tetradactyl, mesaxonic without web or central pad impressions. They are wider than long (around $2.2 \mathrm{~cm}$ pes length and $2.5 \mathrm{~cm}$ pes width) except when the hallux is preserved (which increases pes length to around $3.5 \mathrm{~cm}$ ). Digit impressions are slender, their proximal ends are not in contact with each other, and digit impressions generally present an acuminated distal end. Digit impression proportions: I < II < IV < III. The digit divarication between II and IV ranges from $57^{\circ}$ to $114^{\circ}$. The angle 
between digit impressions I and II is $81^{\circ}$ to $138^{\circ}$. Digital pad impressions are recognizable in digit impressions II-IV in some tracks. High pace angulation $\left(129-161^{\circ}\right)$.

12.7.1.5. M-preservation. Small unwebbed bird footprints with slender, proximally unconnected digit, pad and claw impressions have been classified into different ichnogenera based on only a few ichnotaxonomic differences. The presented morphological features in the tracks analysed here (those with grade 2.0) allow classifying them into the ichnotaxon Koreanaornis Kim, 1969 (see more in Díaz-Martínez et al., 2015c). Some ichnospecies within Koreanaornis and others similar in shape that are assigned to Aviadactyla, differ from each other mainly in the number of impressed digits and in the II-IV divarication angle. For instance, K. hamanensis Kim, 1969 and K. sinensis (Zhen et al., 1995) are generally tridactyl, but hallux impressions are also preserved in some specimens and display a II-IV divarication of about $120^{\circ}$ (Lockley et al., 1992; Lockley et al., 2012). On the other hand, K. dodsoni Xing et al., 2011b, Aviadactyla media Kordos, 1983 and $A$. vialovi (Kordos and Prakfalvi, 1990) are tridactyl, with a II-IV divarication that ranges between $58^{\circ}$ and $109^{\circ}$ in the former, between $81^{\circ}$ and $125^{\circ}$ in the second, and from about $80^{\circ}$ to over $155^{\circ}$ in the last.

The differences in the number of impressed digits and in divarication angle among these ichnotaxa are similar to those recognized above for the footprints of 14 MPE within the same trackway $14 \mathrm{MPE}$ 3. Thereby, the track R2 (Fig. 22B) is tetradactyl while the rest are tridactyl (Fig. 22C), and the divarication II-IV varies from $73^{\circ}$ to $105^{\circ}$ within the footprints of the same trackway. Sarjeant and Reynolds (2001) pointed out the divarication can be variable depending on pace and substrate hardness, and so the absence or presence of a hallux impression may be the result of variable M-preservation and the inherently small size of the hallux (Anfinson et al., 2009). Almost all the tracks are well preserved (grade 2.0) with distinct contours (Fig. 22), but some are more shallowly impressed (grade 1.5), with contours that are less distinct (e.g., 14 MPE 2.1, Fig. 22D). Moreover, there are tracks (e.g., 14 MPE 14, Fig. 22E) close to wrinkle marks that preserve modified substrate in the sole area (grade 1.5), in which the digit impressions are wider than the rest of the tracks. In this case, there is no direct relationship between the number of digit impressions 
and divarication and the M-preservation. Consequently these features, although important ichnotaxobases, should be used with caution, because they are not consistent morphological features.

12.7.2. Bird tracks: Uvaichnites riojana Díaz-Martínez et al., 2012 (Fig. 23)

12.7.2.1. Material. CIBR 1, a block with three tracks; CIBR 2, a block with two tracks; convex hyporelief.

12.7.2.2. Stratigraphy and provenance. Lerín Formation, Agenian European Land Mammal Age, lower Miocene. Aguilares, Comunidad de Bardenas Reales, Navarra, Spain.

12.7.2.3. Lithofacies and depositional environment. The footprints have been found in fine-grained sandstone blocks with invertebrate fossil traces, which are accumulated in a mud dominated, distal alluvial floodplain (Díaz-Martínez et al., 2016).

12.7.2.4. Description. These footprints are tridactyl, mesaxonic and unwebbed. The tracks present a prominent central pad impression,
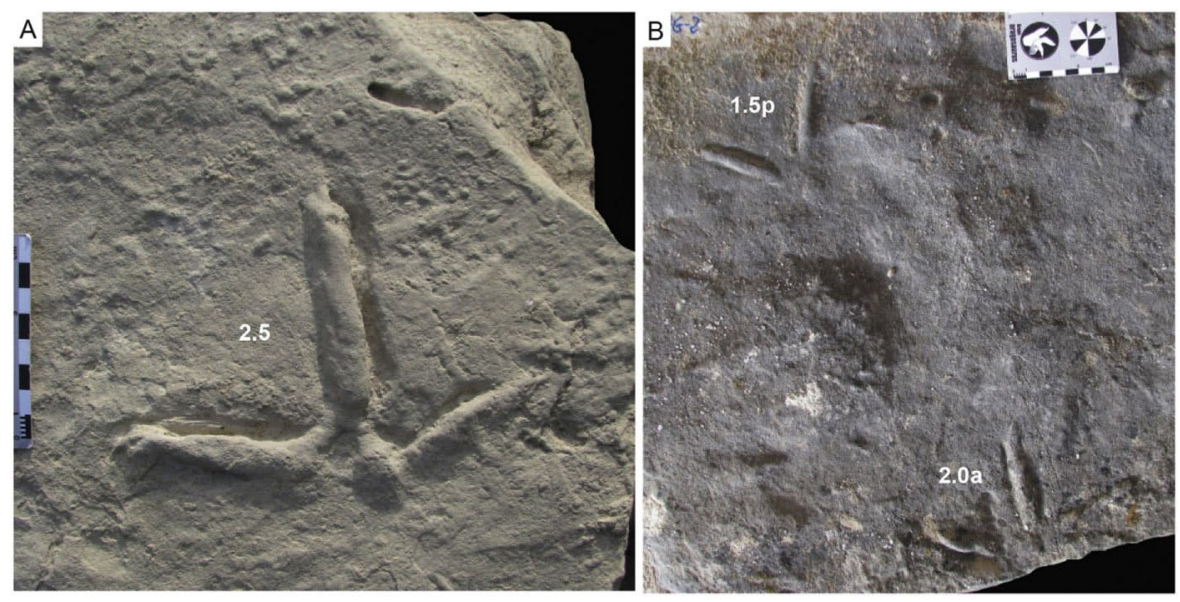

Fig. 23. Neogene, bird footprints. Uvaichnites riojana, convex hyporelief. Lerín Formation, Miocene. Aguilares, Comunidad de Bardenas Reales, Navarra, Spain. A) CIBR 1. Well-preserved pes imprint. B) CIBR 2. More incomplete pes imprints. Numbers and lower-case letters beside tracks indicate the preservation values and significant features according to our scale. 
and forwardly directed digit impressions. They are wider (around 17 $\mathrm{cm}$ ) than long (around $13 \mathrm{~cm}$ ). The divarication angle between digit impressions II and IV varies from $116^{\circ}$ to $150^{\circ}$. Digit impressions are slender, are not proximally joined, and show very acuminate claw traces. The digit impression III (about $9.5 \mathrm{~cm}$ ) is longer than that of digit impression II (about $5.7 \mathrm{~cm}$ ) and IV (about $7.6 \mathrm{~cm}$ ). The digit impression II is shallower than the others.

12.7.2.5. M-preservation. These tracks were classified as Uvaichnites riojana according to their main ichnotaxobases (see Díaz-Martínez et al., 2016) recorded in the footprints with the best morphological preservation (grade 2.0-2.5). They are better preserved than the type series, so the diagnosis was emended and converted to a more complete and robust definition. The tracks described here vary in M-preservation. The best preserved specimen (grade 2.5; Fig. 3.1 in Díaz-Martínez et al., 2016) is well defined and has very clear digit and central pad impressions, lateral constrictions related to digit pad impressions, and very delicate claw traces (Fig. 23A). Other tracks are well preserved (grade 2.0) but lack digit pad impressions and claw traces (Fig. 23B). On the other hand, taking into account that the digit impression II is very shallow, and in some tracks is not preserved (grade 1.5) such tracks seem didactyl (Fig. 23B). An interesting point to keep in mind is that regardless of their M-preservation, the hallux and the interdigital web impressions are absent.

\subsection{Quaternary}

12.8.1. Mammal tracks: Canipeda gracilis (Vialov, 1965) (Fig. 24)

12.8.1.1. Material. In situ trackway composed of five consecutive pesmanus couples (L1-3, R1-2), now lost due to erosion (Fig. 3, Aramayo and de Bianco, 1987). MD-YPI-16-O2 and MD-YPI-16-01, containing five and two footprints, respectively. Concave epirelief.

12.8.1.2. Stratigraphy and provenance. Upper part of the Agua Blanca sequence (Zavala and Quattrocchio, 2001), latest Pleistocene (Aramayo and de Bianco, 1996). Pehuen Co Palaeoichnological site, located at the sea side $1.5 \mathrm{~km}$ east of Pehuen Co town, Buenos Aires province, Argentina. 


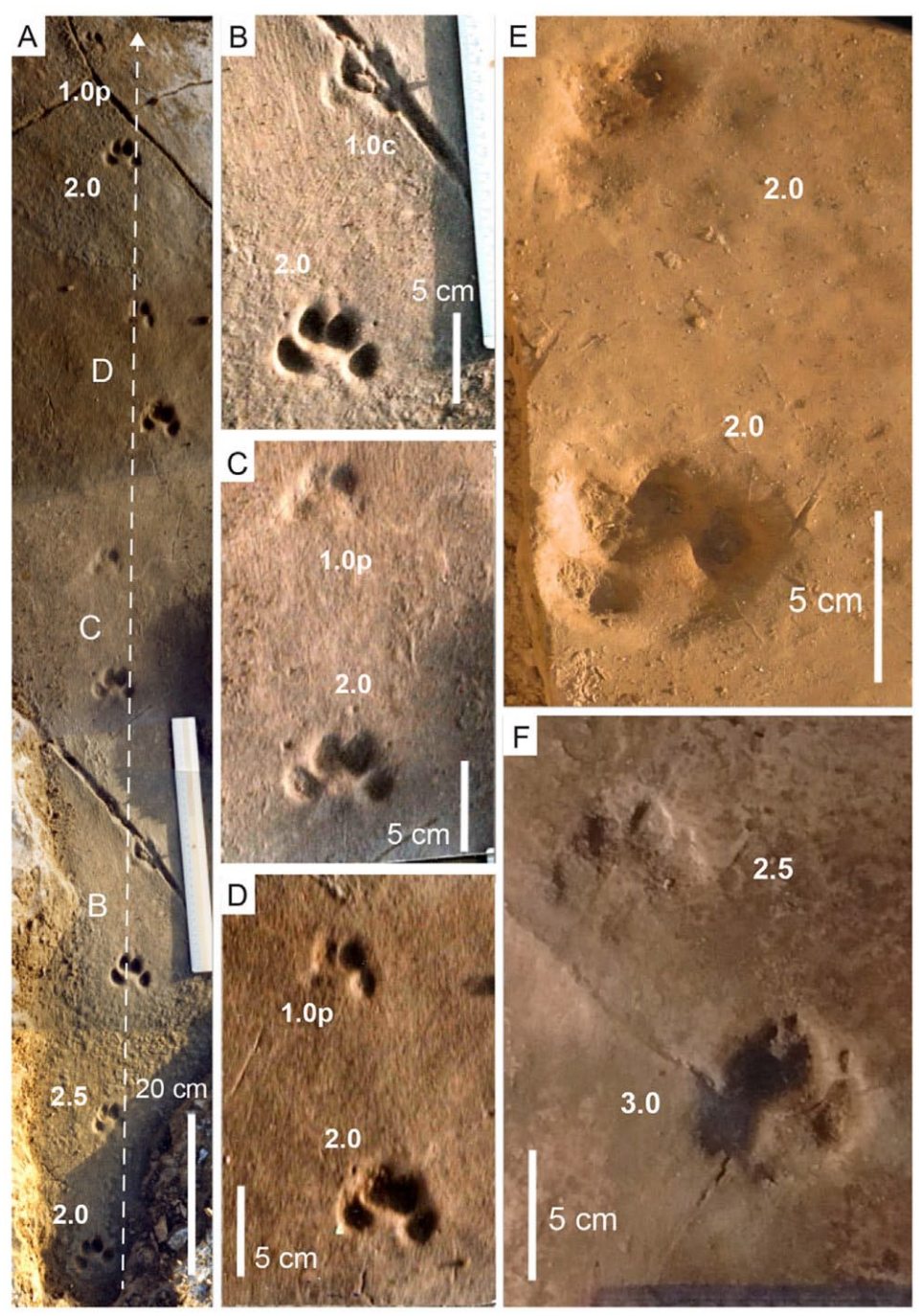

Fig. 24. Quaternary, mammal footprints. Canid footprints, Canipeda gracilis, concave epireleif. Agua Blanca sequence, Pleistocene. Pehuen Co, Buenos Aires, Argentina. A) Photomosaic of the in situ trackway showing ten footprints. B-D) Enlargements of A. Pes-manus couples. E) Pes-manus couple from MD-YPI-16-02. F) Pesmanus couple from MD-YPI-16-01. Note the complete primary overstep of the pes on the manus in all the couples. Numbers and lower-case letters beside tracks indicate the preservation values and significant features according to our scale, arrows indicate the trackway midline and the direction of locomotion.

12.8.1.3. Lithofacies and depositional environment. The outcrops of footprint-bearing sediments are about $1.2 \mathrm{~m}$ thick, flat-bedded, reddish-brown siltstone and claystone with mud cracks and subordínate friable sand. Shallow lacustrine deposits (Aramayo and de Bianco, 1987; Aramayo et al., 2015). 
12.8.1.4. Description. Digitigrade to semidigitigrade, tetradactyl, paraxonic, longer than wide footprints. Each footprint composed by an anterior arc of elliptical digital pad impressions (commonly showing clear claw marks) separated from a rounded, triangular or trapezoidal metapodial pad impression. Pes imprints are smaller (average length $4.8 \mathrm{~cm}$, average width $4.3 \mathrm{~cm}$ ) than the manus (average length 5.3 $\mathrm{cm}$, average width $5.1 \mathrm{~cm}$ ). Tracks are arranged in quadrupedal and slightly heteropodial trackways composed of alternating manus-pes couples and the pes imprints overstep the manus (primary overstep).

The in situ trackway (Fig. 22A) is $1.70 \mathrm{~m}$ long and $0.16 \mathrm{~m}$ wide, average pace angulation is $165^{\circ}$, mean stride length is $67 \mathrm{~cm}$ and the average rotation of the foot from the midline is $17^{\circ}$ (see further details in Melchor et al., 2018).

MD-YPI-16-02 is a partial trackway composed of two manus-pes couples (Fig. 22E) and one incomplete footprint of the first couple (Figs. 6 and 7, Melchor et al., 2018). Digital pad impressions tend to be elliptical and of similar size, with claw marks especially in the manus imprints and considerably deeper than the accompanying metapodial pad impression.

MD-YPI-16-01 includes a right manus-pes couple (Fig. 22F). The $5.9 \mathrm{~cm}$ long manus print is isometric in shape (manus length/ width = 1) with four elliptical digit impressions showing claw marks and a subrounded metapodial pad impression. The $5.7 \mathrm{~cm}$ long pes print is longer than wide (pes length/width $=1.1$ ) and exhibits a subcircular metapodial pad impression.

12.8.1.5. M-preservation. The analysed examples of C. gracilis display a contrasting morphological preservation between better preserved manus (grade 2.0-3.0) and moderately to poorly preserved pes (grade 1.0-2.5) in the same couple (Fig. 22B-F) or even within the same trackway (Fig. 22A). Evaluation of the M-preservation is made on the basis of the distinctiveness of digital pad impressions, presence/absence and definition of metapodial pad and claw marks. The in situ trackway (Fig. 22A) displays a decrease in overall preservation grade in the pedes (from 2.5 to 1.0 ) and a nearly constant grade of the manus (2.0-2.5). The pes has a grade of 1.0 either because of a poorly defined digital pad impressions, with or without a metapodial pad impression and occasional claw marks (pes imprint L2, R2; Fig. 
22C, D); and also because of a joint intersecting the track (pes imprint R1; grade 1.0; Fig. 22B). In the illustrated couple of MD-YPI-16-02 (Fig. $22 \mathrm{E}$ ), both footprints have a 2.0 grade because of the occasional occurrence of claw marks. The best-preserved couple is MD-YPI-16-01 (Fig. 22F) with optimal M-preservation of the manus (grade 3.0) and good Mpreservation of the pes (grade 2.5), especially because of the shallowly impressed metapodial pad impression.

\subsubsection{Human tracks: Homo sapiens footprints (Fig. 25)}

12.8.2.1. Material. 15 pedal footprints, concave epirelief, in situ. Footprints BJ 1-2, SP 1-6, SS 1, HJ 1 produced by the author DM $(23 \mathrm{~cm}$ foot length, $70 \mathrm{~kg}$ weight), footprints $\mathrm{HJ}$ 2-6 produced by unknown individuals.

12.8.2.2. Stratigraphy and provenance. Present-day. BJ 1-2: sabkha Bou Jemel, southern Tunisia (Fig. 25A, I). SP 1-6: mangrove swamps near South Beach and supratidal flats and marshes SW of San Pedro airport, Ambergris Caye, Belize (Fig. 25B-D, F-I). SS 1: hypersaline pond, southern Sinai, Egypt (Fig. 25J). HJ 1-6: intertidal and supratidal flats NW of Hassi Jerbi, southern Tunisia (Fig. 25E, K-O).

12.8.2.3. Lithofacies and depositional environment. Fine-grained carbonate sediment with different conditions of water-saturation, microbial mat thickness and microbial mat overgrowth. Present-day (Marty et al., 2009).

12.8.2.4. Description. Entaxonic footprints of pentadactyl bipedal individuals. Digit impressions are very short compared to the footprint length (1/4). Digit length and width increase medially; digit impression I is noticeably wider than all the others. The digit impressions are well-separated from the sole impression, and their rounded distal part is more deeply impressed than their middle part. The sole impression is long, longer than wide, and well-impressed. The metatarsal-phalangeal part has a semi-circular arrangement. The sole impression is distally wider and the medial margin is concave. The middle part of the sole impression is less-deeply impressed. 

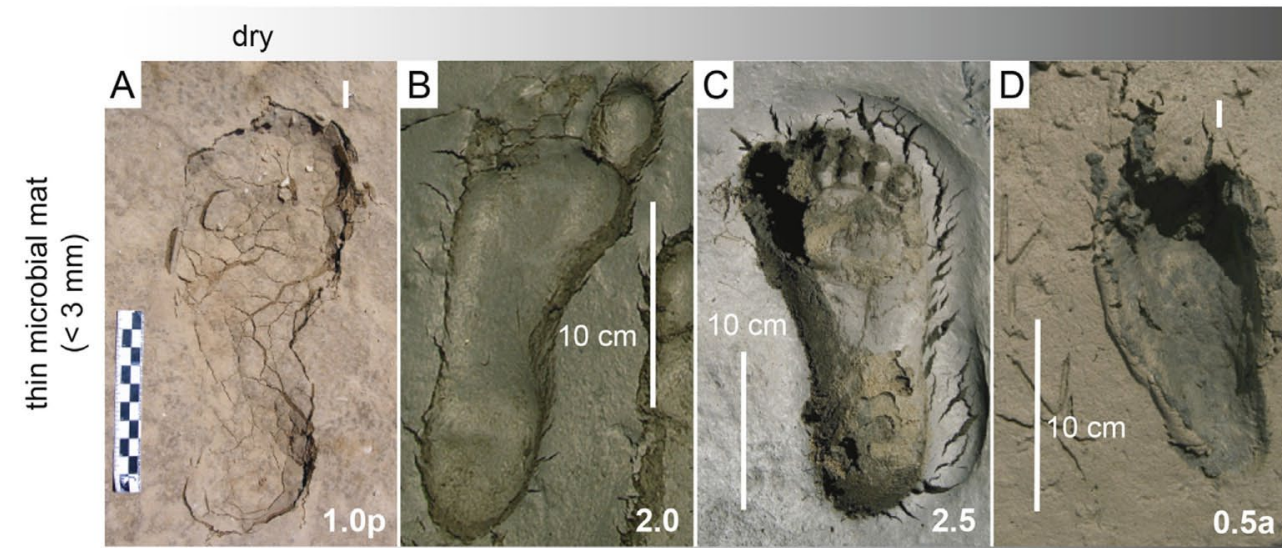

water-saturated

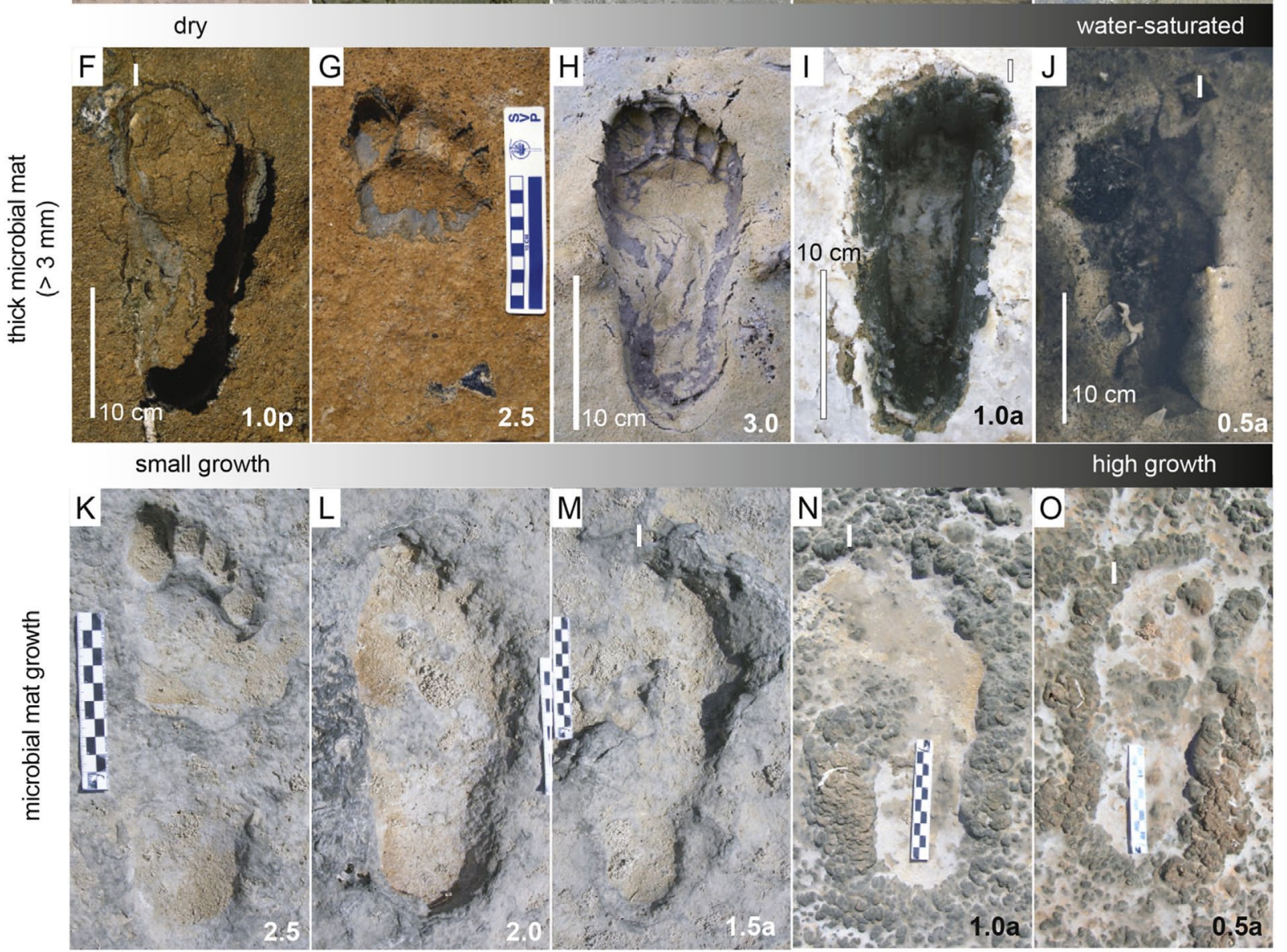

Fig. 25. Quaternary (present-day), human tracks. Modified after Marty et al. (2009). A-E) Morphological variability due to water saturation in case of thin microbial mat. F-J) Morphological variability due to water saturation in case of thick microbial mat. K-O) Morphological variability due to microbial mat overgrowth. A, I) Pes imprints BJ 1-2. Sabkha Bou Jemel, southern Tunisia. Fig. 23B-D, F-I) Pes imprints SP 1-6. Mangrove swamps near South Beach and supratidal flats and marshes SW of San Pedro airport, Ambergris Caye, Belize. J) Pes imprint SS 1. Hypersaline pond, southern Sinai, Egypt. E, K-O) Pes imprints HJ 1-6. Intertidal and supratidal flats NW of Hassi Jerbi, southern Tunisia. Digit impression I is indicated by the acronym I. Numbers and lower-case letters beside tracks indicate the preservation values and significant features according to our scale. 
12.8.2.5. M-preservation. Footprints impressed on thin (Fig. 25A-E) and thick (Fig. 25F-J) microbial mats show a similar M-preservation depending on the water saturation of the sediment. We observe the best morphological preservation associated with an intermediate water content condition (Fig. 25B-C, G-H, preservation grade 2.03.0). These are very well-preserved tracks showing all toe impressions, and also the overall shape of the foot, with a very definite outline. Footprints impressed in dry condition are poorly-preserved (Fig. $25 \mathrm{~A}, \mathrm{~F}$, preservation grade 1.0) because the outline is irregular and cracked, and not all the footprint elements are visible. Footprints impressed in water-saturated condition are poorly-preserved (Fig. 25D-E, I-J, preservation grade 0.5-1.5) because the foot penetrated deeply into the sediment producing underprints (sensu Marty et al., 2009), where only an elongate shape is recognizable. Footprints subject to microbial mat overgrowth (Fig. 25K-O) show instead an inverse correlation between microbial mat overgrowth and footprint M-preservation. Best-preserved footprints are characterized by a small overgrowth (Fig. 25K-L, preservation grade 2.0-2.5). Footprints characterized by a high overgrowth (Fig. 25M-O, preservation grade $0.5^{-}$ 1.0) are "taphonomically-modified" footprints (by ongoing growth of microbial mats on top, after that the footprints were emplaced). Thus, they can also be considered as "overtracks". Depending on how the sediment will split in the future sedimentary record (after compaction and diagenesis), it could also be that an original, well-preserved track will be found. Even this is unlikely, however, because the mats are pustular and not growing over the entire surface/track as layers.

\section{Conclusions and perspectives}

Evaluation of the morphological quality of footprints plays a central role in vertebrate footprint ichnology. In order to provide clear guidelines for an anatomy-consistent ichnotaxonomic study, several concepts linked to tetrapod footprint morphology and the processes that can deform and preserve it were discussed (Marty et al., 2009). The concepts of ichnotaphonomy, ichnostratinomy, taphonomy, biostratinomy, registration and diagenesis in ichnology were re-defined and linked to definite stages of footprint fossilization. We defined the concepts of physical preservation (P-preservation, acronym PP) 
and morphological preservation (M-preservation, MP). P-preservation describes the extent to which a footprint resists all taphonomic processes, while M-preservation defines the morphological quality of footprints, compared to the initial biologic record (anatomy-consistent morphology). Substages of the morphological preservation, such as the taphonomic preservation (= preservation quality defined by Gatesy and Falkingham, 2017) were defined and identified by a lowercase letter. The preservation numerical scale introduced by Belvedere and Farlow (2016) is here updated, and associated with M-preservation. The scale ranges from o (worst preservation) to 3 (best preservation), and intermediate values may be used. These values were compared to the common expressions used in the evaluation of the morphological preservation of footprints, such as: poor, well, good. The morphological features indicated in the scale were also related to the possible processes which generated them.

The anatomy-consistent morphology and secondarily the trackway pattern are here considered the only acceptable ichnotaxobases in ichnotaxonomy. Deformation in this morphology results in extramorphologies, and ichnotaxa based on such deformations are considered ichnotaphotaxa and have little ichnotaxonomic value (nomina dubia). These deformed footprints have low grade on the preservation scale (0.0-1.5). Conversely, ichnotaxa based on well-preserved footprints have strong anatomic bases and are the ideal basis for any further study about trackmakers, biostratigraphy, palaeoecology and palaeobiogeography. These footprints have high values in the preservation scale (2.0-3.0). Twenty-one examples of ichnotaxa and morphotypes spanning from the Palaeozoic to the recent, including footprints of several groups of terrestrial vertebrates preserved in several kinds of lithofacies and depositional environments, tested the utility, readability and suitability of the revised preservation scale. In order to facilitate understanding of the preservation values assigned to different footprints, the numerical values and letters of the preservation scale were figured beside photos of the corresponding footprints (the same can be done with 3D models). Results are noteworthy: in all cases the evaluation of the M-preservation using numbers and letters helped in understanding footprint morphology, so that the reader can readily distinguish between deformed footprints and footprints which show well-preserved anatomic features, and therefore 
are suitable for ichnotaxonomy. The method is easily applicable, fast, and substantiates the footprint descriptions and the material selection. Moreover, it was suitable for all the provided examples, so potentially it can be used in the whole track record and in any footprintbearing lithofacies. Therefore, we recommend the use of the preservation scale herein revised in all future studies of vertebrate footprint ichnotaxonomy, on a selection of ichnotaxonomically and ichnotaphonomically relevant figured and described tracks.

Acknowledgments We would like to thank all the curators of the institutions and ichnosites which provided access for the study of the material. We also thank S. G. Lucas for providing photographs of the CMN material. We also thank two anonymous reviewers for their constructive comments. This study was funded by the Alexander von Humboldt Foundation. DC is supported by AGAUR (Beatriu de Pinós Programme, BP2017). RM research was funded by project PICT 2013-1129 (Agencia Nacional de Promoción Científica y Tecnológica, Argentina).

\section{References}

Allen, J.R.L., 1997. Subfossil mammalian tracks (Flandrian) in the Severn Estuary, S.W. Britain: mechanics of formation, preservation and distribution. Philos. Trans. R. Soc. Lond. B 352, 481-518.

Anfinson, O.A., Lockley, M.G., Kim, S.H., Kim, K.S., Kim, J.Y., 2009. First report of thesmall bird track Koreanaornis from the cretaceous of North America: implications for avian ichnotaxonomy and paleoecology. Cretac. Res. 30, 885-894.

Aramayo, S.A., de Bianco, T.M., 1987. Hallazgo de una icnofauna continental (Pleistoceno tardío) en la localidad de Pehuén-Co (partido de Coronel Rosales), provincia de Buenos Aires, Argentina. In: Parte II. Carnivora, Artiodactyla Y Aves. IV Congreso Latinoamericano de Paleontología, Santa Cruz de la Sierra, Bolivia, pp.532-547.

Aramayo, S.A., de Bianco, T.M., 1996. Edad y nuevos hallazgos de icnitas de mamiferos y aves en el yacimiento paleoicnologico de Pehuen-Có (Pleistoceno Tardio), Provincia de Buenos Aires, Argentina. vol. 4. Asociación Paleontológica Argentina, Publicación Especial, pp. 47-57.

Aramayo, S.A., de Bianco, T.M., Bastianelli, N.V., Melchor, R.N., 2015. Pehuen Co: Updated taxonomic review of a late Pleistocene ichnological site in Argentina. Palaeogeogr. Palaeoclimatol. Palaeoecol. 439, 144-165.

Avanzini, M., Wachtler, M., 2012. Sphingopus ladinicus isp. Nov. from the Anisian of the Braies Dolomites (Southern Alps, Italy). Boll. Soc. Paleontol. Ital. 51, 63-70. 
Avanzini, M., Piñuela, L., García-Ramos, J.C., 2012. Late Jurassic footprints reveal walking kinematics of theropod dinosaurs. Lethaia 45, 238-252.

Baird, D., 1957. Triassic reptile footprint faunules from Mildford, New Jersey. Bull. Mus.Comp. Zool. 117, 449-520.

Behrensmeyer, A.K., Kidwell, S.M., 1985. Taphonomy's contributions to paleobiology. Paleobiology 11, 105-119.

Behrensmeyer, A.K., Kidwell, S.M., Gastaldo, R.A., 2000. Taphonomy and paleobiology. Paleobiology 26, 103-147.

Belvedere, M., Farlow, J.O., 2016. A numerical scale for quantifying the quality of preservation of vertebrate tracks. In: Falkingham, P.L., Marty, D., Richter, A. (Eds.), Dinosaur Tracks: The Next Steps. Indiana University Press, Bloomington, pp. 92

Belvedere, M., Bennett, M.R., Marty, D., Budka, M., Reynolds, S.C., Bakirov, R., 2018. Stat-tracks and mediotypes: powerful tools for modern ichnology based on 3D models. Peer J. 6, e4247.

Bertling, M., Braddy, S.J., Bromley, R.G., Demathieu, G.R., Genise, J., Mikuláš, R., Nielsen, J.K., Nielsen, K.S.S., Rindsberg, A.K., Schlirf, M., Uchman, A., 2006. Names for trace fossils: a uniform approach. Lethaia 39, 265-286.

Blakey, R.C., Knepp, R., 1989. Pennsylvanian and Permian geology of Arizona. Geologic evolution of Arizona. Ariz. Geol. Soc. Digest. 17, 313-347.

Bock, W., 1952. Triassic reptilian tracks and trends of locomotive evolution: with remarks on correlation. J. Paleontol. 3, 395-433.

Boy, J.A., Fichter, J., 1988. Zur Stratigraphie des höheren Rotliegend im SaarNahe-Becken (Unter-Perm; SW-Deutschland) und seiner Korrelation mit anderen Gebieten. Neues Jb. Geol. Paläontol. Abh. 176, 331-394.

Bromley, R.G., 1990a. Elite trace fossils, ichnotaphonomy and ichnoguilds. In: 13th International Sedimentological Congress, August, Nottingham, pp. 63-64 Abstract volume.

Bromley, R.G., 199ob. Trace fossils. In: Biology and Taphonomy. Unwin Hyman, Boston. Bromley, R.G., 1996. Trace Fossils: Biology, Taphonomy and Applications, 2nd edition.Chapman \& Hall, London.

Buatois, L.A., Mángano, M.G., 2011. Ichnology: Organism-Substrate Interactions in Space and Time. Cambridge University Press, Cambridge.

Buatois, L.A., Wisshak, M., Wilson, M.A., Mangano, M.G., 2017. Categories of architectural designs in trace fossils: a measure of ichnodisparity. Earth Sci. Rev. 164, 102-181.

Buck, P.V., Ghilardi, A.M., dos Reis Fernandes, L.B., Fernandes, M.A., 2017. A new tetrapod ichnotaxon from Botucatu Formation, lower cretaceous (Neocomian), Brazil, with comments on fossil track preservation on inclined planes and local paleoecology. Palaeogeogr. Palaeoclimatol. Palaeoecol. 466, 21-37.

Butts, E., 1891. Recently discovered footprints of the amphibian age in the Upper Coal Measure Group of Kansas City, Missouri. Kansas City Scient. 5, 17-19.

Canudo, J.I., Barco, J.L., Cuenca-Bescós, G., Rubio, J., 2007. Icnitas de Abiego. Prames, Zaragoza. 
Carrano, M.T., Wilson, J.A., 2001. Taxon distributions and the tetrapod track record.Paleobiology 27, 564-582.

Castanera, D., Vila, B., Razzolini, N.L., Falkingham, P.L., Canudo, J.I., Manning, P.L., Galobart, À., 2013a. Manus track preservation bias as a key factor for assessing trackmaker identity and quadrupedalism in basal ornithopods. PLoS One 8, e54177.

Castanera, D., Pascual, C., Razzolini, N.L., Vila, B., Barco, J.L., Canudo, J.I., 2013b. Discriminating between medium-sized tridactyl trackmakers: tracking ornithopod tracks in the base of the cretaceous (Berriasian, Spain). PLoS One 8, e81830.

Castanera, D., Santos, V.F., Piñuela, L., Pascual, C., Vila, B., Canudo, J.I., Moratalla, J.J., 2016. Iberian Sauropod Tracks through Time: Variations in Sauropod Manus and Pes Track Morphologies. Dinosaur Tracks: The Next Steps. pp. 121-137.

Castanera, D., Belvedere, M., Marty, D., Paratte, G., Lapaire-Cattin, M., Lovis, C., Meyer, C.A., 2018. A walk in the maze: variation in late Jurassic tridactyl dinosaur tracks from the Swiss Jura Mountains (NW Switzerland). Peer J. 6, e4579. https://doi.org/ 10.7717/peerj.4579.

Chesnut, D.R., Baird, D., Smith, J.H., Lewis, R.Q., 1994. Reptile trackway from the Lee Formation (lower Pennsylvanian) of south-Central Kentucky. J. Paleontol. $68,154-158$.

Clack, J.A., 1997. Devonian tetrapod trackways and trackmakers; a review of the fossils and footprints. Palaeogeogr. Palaeoclimatol. Palaeoecol. 130, 227-250.

Cohen, A., Lockley, M., Halfpenny, J., Michel, A.E., 1991. Modern vertebrate track taphonomy at Lake Manyara, Tanzania. Palaios 6, 371-389.

Cohen, A.S., Halfpenny, J., Lockley, M., Michel, E., 1993. Modern vertebrate tracks from Lake Manyara, Tanzania and their paleobiological implications. Paleobiology 19, 433-458.

Collareta, A., Farina, S., 2015. A new record of Triassic dinosaur footprint from Monte Pisano (Northern Apennines, Italy): true or false? Atti della Soc. Toscana Sci. Nat. Mem. Ser. A 121, 13-17.

Comment, G., Ayer, J., Becker, D., 2011. Deux nouveaux membres lithostratigraphiques de la Formation de Reuchenette (Kimméridgien, Ajoie, Jura suisse) - Nouvelles données géologiques et paléontologiques acquises dans le cadre de la construction de l'autoroute A16 (Transjurane). Swiss Bull. Appl. Geol. 16, 3-24.

Comment, G., Lefort, A., Koppka, J., Hantzpergue, P., 2015. Le Kimméridgien d'Ajoie (Jura, Suisse): lithostratigraphie et biostratigraphie de la Formation de Reuchenette. Rev. Paléobiol. 34, 161-194.

Costeur, L., Balme, C., Legal, S., 2009. Early Oligocene mammal tracks from southeastern France. Ichnos 16, 257-267.

Courel, L., Demathieu, G., 200o. Une nouvelle ichnoespèce Coelurosaurichnus grancieri du Trias supérieur de l'Ardèche, France. Geodiversitas 22, 35-46. 
Dauphin, Y., Williams, C.T., Andrews, P., Denys, C., Fernandez-Jalvo, Y., 1999. Diagenetic alterations of micromammal fossil bones from Olduvai Bed I of the lower Pleistocene sequence at Olduvai Gorge, Tanzania. J. Sediment. Res. 69, 612-621.

Dawson, J.W., 1863. Air-Breathers of the Coal Period: A Descriptive Account of the Remains of Land Animals Found in the Coal Formation of Nova Scotia, with Remarks on their Bearing on Theories of the Formation of Coal and of the Origin of Species. vol. 4 Dawson Brothers, Montreal.

Dawson, J.W., 1872. V.-note on footprints from the carboniferous of Nova Scotia, in the collection of the geological survey of Canada. Geol. Mag. 9, 251-253.

De Valais, S., Melchor, R.N., 2008. Ichnotaxonomy of bird-like footprints: an example from the late Triassic-early Jurassic of Northwest Argentina. J. Vertebr. Paleontol. 28, 145-159.

Demathieu, G., Demathieu, P., 2003. Concerning the erection of ichnogenera and ichnospecies in vertebrate ichnotaxonomy. Ichnos 9, 117-121.

Demathieu, G., Gand, G., 1972. Coelurosaurichnus perriauxi - empreinte dinosauroide du Trias nouvelle. Bull. Soc. Hist. Nat. Autun. 62, 2-3.

Díaz-Martínez, I., Pérez-Lorente, F., Canudo, J.I., Pereda-Suberbiola, X., 2009. Causas de la variabilidad en icnitas de dinosaurios y su aplicación en icnotaxonomía. In: Actas de las IV Jornadas Internacionales sobre Paleontología de Dinosaurios y su Entorno. Salas de los Infantes, Burgos, pp. 207-220.

Díaz-Martínez, I., Hernández, J.M., Fernández, S.G., Murelaga, X., Pérez-Lorente, F., 2012. Uvaichnites riojana: a new crane-like bird ichnotaxon from the lower Miocene of La Rioja (Ebro Basin, Spain). Proc. Geol. Assoc. 123, 464-470.

Díaz-Martínez, I., Pereda-Suberbiola, X., Pérez-Lorente, F., Canudo, J.I., 2015a. Ichnotaxonomic review of large ornithopod dinosaur tracks: temporal and geographic implications. PLoS One 10, e0115477.

Díaz-Martínez, I., García-Ortiz, E., Pérez-Lorente, F., 2015b. A new dinosaur tracksite with small footprints in the Urbión Group (Cameros Basin, lower cretaceous, La Rioja, Spain). J. Iber. Geol. 41, 167-175.

Díaz-Martínez, I., Suarez-Hernando, O., Martinez-Garcia, B., Hernández, J.M., Fernández, S.G., Perez-Lorente, F., Murelaga, X., 2015c. Early Miocene shorebird-like footprints from the Ebro Basin, La Rioja, Spain: paleoecological and paleoenvironmental significance. Palaios 30, 424-431.

Díaz-Martínez, I., Suarez-Hernando, O., Martínez-García, B.M., Larrasoaña, J.C., Murelaga, X., 2016. First bird footprints from the lower Miocene Lerín Formation, Ebro Basin, Spain. Palaeontol. Electron. 19, 1-15.

Díaz-Martínez, I., González, S.N., de Valais, S., 2017. Dinosaur footprints in the early Jurassic of Patagonia (Marifil Volcanic complex, Argentina): biochronological and palaeobiogeographical inferences. Geol. Mag. 154, 914-922.

Díaz-Martínez, I., Cónsole-Gonella, C., de Valais, S., Salgado, L., 2018. Vertebrate tracks from the Paso Córdoba fossiliferous site (Anacleto and Allen formations, 
Upper cretaceous), Northern Patagonia, Argentina: Preservational, environmental and palaeobiological implications. Cretac. Res. 83, 207-220.

D’Orazi Porchetti, S., Bertini, R.J., Langer, M.C., 2018. Proposal for ichnotaxonomic allocation of therapsid footprints from the Botucatu formation (Brazil). Ichnos 25, 192-207.

Eberth, D.A., Berman, D.S., Sumida, S.S., Hopf, H., 200o. Lower Permian terrestrial paleoenvironments and vertebrate paleoecology of the Tambach Basin (Thuringia, Central Germany): the upland holy grail. Palaios 15, 293-313.

Efremov, J.A., 1940. Taphonomy: a new branch of geology. Pan.-Am. Geol. 74, 81-93. Ellenberger, P., 1980. Sur les empreintes de pas de gros mammiféres de l'Eocène supérieur de Garrigues-Ste-Eulalie (Gard). Paleovertebrata. Mém. Jub. R. Lavocat 37-78.

Ellenberger, P., 1983a. Sur la zonation ichnologique du Permien inférieur (Autunien) du bassin de Lodève (Hérault). In: Comptes-rendus des séances de l'Académie des sciences. Série 2, Mécanique-physique, chimie, sciences de l'univers, sciences de la terre 297pp. 631-636.

Ellenberger, P., 1983b. Comptes-rendus des séances de l'Académie des sciences. Série 2, Mécanique-physique, chimie, sciences de l'univers, sciences de la terre 297. pp.553-558 Sur la zonation ichnologique du Permien moyen (Saxonien) du bassin de Lodève (Hérault).

Falcon-Lang, H.J., Benton, M.J., Stimson, M., 2007. Ecology of earliest reptiles inferred from basal Pennsylvanian trackways. J. Geol. Soc. 164, 1113-1118.

Falkingham, P.L., 2014. Interpreting ecology and behavior from the vertebrate fossil track record. J. Zool. 292, 222-228.

Falkingham, P.L., Gatesy, S.M., 2014. The birth of a dinosaur footprint: subsurface 3D motion reconstruction and discrete element simulation reveal track ontogeny. Proc. Natl. Acad. Sci. 111, 18279-18284.

Farlow, J.O., 1992. Sauropod tracks and trackmakers integrating the ichnological and skeletal records. Zubia 10, 89-138.

Farlow, J.O., Pittman, J.G., Hawthorne, J.M., 1989. Brontopodus birdi, lower cretaceous sauropod footprints from the US Gulf coastal plain. In: Gillette, D.D., Lockley, G.M. (Eds.), Dinosaur Tracks and Traces. Cambridge University Press, Cambridge, pp.371-394.

Farlow, J.O., O’Brien, M., Kuban, G.J., Dattilo, B.F., Bates, K.T., Falkingham, P.L., Piñuela, L., Rose, A., Freels, A., Kumagai, C., Libben, C., Smith, J., Whitcraft, J., 2012. Dinosaur tracksites of the Paluxy River valley (Glen Rose Formation, Dinosaur Valley State Park, Somervell County, Texas). In: V Actas de las Jornadas Internacionales Paleontología de Dinosaurios y Su Entorno (Salas de los Infantos, Burgos, España), pp. 41-69.

Farlow, J.O., Bates, K.T., Bonem, R.M., Dattilo, B.F., Falkingham, P.L., Gildner, R., Jacene, J., Kuban, G.J., Martin, A.J., O’Brian, M., Whitcraft, J., 2015. Dinosaur footprints from the Glen Rose Formation (Paluxy River, Dinosaur Valley State Park, Somervell County, Texas). In: Noto, C. (Ed.), Early- and Mid-Cretaceous 
Archosaur Localities of North-Central Texas, Field Trip Guidebook, 75th Annual Meeting. Society of Vertebrate Paleontology, Dallas, Texas, pp. 14-37.

Farlow, J.O., Coroian, D., Currie, P.J., 2018a. Noah's Ravens: Interpreting the Makers of Tridactyl Dinosaur Footprints. Indiana University Press, Bloomington.

Farlow, J.O., Robinson, N.J., Kumagai, C.J., Paladino, F.V., Falkingham, P.L., Elsey, R.M., Martin, A.J., 2018b. Trackways of the American crocodile (Crocodylus acutus) in northwestern Costa Rica: implications for crocodylian ichnology. Ichnos 25, 30-65.

Fernández-López, S., Fernández Jalvo, Y., 2002. The limit between biostratinomy and fossil diagenesis. In: De Renzi, M., Pardo Alonso, M.V., Belinchón, M., Peñalver, E., Montoya, P., Márquez-Aliaga, A. (Eds.), Current Topics on Taphonomy and Fossilization, pp. 27-37 Valencia.

Fichman, M.E., Crespi, J.M., Getty, P.R., Bush, A.M., 2015. Retrodeformation of Carboniferous trace fossils from the Narragansett Basin, United States, using raindrop imprints and bedding-cleavage intersection lineation as strain markers. Palaios 30, 574-588.

Fillmore, D.L., Lucas, S.G., Simpson, E.L., 2012. Ichnology of the Mississippian Mauch Chunk Formation, eastern Pennsylvania. N. M. Mus. Nat. Hist. Sci. Bull. $54,1-136$.

Francischini, H., Lucas, S.G., Voigt, S., Marchetti, L., Santucci, V.L., Knight, C.L., Dentzien-Dias, P., 2018. The first record of Ichniotherium in the Cisuralian Coconino Sandstone of the Grand Canyon National Park (Arizona, USA). In: XI Simpósio Brasileiro de Paleontologia de Vertebrados. Boletim de Resumos, Teresina, Brazil, pp. 52.

Fuglewicz, R., Ptaszynski, T., Rdzanek, K., 1990. Lower Triassic footprints from the Świętokrzyskie (Holy Cross) Mountains, Poland. Acta Palaeontol. Pol. 35, 109-164.

Gand, G., 1988. Les traces de Vertébrés tétrapodes du Permien français (paléontologie, stratigraphie, paléoenvironnements). (Doctoral dissertation, Dijon).

Gand, G., Demathieu, G., 2005. Les pistes dinosauroides du Trias moyen francais: interprétation et réévaluation de la nomenclature. Geobios 38, 725-749.

Gand, G., Durand, M., 2006. Tetrapod footprint ichno-associations from French Permian basins. Comparisons with other Euramerican ichnofaunas. Geol. Soc. Lond., Spec. Publ. 265, 157-177.

Gand, G., Demathieu, G., Ballestra, F., 1995. La palichnofaune de vertebres tetrapodes du Permien superieur de l'Esterel (Provence, France). Palaeontograph. A 235, 97-139.

Gand, G., Garric, J., Demathieu, G., Ellenberger, P., 200o. La palichnofaune de vertebres tetrapodes du Permien superieur du bassin de Lodeve (LanguedocFrance). Palaeovertebrata 29, 1-82.

Gand, G., Demathieu, G., Grancier, M., Sciau, J., 2005. Les traces dinosauroides du Trias supérieur francais: discrimination, interprétation et comparaison. Bull. Soc. Géol.France 176, 69-79. 
Gatesy, S.M., Falkingham, P.L., 2017. Neither bones nor feet: track morphological variation and 'preservation quality'. J. Vertebr. Paleontol. 37, e1314298.

Gatesy, S.M., Middleton, M.K., Jenkins Jr., F.A., Shubin, N.H., 1999. Threedimensional preservation of foot movements in Triassic theropod dinosaurs. Nature 399, 141-144.

Geinitz, H.B., 1863. Beiträge zur Kenntnis der organischen Überreste in der Dyas (oder permischen Formation zum Theil) and Über den Namen Dyas. Neues Jahrb. Mineral. Geol. Paläontol. 385-389.

Geng, Q., 2011. Tectonic sequence stratigraphy and lithofacies paleogeography of Cretaceous-Paleogene in Sichuan Basin of China. J. Chengdu Univ. Technol. Sci. Technol. Edn. 38, 394e401.

Genise, J.F., 2004. Ichnotaxonomy and ichnostratigraphy of chambered trace fossils in palaeosols attributed to coleopterans, ants and termites. In: McIlroy, D. (Ed.), The Application of Ichnology to Palaeoenvironmental and Stratigraphic Analysis. 228. Geological Society, London, pp. 419-453 Special Publications.

Genise, J.F., Melchor, R.N., Archangelsky, M., Bala, L.O., Straneck, R., de Valais, S., 2009. Application of neoichnological studies to behavioral and taphonomic interpretation of fossil bird-like tracks from lacustrine settings: the late Triassic-early Jurassic? Santo Domingo Formation, Argentina. Palaeogeogr. Palaeoclimatol. Palaeoecol. 272, 143-161.

Gillette, D.D., 1986. First international symposium on dinosaur track and traces. New Mexico Museum Nat. Hist. 1-31 Albuquerque, New Mexico, May 22-24. Abstract Volume.

Gilmore, G.W., 1927. Fossil footprints from the Grand Canyon II. Smith. Miscell. Collect.80, 1-78.

Gygi, R.A., 200o. Integrated Stratigraphy of the Oxfordian and Kimmeridgian (late Jurassic) in Northern Switzerland and Adjacent Southern Germany. Mem. Swiss Acad. Sci. 104, 1-152.

Haubold, H., 1971. Die Tetrapodenfährten des Buntsandsteins. Palaontol. Abhand. A 4, 395-548.

Haubold, H., 1996. Ichnotaxonomie und Klassifikation von Tetrapodenfährten aus dem Perm. Hallesch. Jahr. Geowiss. B 18, 23-88.

Haubold, H., 200o. Tetrapodenfährten aus dem Perm-Kenntnisstand und progress 2000. Hallesch. Jahr. Geowiss. B 22, 1-16.

Haubold, H., Klein, H., 2002. Chirotherien und Grallatoriden aus der Unteren bis Oberen Trias Mitteleuropas und die Entstehung der Dinosauria. Hallesch. Jahr. Geowiss. B 24, 1-22.

Haubold, H., Lucas, S.G., 2003. Tetrapod footprints of the lower permian choza formation at Castle Peak, Texas. Paläontol. Z. 77, 247-261.

Haubold, H., Sarjeant, W.A.S., 1973. Tetrapodenfährten aus den Keele und Enville groups (Permokarbon: Stefan und Autun) von Shropshire und South Staffordshire, Grossbritannien. Z. Geol. Wiss. 1, 895-933. 
Haubold, H., Hunt, A.P., Lucas, S.G., Lockley, M.G., 1995. Wolfcampian (early Permian) vertebrate tracksfrom Arizona and New Mexico. N. M. Mus. Nat. Hist. Sci. Bull. 6, 135-165.

Hernández-Pacheco, F., 1929. Pistas de aves fósiles en el Oligoceno de Peralta de la Sal (Lérida). Mem. Real Soc. Esp. Hist. Nat 15, 379-382.

Hitchcock, E., 1845. An attempt to name, classify and describe the animals that made the fossil footprints of New red Sandstone in Massachusetts. Am. J. Sci. 29, 129-140.

Hitchcock, E., 1858. Ichnology of New England: A Report on the Sandstone of the Connecticut Valley Especially its Fossil Footmarks, Made to the Government of the Commonwealth of Massachusetts. William White, Boston.

Hu, B., Wang, Y.Y., Song, H.B., 2014. The ichnofacies and ichnoassemblages in terrestrial deposits of China. J. Palaeogr. 3, 61e73.

Huene, F.V., 1941. Die Tetrapoden-Fährten im toskanischen Verrucano und ihre Bedeutung. Neues Jahr. Mineral. Geol. Paleontol. 86, 1-34.

International Commission on Zoological Nomenclature, 1999. International Code of Zoological Nomenclature, 4th edition. International Trust for Zoological Nomenclature, London.

Jank, M., Meyer, C.A., Wetzel, A., 2006a. Late Oxfordian to late Kimmeridgian carbonate deposits of NW Switzerland (Swiss Jura): Stratigraphical and palaeogeographical implications in the transition area between the Paris Basin and the Tethys. Sediment. Geol. 186, 237-263.

Jank, M., Wetzel, A., Meyer, C.A., 2006b. A calibrated composite section for the late Jurassic Reuchenette Formation in northwestern Switzerland (Oxfordian, Kimmeridgian sensu gallico, Ajoie-Region). Eclogae Geol. Helv. 99, 175-191.

Keighley, D.G., Calder, J.H., Park, A.F., Pickerill, R.K., Waldron, J.W., Falcon-Lang, H.J., Benton, M.J., 2008. Discussion on ecology of earliest reptiles inferred from basal Pennsylvanian trackways. Journal, Vol. 164, 2007, 1113-1118. J. Geol. Soc. 165, 983-987.

Kim, B.K., 1969. A study of several sole marks in the Haman Formation. J. Geol. Soc. Kor.5, 243-258.

Klein, H., Lucas, S.G., 2010a. Tetrapod footprints-their use in biostratigraphy and biochronology of the Triassic. Geol. Soc. Lond., Spec. Publ. 334, 419-446.

Klein, H., Lucas, S.G., 2010b. Review of the tetrapod ichnofauna of the Moenkopi Formation/Group (Early-Middle Triassic) of the American Southwest. N. M. Mus. Nat. Hist. Sci. Bull. 50, 1-67.

Klein, H., Lucas, S.G., 2018. Diverse Middle Triassic Tetrapod Footprint Assemblage from the Muschelkalk of Germany. Ichnos 25, 162-176.

Klein, H., Niedzwiedzki, G., 2012. Revision of the lower Triassic Tetrapod Ichnofauna from Wiory, Holy Cross Mountains, Poland. N. M. Mus. Nat. Hist. Sci. Bull. 56, 1-62.

Kordos, L., 1983. Footprints in lower Miocene Sandstone at Ipolytarnóc, N Hungary. Geol. Hungar. ser. Palaeöntol. 44-46. 
Kordos, L., Prakfalvi, P., 1990. Újabb adatok az európai neogén lábnyomos rétegek ismeretéhez. Földtani Int. Évi Jelent. 50, 201-212.

Kuban, G.J., 1989. Elongate dinosaur tracks. In: Gillette, D.D., Lockley, M.G. (Eds.), Dinosaur Tracks and Traces. Cambridge University Press, Cambridge, pp. 57-72.

Laporte, L.F., Behrensmeyer, A.K., 1980. Tracks and substrate reworking by terrestrial vertebrates in Quaternary sediments of Kenya. J. Sediment. Res. 50, 1337-1346.

Lawrence, D.R., 1979. Diagenesis of fossils-fossildiagenese. In: Fairbridge, R.W. (Ed.), Paleontology. Encyclopedia of Earth Science. Springer, Berlin, Heidelberg, pp.245-247.

Lee, H.J., Lee, Y.N., Fiorillo, A.R., Lü, J., 2018. Lizards ran bipedally 110 million years ago. Sci. Rep. 8, 2617.

Leonardi, G., 1987. Glossary and Manual of Tetrapod Palaeoichnology. Departamento Nacional da Produção Mineral, Brasilia.

Leonardi, G., 1994. Annotated Atlas of South America Tetrapod Fooprints (Devonian to Holocene) with an Appendix on Mexico and Central America. Companhia de Pesquisa de Recursos Minerales, Brasilia.

Leonardi, G., Lockley, M.G., 1995. A proposal to abandon the ichnogenus Coelurosaurichnus Huene, 1941, a junior synonym of Grallator E. Hitchcock, 1858. J. Vertebr. Paleontol. 15, 40.

Leonardi, P., Conti, M.A., Leonardi, G., Mariotti, N., Nicosia, U., 1975. Pachypes dolomiticus n. gen. N.sp.; Pareiasaur footprint from the 'Val Gardena Sandstone'(Middle Permian) in the western Dolomites (N. Italy). Atti della Acad. Nazion. Lincei 57, 221-232.

Liu, G., Luo, C., 2015. Analysis and application of reliability theory in rock slope dumping damage. Water Conservancy Constr. Manag. 35, 31-34.

Lockley, M.G., 1986. The paleobiological and paleoenvironmental importance of dinosaur footprints. Palaios 1, 37-47.

Lockley, M.G., 1994. Dinosaur ontogeny and population structure: Interpretations and speculations based on fossil footprints. In: Carpenter, K., Hirsch, K.F., Horner, J.R. (Eds.), Dinosaur eggs and babies. Cambridge University Press, Cambridge, pp.347-370.

Lockley, M.G., 1998. The vertebrate track record. Nature 396, 429-432.

Lockley, M.G., 2009. New perspectives on morphological variation in tridactyl footprints: clues to widespread convergence in developmental dynamics. Geol.1 Quart. 53, 415-432.

Lockley, M.G., Hunt, A.P., 1995. Dinosaur Track Sand Other Fossil Footprints of the Western United States. Columbia University Press, New York.

Lockley, M.G., Xing, L., 2015. Flattened fossil footprints: implications for paleobiology. Palaeogeogr. Palaeoclimatol. Palaeoecol. 426, 85-94.

Lockley, M.G., Yang, S.Y., Matsukawa, M., Fleming, F., Lim, S.K., 1992. The track record of Mesozoic birds: evidence and implications. Philos. Trans. R. Soc. Lond. B 336, 113-134. 
Lockley, M.G., Matsukawa, M., Li, J., 2003. Crouching theropods in taxonomic jungles: ichnological and ichnotaxonomic investigations of footprints with metatarsal and ischial impressions. Ichnos 10, 169-177.

Lockley, M.G., Houck, K., Yang, S.Y., Matsukawa, M., Lim, S.K., 2006. Dinosaur dominated footprint assemblages from the cretaceous Jindong Formation, Hallayo Haesang National Park, Goseong County, South Korea: evidence and implications. Cretac. Res. 27, 70-101.

Lockley, M.G., Li, J., Matsukawa, M., Li, R., 2012. A new avian ichnotaxon from the cretaceous of Nei Mongol, China. Cretac. Res. 34, 84-93.

Lockley, M.G., Li, J., Li, R., Matsukawa, M., Harris, J.D., Xing, L., 2013. A review of the tetrapod track record in China with special reference to type ichnospecies: implications for ichnotyxonomy and paleobiology. Acta Geol. Sin. 87, 1-20.

Lockley, M.G., Houck, K.J., Matthews, N., McCrea, R.T., Xing, L., Tsukui, K., Ramezani, J., Brent Breithaupt, B., Cart, K., Martin, J., Buckley, L.G., Hadden, G., 2018. New theropod display arena sites in the cretaceous of North America: Clues to distributions in space and time. Cretac. Res. 81, 9-25.

Loope, D.B., 1992. Comment and reply on "Fossil vertebrate footprints in the Coconino sandstone (Permian) of northern Arizona: evidence for underwater origin”. Geology 20, 666-670. Lucas, S.G., 2001. Taphotaxon. Lethaia 34, 30.

Lucas, S.G., 2015. Thinopus and a critical review of Devonian tetrapod footprints. Ichnos 22, 136-154.

Lucas, S.G., Lerner, A.J., Bruner, M., Shipman, P., 2004. Middle Pennsylvanian ichnofauna from eastern Oklahoma, USA. Ichnos 11, 45-55.

Lull, R.S., 1904. Fossil footprints of the Jura-Trias of North America. Mem. Boston Soc. Nat. Hist. 5, 461-557.Luzón, A., 2005. Oligocene NE Spain: tectonic control and palaeogeographical evolution. Sediment. Geol. 177, 19-39.

Lyman, R.L., 1994. Vertebrate Taphonomy. Cambridge University Press, Cambridge. Marchetti, L., 2016. New occurrences of tetrapod ichnotaxa from the Permian Orobic Basin (Northern Italy) and critical discussion of the age of the ichnoassociation. Pap. Palaeontol. 2, 363-386.

Marchetti, L., 2018. Can undertracks show higher morphologic quality than surface tracks? Remarks on large amphibian tracks from the early Permian of France. J. Iber. Geol. 1-11. https://doi.org/10.1007/s41513-018-008o-4.

Marchetti, L., Avanzini, M., Conti, M.A., 2013. Hyloidichnus bifurcatus Gilmore, 1927 and Limnopus heterodactylus (King, 1845) from the early Permian of Southern Alps (N Italy): a new equilibrium in the ichnofauna. Ichnos 20, 202-217.

Marchetti, L., Ronchi, A., Santi, G., Voigt, S., 2015a. The Gerola Valley site (Orobic Basin, Northern Italy): a key for understanding late early Permian tetrapod ichnofaunas. Palaeogeogr. Palaeoclimatol. Palaeoecol. 439, 97-116.

Marchetti, L., Ronchi, A., Santi, G., Schirolli, P., Conti, M.A., 2015b. Revision of a classic site for Permian tetrapod ichnology (Collio Formation, Trompia and Caffaro valleys, N. Italy), new evidences for the radiation of captorhinomorph footprints. Palaeogeogr. Palaeoclimatol. Palaeoecol. 433, 140-155. 
Marchetti, L., Mujal, E., Bernardi, M., 2017a. An unusual Amphisauropus trackway and its implication for understanding seymouriamorph locomotion. Lethaia 50, 162-174.

Marchetti, L., Voigt, S., Klein, H., 2017b. Revision of late Permian tetrapod tracks from the Dolomites (Trentino-Alto Adige, Italy). Hist. Biol. 1-36. https://doi. org/10.1080/ 08912963.2017.1391806.

Marchetti, L., Tessarollo, A., Felletti, F., Ronchi, A., 2017c. Tetrapod Footprint Paleoecology: Behavior, Taphonomy and Ichnofauna Disentangled. A Case Study from the lower Permian of the Southern Alps (Italy). Palaios 32, 506-527.

Marchetti, L., Voigt, S., Santi, G., 2018. A rare Occurrence of Permian Tetrapod Footprints: Ichniotherium cottae and Ichniotherium sphaerodactylum on the same stratigraphic surface. Ichnos 25, 106-118.

Marchetti, L., Voigt, S., Lucas, S.G., Francischini, H., Dentzien-Dias, P., Sacchi, R., Mangiacotti, M., Scali, S., Gazzola, A., Ronchi, A., Millhouse, A., 2019. Tetrapod ichnotaxonomy in eolian paleoenvironments (Coconino and De Chelly formations, Arizona) and late Cisuralian (Permian) sauropsid radiation. Earth Sci. Rev. 190, 148-170.

Marsh, O.C., 1894. I.-Footprints of Vertebrates in the Coal-measures of Kansas. Geol. Mag. 1, 337-339.

Marty, D., 2008. Sedimentology, taphonomy, and ichnology of late Jurassic dinosaur tracks from the Jura carbonate platform (Chevenez-Combe Ronde tracksite, NW Switzerland): insights into the tidal-flat palaeoenvironment and dinosaur diversity, locomotion, and palaeoecology. GeoFocus 21, 1-278 (PhD Thesis).

Marty, D., Strasser, A., Meyer, C.A., 2009. Formation and taphonomy of human footprints in microbial mats of present-day tidal-flat environments: implications for the study of fossil footprints. Ichnos 16, 127-142.

Marty, D., Belvedere, M., Meyer, C.A., Mietto, P., Paratte, G., Lovis, C., Thüring, B., 2010. Comparative analysis of late Jurassic sauropod trackways from the Jura Mountains (NW Switzerland) and the central High Atlas Mountains (Morocco): implications for sauropod ichnotaxonomy. Hist. Biol. 22, 109-133.

Marty, D., Falkingham, P., Richter, A., 2016. Dinosaur track terminology: A glossary of terms. In: Falkingham, P., Marty, D., Richter, A. (Eds.), Dinosaur Tracks - The Next Steps. Indiana University Press, Bloomington, pp. 399-402.

Marty, D., Belvedere, M., Razzolini, N.L., Lockley, M.G., Paratte, G., Cattin, M., Lovis, C., Meyer, C.A., 2018. The tracks of giant theropods Uurabrontes curtedulensis ichnogen. \& ichnosp. Nov.) from the late Jurassic of NW Switzerland: palaeoecological \& palaeogeographical implications. Hist. Biol. 30, 928-956.

Matthew, G.F., 1903. On batrachian and other footprints from the coal measures of Joggins. N.S. Nat. Hist. Soc. New Bruns. Bull. 21, 103-108.

Matthews, S.C., 1973. Notes on open nomenclature and on synonymy lists. Paleontology 16, 713-719. 
McCrea, R.T., Tanke, D.H., Buckley, L.G., Lockley, M.G., Farlow, J.O., Xing, L., Matthews, N.A., Helm, C.W., Pemberton, S.G., Breithaupt, B.H., 2015. Vertebrate ichnopathology: pathologies inferred from dinosaur tracks and trackways from the Mesozoic. Ichnos 22, 235-26o.

Melchor, R.N., Feola, S.F., de Bianco, T.M., 2018. Canid Paleoichnology: Taxonomic Review and producers of Canipeda from the late Pleistocene of Argentina. Ichnos 1-23. https://doi.org/10.1080/10420940.2018.1447466.

Meyer, C.A., Marty, D., Belvedere, M., 2018. Titanosaur trackways from the late cretaceous El Molino Formation of Bolivia (Cal Orck'o, Sucre). Ann. Soc. Geol. Pol. 88, 223-241.

Milàn, J., Bromley, R.G., 2006. True tracks, undertracks and eroded tracks, experimental work with tetrapod tracks in laboratory and field. Palaeogeogr. Palaeoclimatol. Palaeoecol. 231, 253-264.

Milan, J., Bromley, R.G., 2007. The impact of sediment consistency on track and undertrack morphology: experiments with emu tracks in layered cement. Ichnos 15, 19-27.

Milner, A.R.C., Harris, J.D., Lockley, M.G., Kirkland, J.L., Matthews, N.A., 2009. Bird-like anatomy, posture, and behavior revealed by an early Jurassic theropod dinosaur resting trace. PLoS One e4591.

Moodie, R.L., 1929. Vertebrate footprints from the red beds of Texas. Am. J. Sci. 100, 352-368.

Moratalla García, J.J., 1993. Restos indirectos de dinosaurios del registro español: Paleoicnología de la Cuenca de Cameros (Jurásico superior-Cretácico inferior) y Paleoología del Cretácico superior. PhD thesis. Universidad Complutense de Madrid.

Mujal, E., Fortuny, J., Bolet, A., Oms, O., López, J.Á., 2017. An archosauromorph dominated ichnoassemblage in fluvial settings from the late early Triassic of the Catalan Pyrenees (NE Iberian Peninsula). PLoS One 12, e0174693.

Nicosia, U., Loi, M., 2003. Triassic footprints from Lerici (La Spezia, northern Italy). Ichnos 10, 127-140.

Niedźwiedzki, G., Szrek, P., Narkiewicz, K., Narkiewicz, M., Ahlberg, P.E., 2010. Tetrapod trackways from the early Middle Devonian period of Poland. Nature $463,43-48$.

Nopcsa, F., 1923. Die Familien der Reptilien (No. 2). Gebrüder Borntraeger, Stuttgart. Pabst, W., 1895. Thierfährten aus dem Rothliegenden von Friedrichroda, Tambach und Kabarz in Thüringen. Z. Dtsch. Geol. Ges. 47, 570-576.

Pabst, W., 1908. Die Tierfährten in dem Rotliegenden” Deutschlands”. In: Engelmann, W. (Ed.), Komm. vol. 82.

Padian, K., Olsen, P.E., 1984. The fossil trackway Pteraichnus not pterosaurian, but crocodilian. J. Paleontol. 58, 178-184.

Paratte, G., Lapaire, M., Lovis, C., Marty, D., 2017a. Traces de dinosaures jurassiques -Courtedoux Tchâfouè. In: Office de la culture - Paléontologie A16, Porrentruy, 490 p. (Catalogues du patrimoine paléontologique jurassien A16). 9782884360456, . 
Paratte, G., Lapaire, M., Lovis, C., Marty, D., 2017b. Traces de dinosaures jurassiques - Courtedoux Bois de Sylleux. In: Office de la culture Paléontologie A16, Porrentruy. 9782884360470, pp. 500 Catalogues du patrimoine paléontologique jurassien A16.

Peabody, F.E., 1948. Reptile and Amphibian Trackways from the Lower Triassic Moenkopi Formation of Arizona and Utah. University of California Press, Berkeley.

Peabody, F.E., 1955. Taxonomy and the Footprints of Tetrapods. J. Paleontol. 29, 915-918Plotnick, R.E., 2012. Behavioral biology of trace fossils. Paleobiology 38, 459-473.

Presley, M.W., McGillis, K.A., 1982. Coastal Evaporite and Tidal-Flat Sediments of the Upper Clear Fork and Glorieta Formations, Texas Panhandle. Bureau of Economic Geology, University of Texas, Austin.

Quijada, I.E., Suarez-Gonzalez, P., Benito, M.I., Mas, R., 2013. New insights on stratigraphy and sedimentology of the Oncala group (eastern Cameros Basin): implications for the paleogeographic reconstruction of NE Iberia at Berriasian times. J. Iber. Geol. 39, 313-334.

Quijada, I.E., Suarez-Gonzalez, P., Benito, M.I., Mas, R., 2016. Tidal versus continental sandy-muddy flat deposits: Evidence from the Oncala group (early cretaceous, N Spain). In: Tessier, B., Reynaud, J.Y. (Eds.), Contributions to Modern and Ancient Tidal Sedimentology, Proceedings of the Tidalites 2012 Conference. John Wiley \& Sons, pp. 133-159.

Rabal-Garcés, R., Castanera, D., Luzón, A., Barco, J.L., Canudo, J.I., 2018. A Palaeoichnological Itinerary through the Cenozoic of the Southern margin of the Pyrenees and the Northern Ebro Basin (Aragón, Northeast Spain). Geoheritage 10, 499-509.

Razzolini, N.L., Klein, H., 2018. Crossing slopes: unusual trackways of recent birds and implications for tetrapod footprint preservation. Ichnos 25, 252-259.

Razzolini, N.L., Vila, B., Castanera, D., Falkingham, P.L., Barco, J.L., Canudo, J.I., Manning, P.L., Galobart, À., 2014. Intra-trackway morphological variations due to substrate consistency: the El Frontal dinosaur tracksite (lower cretaceous, Spain). PLoS One 9, e93708.

Razzolini, N.L., Vila, B., Díaz-Martínez, I., Manning, P.L., Galobart, À., 2016. Pes shape variation in an ornithopod dinosaur trackway (lower cretaceous, NW Spain): new evidence of an antalgic gait in the fossil track record. Cretac. Res. $58,125-134$.

Razzolini, N.L., Belvedere, M., Marty, D., Paratte, G., Lovis, C., Cattin, M., Meyer, C.A., 2017. Megalosauripus transjuranicus nov. a new late Jurassic theropod ichnotaxon from NW Switzerland and implications for tridactyl dinosaur ichnology and ichnotaxomy. PLoS One 12, e0180289. https://doi.org/10.1371/ journal.pone.0180289.

Rindsberg, A.K., 2012. In: Knaust, D. (Ed.), Ichnotaxonomy: Finding Patterns in a Welter of Information. 
Romano, M., Whyte, M.A., 2003. Jurassic dinosaur tracks and trackways of the Cleveland Basin, Yorkshire: Preservation, diversity and distribution. Proc. Yorks. Geol. Soc. 54, 185-215.

Sarjeant, W.A.S., 1989. Ten Paleoichnological commandments': A Standardized Procedure for the Description of Fossil Vertebrate Footprints. Cambridge University Press, Cambridge.

Sarjeant, W.A.S., Langston Jr., W., 1994. Vertebrate footprints and invertebrate traces from the Chadronian (late Eocene) of Trans-Pecos Texas. TX Memorial Museum Bull. 36, 1-86.

Sarjeant, W.A.S., Reynolds, R.E., 2001. Bird footprints from the Miocene of California. In: Reynolds, R.E. (Ed.), The Changing Face of the East Mojave Desert: Abstracts from the 2001 Desert Symposium. California State University, Fullerton, pp. 21-40.

Savrda, C.E., 2007. Taphonomy of trace fossils. In: Miller, W.I.I.I. (Ed.), Trace Fossils: Concepts, Problems, Prospects. Elsevier Science \& Technology Books, pp. 92-109.

Scott, J.J., 2010. Saline Lake Ichnology: Composition and Distribution of Cenozoic Traces in the Saline, Alkaline Lakes of the Kenya Rift Valley and Eocene Green River Formation, USA. Doctoral dissertation. University of Saskatchewan.

Scott, J.J., Renaut, R.W., Owen, R.B., 2010. Taphonomic controls on animal tracks at saline, alkaline Lake Bogoria, Kenya Rift Valley: impact of salt efflorescence and clay mineralogy. J. Sediment. Res. 80, 639-665.

Scott, J.J., Renaut, R.W., Owen, R.B., 2012. Impacts of flamingos on saline lake margin and shallow lacustrine sediments in the Kenya Rift valley. Sediment. Geol. 277-278, 32-51.

Seilacher, A., 1967. Bathymetry of trace fossils. Mar. Geol. 5, 413-428.

Seilacher, A., 1973. Biostratinomy: The sedimentology of biologically standardized particles. In: Ginsburg, R.N. (Ed.), Evolving Concepts in Sedimentology. Johns Hopkins University Press, Baltimore, pp. 159-177.

Seilacher, A., 1984. Sedimentary structures tentatively attributed to seismic events. Mar. Geol. 55, 1-12.

Seilacher, A., 1992. Feature article. Europal 1, 11-13.

Seilacher, A., 2007. Trace Fossil Analysis. Springer Science \& Business Media.

Selwyn, A.R., 18 2. IV.-On the Discovery of Reptilian Footprints in Nova Scotia. Geol. Mag. 9, 250

Senz, J.G., Zamorano, M., 1992. Evolución tectónica y sedimentaria durante el Priaboniense superior-Mioceno inferior, en el frente de cabalgamiento de $1 \mathrm{~s}$ Sierras Marginales occidentales. Acta Geol. Hisp. 27, 195-209.

Singer, A., Müller, G., 1979. Diagenesis in argillaceous sediments. In: Developments in Sedimentology. vol. 25. pp. 115-212.

Stampfli, G., Borel, G., 2002. A plate tectonic model for the Paleozoic and Mesozoic constrained by dynamic plate boundaries and restored synthetic oceanic isochrons. Earth Planet. Sci. Lett. 196, 17-33. 
Thalmann, H.K., 1966. Zur Stratigraphie des oberen Malm im südlichen Berner und Solothurner Jura. University of Bern.

Thulborn, T., 1990. Dinosaur tracks. Chapman and Hall, London.

Tongiorgi, M., Rau, A., Martini, I.P., 1977. Sedimentology of early-alpine, fluviomarine, clastic deposits (Verrucano, Triassic) in the Monti Pisani (Italy). Sediment. Geol. 17, 311-332.

Tucker, L., Smith, M.P., 2004. A multivariate taxonomic analysis of the late Carboniferous vertebrate ichnofauna of Alveley, southern Shropshire, England. Palaeontology 47, 679-710.

Valentini, M., Conti, M.A., Mariotti, N., 2007. Lacertoid footprints of the Upper Permian Arenaria di Val Gardena Formation (Northern Italy). Ichnos 14, 193-218.

Vialov, O.S., 1965. Sztratigrafija neogenovüh molassez Predkarpatszkovo progiva. Naukova Dumka, Kiev.

Voigt, S., 2005. Die Tetrapodenichnofauna des kontinentalen Oberkarbon und Perm im Thüringer Wald - Ichnotaxonomie. In: Paläoökologie und Biostratigraphie. Cuvillier, Göttingen.

Voigt, S., Ganzelewski, M., 2009. Toward the origin of amniotes: Diadectomorph and synapsid footprints from the early late Carboniferous of Germany. Acta Palaeontol. Pol. 55, 57-72.

Voigt, S., Lucas, S.G., 2018. Outline of a Permian tetrapod footprint ichnostratigraphy. In: Lucas, S.G., Shen, S.Z. (Eds.), The Permian Timescale. vol. 450 Geological Society, London. https://doi.org/10.1144/SP450.10. Special Publications.

Voigt, S., Berman, D.S., Henrici, A.C., 2007. First well-established tracktrackmaker association of Paleozoic tetrapods based on Ichniotherium trackways and diadectid skeletons from the lower Permian of Germany. J. Vertebr. Paleontol. 27, 553-570.

Voigt, S., Lucas, S.G., Buchwitz, M., Celeskey, M.D., 2013. Robledopus macdonaldi, a new kind of basal eureptile footprint from the early Permian of New Mexico. N. M. Mus. Nat. Hist. Sci. Bull. 6o, 445-459.

Wilson, M.V.H., 1988. Taphonomic processes: information loss and information gain. Geosci. Can. 15, 131-148.

Wood, N.J., Miller, R.F., 2007. A Mississippian trackway (Pseudobradypus ichnosp.) from the enrage formation, New Brunswick, Canada. Atl. Geol. 43, $180-186$.

Wright, J.L., 2005. Steps in understanding sauropod biology: The importance of sauropod tracks. In: Curry Rogers, K.A., Wilson, J.A. (Eds.), The Sauropods: Evolution and Paleobiology. University of California Press, Berkeley, California, pp. 252-284.

Xing, L.D., Harris, J.D., Jia, C.K., 2010. Dinosaur tracks from the lower cretaceous Mengtuan Formation in Jiangsu, China and morphological diversity of local sauropod tracks. Acta Palaeontol. Sin. 49, 448-46o. 
Xing, L.D., Harris, J.D., Gierliński, G.D., Wang, W.M., Wang, Z.Y., Li, D.Q., 2011a. Middle cretaceous Non-avian Theropod trackways from the Southern margin of the Sichuan Basin, China. Acta Palaeontol. Sin. 50, 470-480.

Xing, L.D., Harris, J.D., Jia, C.K., Luo, Z.J., Wang, S.N., An, J.F., 2011b. Early cretaceous bird-dominated and dinosaur footprint assemblages from the northwestern margin of the Junggar Basin, Xinjiang, China. Palaeoworld 20, 308-321.

Xing, L.D., Lockley, M.G., Zhang, J.P., Klein, H., Marty, D., Peng, G.Z., Ye, Y., McCrea, R.T., Persons, W.S.I.V., Xu, T., 2015. The longest theropod trackway from East Asia, and a diverse sauropod-, theropod-, and ornithopod-track assemblage from the lower cretaceous Jiaguan Formation, Southwest China. Cretac. Res. 56, 345-362.

Xing, L.D., Lockley, M.G., Klein, H., Zeng, R., Cai, S.F., Luo, X.C., Li, C., 2018. Theropod assemblages and a new ichnotaxon Gigandipus chiappei ichnosp. Nov. from the Jiaguan Formation, lower cretaceous of Guizhou Province, China. Geosci. Front. 9, 1745-1754.

Zavala, C., Quattrocchio, M., 2001. Estratigrafía y evolución geológica del río Sauce Grande (Cuaternario), provincia de Buenos Aires, Argentina. Rev. Asoc. Geol. Argent. 56, 25-37.

Zhen, S., Li, J., Chen, W., Zhu, S., 1995. Dinosaur and bird footprints from the lower cretaceous of Emei County, Sichuan, China. Mem. Beijing Nat. Hist. Mus. 54,105 